Portland State University

PDXScholar

Summer 8-6-2014

\title{
Benevolent Racism? : The Impact of Race and Sexual Subtype on Ambivalent Sexism
}

Jean Marie McMahon

Portland State University

Follow this and additional works at: https://pdxscholar.library.pdx.edu/open_access_etds

Part of the Race and Ethnicity Commons, and the Social Psychology Commons Let us know how access to this document benefits you.

\section{Recommended Citation}

McMahon, Jean Marie, "Benevolent Racism? : The Impact of Race and Sexual Subtype on Ambivalent Sexism" (2014). Dissertations and Theses. Paper 1971.

https://doi.org/10.15760/etd.1970

This Thesis is brought to you for free and open access. It has been accepted for inclusion in Dissertations and Theses by an authorized administrator of PDXScholar. Please contact us if we can make this document more accessible: pdxscholar@pdx.edu. 


\title{
Benevolent Racism?:
}

The Impact of Race and Sexual Subtype on Ambivalent Sexism

$$
\text { by }
$$

Jean Marie McMahon

A thesis submitted in partial fulfillment of the requirements for the degree of

\author{
Master of Science \\ in \\ Psychology
}

\section{Thesis Committee:}

Kimberly Barsamian Kahn, Chair

Cynthia Mohr

Todd Bodner

Portland State University

2014 


\begin{abstract}
How does a woman's race influence perceptions of her sexual behavior? This study investigated how race and sexual behavior intersect within an ambivalent sexism framework. Benevolent sexism characterizes women as pure and defenseless, which contrasts with the cultural stereotype of Black women as aggressive and hypersexual. Gender and racial stereotypes may combine to produce different outcomes for women who behave according to negative (promiscuous) or positive (chaste) sexual subtypes. According to shifting standards theory, evaluations and treatment of these women should vary depending on whether the measured behavior is non-zero sum (limitless) or zero sum (finite). To test this hypothesis, participants read about a chaste or promiscuous Black or White woman and reported their hostile and benevolent attitudes about her (nonzero sum) and whether she should be picked to represent an organization that supports women of her sexual subtype (zero sum.) Results suggest, consistent with shifting standards, that more benevolent sexism was expressed to a chaste Black, rather than White, woman. However, the Black woman did not receive more positive trait evaluations or experience an advantage on the zero sum outcome. Minority women who conform to benevolent sexism ideals may be highly praised (non-zero sum reward) but are not given tangible rewards (zero sum reward) for their behavior. This pattern of treatment perpetuates discrimination against Black women within society.
\end{abstract}




\section{Table of Contents}

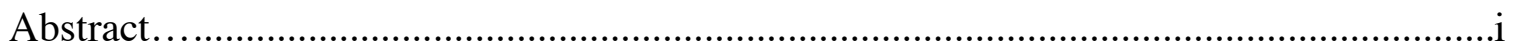

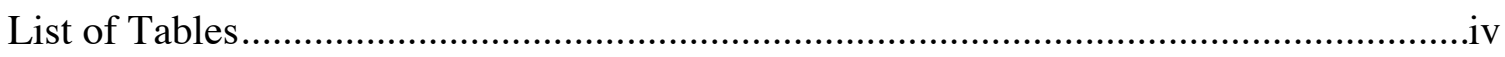

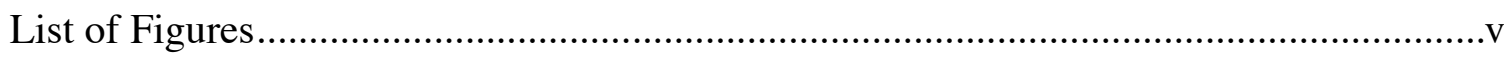

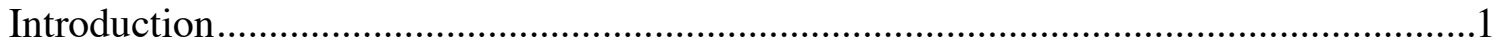

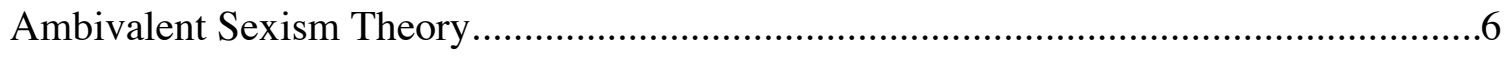

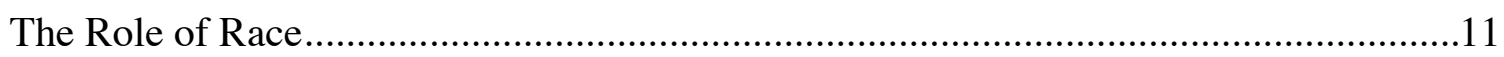

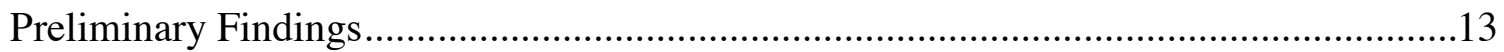

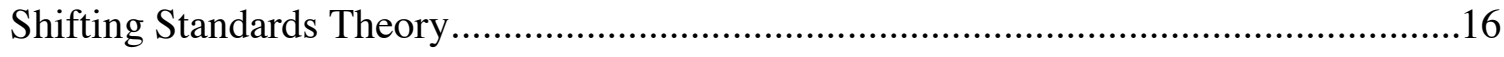

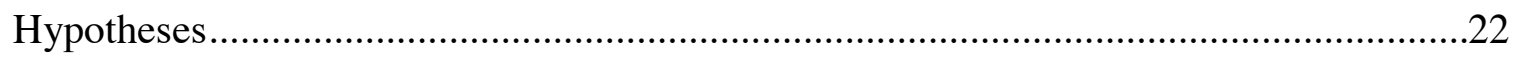

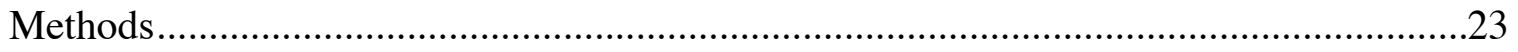

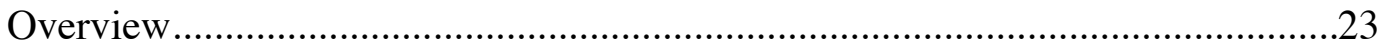

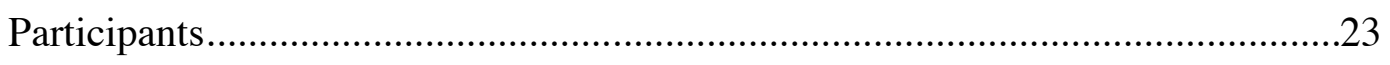

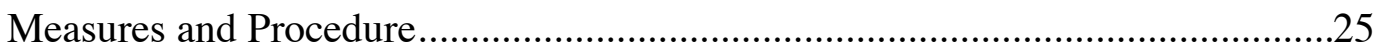

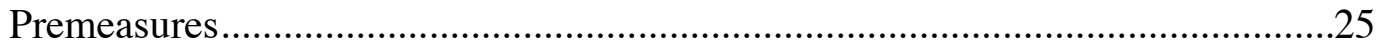

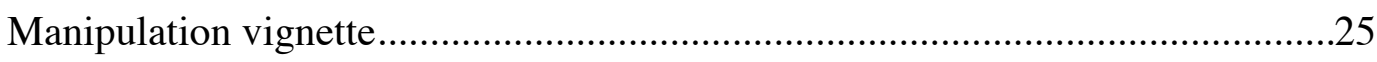

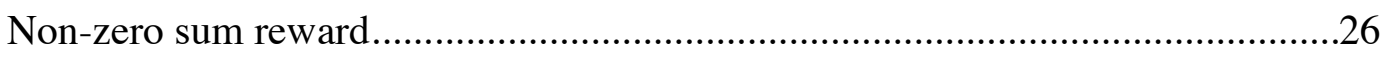

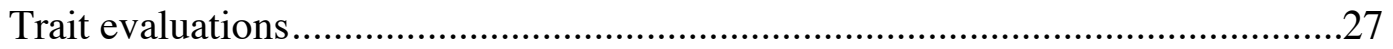

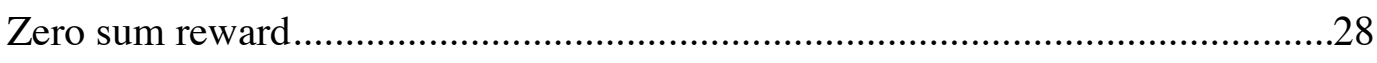

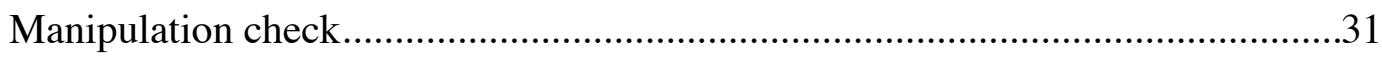

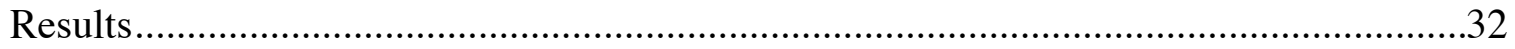

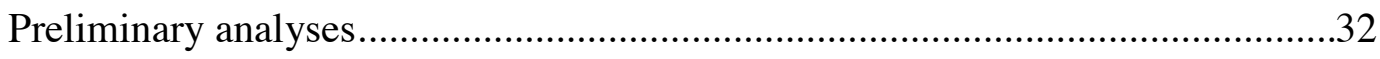

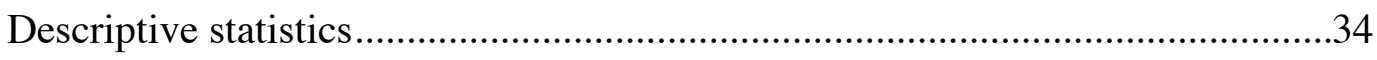

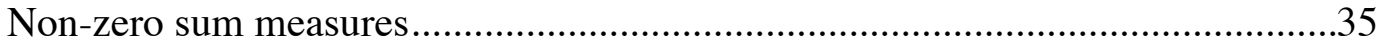

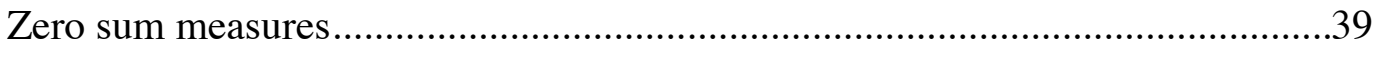

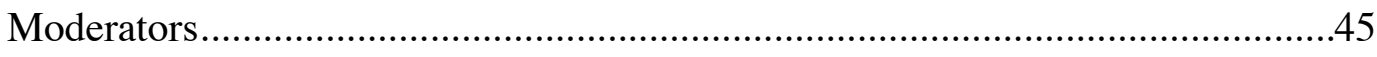

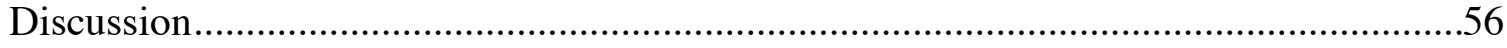

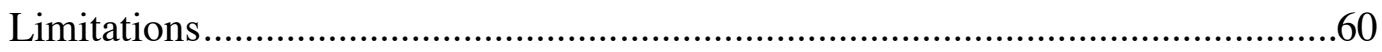

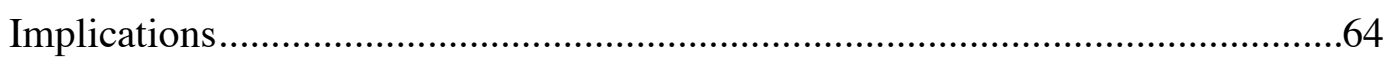

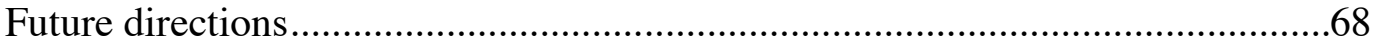




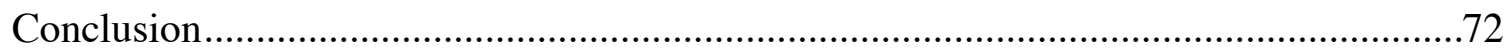

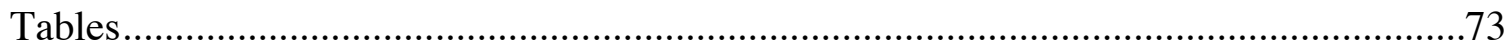

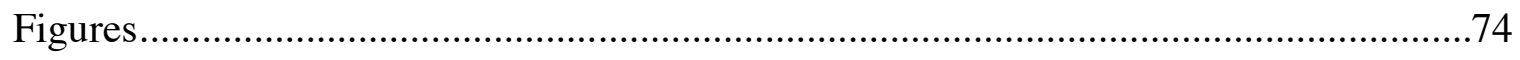

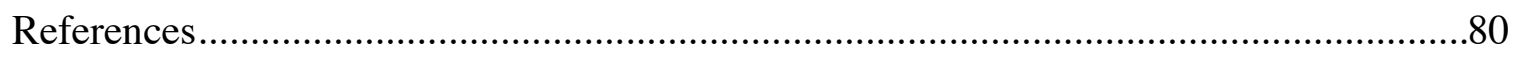

Appendix A: Results of Previous Study (McMahon \& Kahn, 2014) .............................96

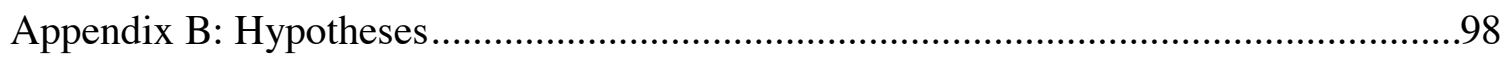

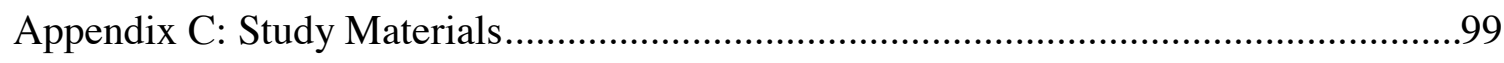


List of Tables

Table 1: Correlations Between Hostile Sexism, Benevolent Sexism, and

Modern Racism.......................................................... 73

Table 2: Means and Standard Deviations for the Non-zero Sum Outcomes...................73 
List of Figures

Figure 1: Expressions of benevolent sexism to White and Black targets

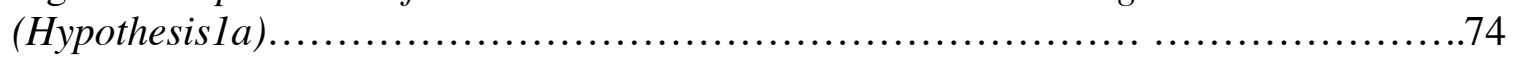

Figure 2: Expressions of hostile sexism to White and Black targets

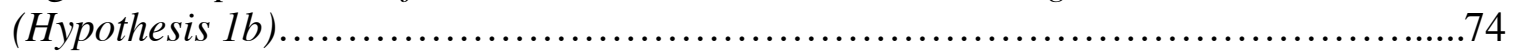

Figure 3: Rates at which targets were chosen to represent the positively

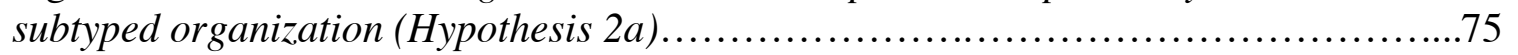

Figure 4: Race of other applicant selected for the positively subtyped organization in the White female condition....................................... 75

Figure 5: Race of other applicant selected for the positively subtyped organization in the Black female condition.....................................76

Figure 6: Rates at which targets were chosen to represent the negatively

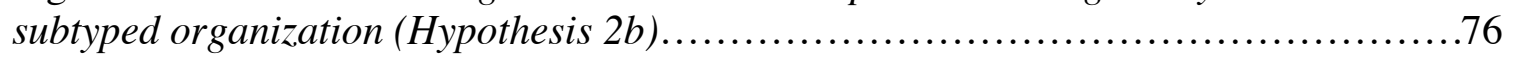

Figure 7: Race of other applicant selected for the negatively subtyped organization in the White female condition....................................... 77

Figure 8: Race of other applicant selected for the negatively subtyped organization in the Black female condition...................................... 77

Figure 9: The interaction of target race and participants' baseline hostile sexism on benevolent evaluations of the chaste targets...........................78

Figure 10: The interaction of target race and participants' modern racism score on benevolent evaluations of the chaste targets..........................78

Figure 11: The interaction of target race and participants' baseline hostile sexism on hostile evaluations of the promiscuous targets........................79

Figure 12: The interaction of target race and participants' modern racism on hostile evaluations of the promiscuous targets.............................79 


\section{Introduction}

Women's sexuality is often subject to intense scrutiny. On the basis of their sexual behavior, they are divided into two groups: chaste virgins or lustful temptresses (Carpenter \& Trentham, 2001; Six \& Eckes, 1991). Pomeroy's (1975) examination of ancient Greek and Roman myths, literature, and art was able to trace the separation of women into "goddesses" or "whores" back to the Bronze Age (3000 BCE). Such polarized characterizations remain ubiquitous in contemporary media (Faludi, 1992; Ristock, 1997; Karam, 2010) and literary theory (Gottschall, Allison, De Rosa, \& Klockeman, 2006). This dichotomy is sometimes used in clinical settings to explain sexual/relational dysfunction (Hartmann, 2009) and is being propagated and reinforced by the modern virginity movement (Valenti, 2009).

Women who are considered sexually pure are placed on a pedestal (Tavris \& Wade, 1984) and held up as exemplars of idealized womanhood. Countless female celebrities have capitalized on this association by talking openly about their virginal status in order to enhance their image and popularity, from Britney Spears and Jessica Simpson in the 1990's to Taylor Swift, Miley Cyrus, and Demi Lovato (Marcus, 2012). Public declarations of purity have become increasingly ritualized with the rise of chastity clubs and purity balls (Fahs, 2010). A thinly veiled abstinence metaphor lies at the heart of the Twilight saga (Grossman, 2008), one of the most popular book series of the last decade. Congress recently renewed the Title $\mathrm{V}$ program, which provides $\$ 50$ million dollars in grants to states for abstinence-only sex education programs in public schools (Boonstra, 2010). 
Inherent in the pro-abstinence movement is the notion that women's morality is inextricably tied to their sexuality (Valenti, 2009), which explains why women who are viewed as promiscuous are often publically condemned (or are targets of "slut-shaming", as the neologism suggests). Hester Prynne was forced to wear the letter "A" for Adultery on her clothes in Hawthorne's "The Scarlet Letter" and sexually available female characters in slasher-horror movies are far more likely to be killed than their chaste counterparts (Cowen \& O’Brien, 1990). Miley Cyrus, a pop singer who once extolled the virtues of abstinence, has come to elicit disgust and ire for her hypersexualized performances (Kincaid, 2010; Smith, 2013). Georgetown law student Sandra Fluke testified before the House Democratic Steering and Policy Committee about the importance of contraceptive coverage in the new health care law and subsequently was branded a "slut" and a "prostitute" (Altman, 2012).

The dialogue over which women are "good" or "bad" becomes much more complicated when put into the context of race. Note that the women in the above examples are all of European decent. For a variety of reasons, perceptions of African American women do not necessarily follow the same pattern.

The United States has a long history of prejudice (Katz \& Braly, 1993; Madon, Guyll, Aboufadel, Montiel, Smith, Palumbo, \& Jussim, 2001) and dehumanization (Lott, 1999) toward Blacks. Less than 150 years ago, a Black woman was still considered property and was only legally only three-fifths of a human being. Today, the definition of racism preferred by academics takes into account not only the bigotry directed at members of ethnic groups but the systematic advantages and institutional policies that favor Whites over Blacks (Tatum, 2001). Sexism, similarly, involves the systematic 
subordination of women (Rothenberg, 2004). Because power is implicit in these definitions, acts of sexism or racism must come from the dominant group and are not bidirectional.

Because of their intersectional identity, Black women face discrimination on the basis of their race as well as their gender, a condition known as "double jeopardy" (Beale, 1971). The differential treatment of Black and White women exists in a variety of domains. For instance, while the wage gap for White women is such that they are paid only 77 cents for every dollar paid to White men, Black women are paid only 64 cents (National Women's Law Center, 2013). In a field experiment with real employers, resumes featuring stereotypically White female names were more likely to receive a callback than the same resume bearing a Black name (Bertrand \& Mullainathan, 2003). For those that do find themselves employed, experiences of racial discrimination and sexual harassment are not uncommon (Krieger, Waterman, Hartman, Bates, Stoddard, Quinn, ... \& Barbeau, 2006). This pattern extends to the military, as Black female enlistees report more sexual coercion than their White counterparts (Buchanan, Settles, \& Woods, 2008). In a study of racial and sexual discrimination while bargaining for a new car, White women were asked to pay an average of $\$ 92$ more than White men, while Black women were charged \$410 more than White men (Ayres \& Siegelman, 1995). When shopping at department and specialty stores, female Black confederates have been shown to wait twice as long for service as White confederates (Ainscough \& Motley, 2000). Over time these experiences can lead to serious negative health outcomes for Black women, as perceptions of discrimination by police, at work, in housing, and in everyday life have been associated with increased incidence of breast cancer (Taylor, 
Williams, Makambi, Mouton, Harrell, Cozier, ... \& Adams-Campbell, 2007), hypertension (Cozier, Palmer, Horton, Fredman, Wise, \& Rosenberg, 2006), preterm birth (Rosenberg, Palmer, Wise, Horton, \& Corwin, 2002) and obesity (Cozier, Yu, Coogan, Bethea, Rosenberg, \& Palmer, 2014).

The largely incompatible stereotypes of Black women and White women, which will be expanded on later, may be partially responsible for their differential treatment. For example, because certain types of women are so highly valued, men are expected to respond protectively when they are in danger (Hurd, 1762; Hearnshaw, 1935). However, young, White girls who go missing garner far more extensive media attention than missing Black girls (Min \& Feaster, 2010). So striking is this over-representation that PBS news anchor Gwen Ifill gave it a name: Missing White Woman Syndrome (Armstrong, 2013). "Nobody matters less to our society than young Black girls," concluded reporter Jim DeRogatis after reading through hundreds of pages of lawsuits against R\&B artist R. Kelly for the abuse, intimidation, and rape of dozens of girls, some as young as 13 and all African American (Hopper, 2013), for which he was later acquitted. Many have speculated that public outrage would have been much greater had his victims been White, since their virtue is more valued and thus more worthy of protection (Neal, 2013; Smith, 2013). This would suggest that for a woman to be placed on the proverbial pedestal, her race might matter as much as her behavior.

In her extemporaneous speech at the Women's Convention (as transcribed by Frances Gage in Stanton et al., 1881), Sojourner Truth remarked how her dark skin prevented men from viewing her as fragile and defenseless and affording her the same treatment as White women, saying, "That man over there says that women need to be 
helped into carriages, and lifted over ditches, and to have the best place everywhere. Nobody ever helps me into carriages, or over mud-puddles, or gives me any best place! And ain't I a woman?" Her intersectional identity as both Black and female left her conflated with Black men and with her womanhood erased, especially when compared to the White ideal of femininity. Her rallying cry has been a source of inspiration for Black feminists, who have written at length about how a feminism that focuses exclusively on the struggles of White women and fails to acknowledge the privileges and power structures that subordinate Black women is crippled and incomplete (Crenshaw, 1993; Davis, 1983; hooks, 1981; Hull, Bell Scott, \& Smith, 1982).

Unfortunately, psychological research as a whole, particularly in the domain of prejudice, has long neglected how gender and race mutually construct each other and influence individuals' experiences with discrimination (Goff \& Kahn, 2013). The result is an androcentric conception of racism and an ethnocentric understanding of sexism, wherein the default target of racism is a Black man and the default target of sexism is a White woman. This oversight has resulted in an "intersectional invisibility" that ignores the unique experiences of individuals who are not the prototypical members of their already subordinate groups, such as Black women (Purdie-Vaughns \& Eibach, 2008). Indeed, many examinations of the stereotypes of African Americans conflate Black men with women, neglecting to consider how perceptions and stereotypes of the sexes might differ (Devine \& Baker, 1991; Madon et al., 2001). The proposed study attempts to address this dearth in the social psychology literature by examining how race and gender stereotypes interact to produce different outcomes for Black and White women. Only by 
further elucidating people's attitudes and subsequent treatment of Black and White women can we begin to mitigate the pernicious effects of both racism and sexism.

\section{Ambivalent Sexism Theory}

Prejudice has long been considered in the field of social psychology and among the laity to be "an antipathy" (Allport, 1954, p. 9) toward a group of people. However, this definition is insufficient to explain why women, who have historically been subordinate to men, are also stereotyped more positively than they are (Swim, 1994) and assigned numerous favorable traits, such as warmth and nurturance (Eagly \& Mladinic, 1994). Glick and Fiske (1996) proposed that sexism is better characterized as "a special case of prejudice marked by a deep ambivalence" (p. 491), whereby women as a group are simultaneously adored and condemned.

Ambivalent Sexism Theory (Glick \& Fiske, 1996) distinguishes sexism on two related yet discrete dimensions: hostile and benevolent. Hostile sexism (HS) is sexism in the traditional sense. It aims to reinforce traditional gender roles and patriarchy through derogatory characterizations of women as easily offended, unappreciative of and seeking to gain power over men, and manipulative with their sexuality. However, men are also didactically dependent on women as mothers and romantic partners, so the group as a whole cannot be rejected. Benevolent sexism (BS) instead takes a far gentler tone by viewing women in stereotypical and restricted domestic roles as being inherently pure, moral, and defenseless. This set of beliefs is comprised of three components: paternalism, gender differentiation, and heterosexuality. Protective paternalism suggests men, with their superior strength and authority, ought to protect and provide for their wives and daughters. Meanwhile, complementary gender differentiation suggests that women have 
many positive qualities that complement those of men, such as nurturing and sensitivity. These traits support the traditional division of labor, with women working inside the home, and the notion that women are the "better half" of a romantic couple. Finally, needs for heterosexual intimacy create a situation in which the dominant group (men) is dependent upon a subordinate group. Benevolently sexist attitudes differ from hostile ones in that they are subjectively positive in nature and based on feelings of genuine affection rather than mistrust or distain. However, benevolent sexism is better understood as a subtle and pernicious form of bias that shares the same ideological underpinnings as more openly hostile forms of sexism. The positive valence of benevolent sexism does not change the fact that it is rooted in traditional beliefs of women as the "weaker sex" who inhabits restricted domestic roles and is entirely dependent on men for financial support, protection, and fulfillment. Paternalistic behaviors towards women are thus condescending and serve to reinforce their lower status (Jackman, 1994). This ideology is akin to the "White Man's Burden”, where the dominant group has a sacred duty to care for a helpless subordinate group (Glick \& Fiske, 1996).

Ambivalent sexist men, compared to non-sexists, are able to reconcile any dissonance that could be generated by holding conflicting beliefs by spontaneously splitting the larger group "women” into distinct subtypes (Glick, Diebold, Bailey-Werner, \& Zhu, 1997), such that certain types of women are placed on a "pedestal" and others are in the "gutter" (Tavris \& Wade, 1984). Women who reject traditional gender roles by being feminists, career-oriented, or lesbians are the targets of hostile sexism, while benevolent sexism is bestowed upon those who adhere to the domestic norms for their gender by being homemakers and mothers (Glick et al., 1997). Beyond their roles in or 
outside of the home, women are also subtyped based on their sexual behavior; hostile sexism is expressed towards those who are promiscuous and benevolent sexism towards those who are chaste (Sibley \& Wilson, 2004).

Though they are both strongly correlated with conservative principles such as Social Dominance Orientation, Right Wing Authoritarianism, and the Protestant Work Ethic (Christopher \& Mull, 2006), hostile and benevolent sexism are distinct, complementary and mutually reinforcing ideologies that maintain the status quo by praising some women and punishing others. Benevolent sexism rewards women who conform to a traditional power structure that rationalizes and maintains their subordination (Glick \& Fiske, 2001a). For example, Forbes, Adams-Curtis, Hamm, and White (2003) found that men's benevolent, but not hostile, sexism was associated with more positive evaluations of a woman breastfeeding her child, likely because her behaviors were consistent with the image of ideal motherhood. Meanwhile, hostile sexism punishes those who challenge the patriarchy (Glick \& Fiske, 2001a). Men higher in hostile sexism are more likely to repeat sexist jokes (Thomas \& Esses, 2004) and selfreport acquaintance rape proclivity (Masser, Viki, \& Power, 2006). Hostile, but not benevolent, sexism is also related to negative attitudes about women who enter typically male-dominated spaces, such as masculine roles in the workplace (Masser \& Abrams, 2004) or natural science majors (Sakalli-Uğurlu, 2010). In a more extreme example of how hostile sexism punishes women who don't conform, Glick, Sakalli-Ugurlu, Ferriera, and de Souza (2002) demonstrated that HS predicts attitudes that legitimize wife abuse. This finding suggests that hostile sexism supports the justification of violence against 
women who violate their husband's authority or step outside their prescribed gender roles.

Hostile and benevolent sexism are measured with Glick and Fiske's (1996) 22item Ambivalent Sexism Inventory (ASI). It has been translated and tested on student and community samples in over 19 countries on six continents (Glick et al., 2000). Correlations between .8 and .9 were found between mean levels of HS and BS across nations, indicating that ambivalent sexism is a coherent ideology at the societal level in numerous cultural contexts. Furthermore, national means on the ASI are negatively correlated with United Nations indices of gender equality that assess women's presence in high status business and government jobs as well as their levels of education, longevity, and standard of living, suggesting that hostile and benevolent sexism are predictive of gender inequality.

Though men who endorse hostile sexism tend to also hold benevolent attitudes, women consistently reject hostile sexism while still endorsing the more positively valenced benevolent sexism (Glick \& Fiske, 2001a). People endorsing benevolent sexist beliefs are less likely to be perceived as sexist than those endorsing hostile ones (Barreto \& Ellemers, 2005). Perpetrators of benevolent sexism are also evaluated very positively, such that men who are described as benevolent (but not hostile) sexists are viewed as the most rare and ideal romantic partner, even compared to non-sexists (Kilianski \& Rudman, 1998).

Though benevolent sexism seems harmless, a growing body of work suggests that it produces a variety of insidious effects. Relative to reports of their actual experiences, women tend to underestimate the intensity and duration of the negative emotional impact 
of a benevolently sexist comment (Bosson, Pinel, \& Vandello, 2010), even more so than a hostile comment. Because benevolent sexists value the role of motherhood so highly, they react negatively towards women who reject it: they express opposition to abortion, even for women seeking to terminate a pregnancy resulting from rape or other circumstances beyond her control (Obsorne \& Davies, 2012), and report negative attitudes about women who violate the stereotype of nurturing behavior towards children (Viki, Massey, \& Masser, 2004). Benevolent sexists also react negatively towards women who violate norms of chastity, be it by willingly engaging in premarital sex (SakalhUğurlu \& Glick, 2003) or being raped by an acquaintance (Abrams, Tendayi Viki, Masser, \& Bohner, 2003). Benevolent sexist women are more likely to derogate a woman who confronts sexism, as the assertive behavior is outside of proscribed gender roles (Kahn, Barreto, \& Kaiser, 2013). Women exposed to benevolent sexism in a controlled setting show decreased cognitive performance (Dardenne, Dumont, \& Bollier, 2007), less motivation to engage in social activism that could benefit them (Becker \& Wright, 2011), increased levels of body surveillance and shame (Shepherd, Erchull, Rosner, Taubenberger, Queen, \& McKee, 2011), and increased system justification for the status quo (Jost \& Kay, 2005).

While ambivalent sexism has been studied for nearly 20 years now, there exists a glaring omission in the literature. To date, no one has systematically considered how race may play a role in shaping hostile or benevolent attitudes towards particular women. As it is been established that individuals with sexist attitudes also tend to have racist attitudes (Glick \& Fiske, 1996; Sidanius \& Pratto, 1999), an examination of the impact of race on ambivalent sexism, particularly benevolent sexism, is long overdue. 


\section{The Role of Race}

Though ambivalent sexism theory makes no assumptions about race, there is evidence to suggest that White women may be the primary recipients of benevolent sexism while Black women may be more frequent targets of hostile sexism. As previously stated, protective paternalism continues to be widely endorsed by both sexes (Glick \& Fiske, 1996; 2001a). This notion that women are defenseless and require male relatives and social institutions to safeguard their chastity and well-being (Young, 2003) has often been used to justify the mistreatment of racially stigmatized groups. In the United States, the need to protect White women from hypersexual and ruthless minority men has historically been "methodically conjured up whenever recurrent waves of violence and terror against the Black community have required convincing justifications" (Davis, 1983, p. 173). It remains a common feature in modern overtly racist movements (Blee, 2002). The notion that Blacks are subhuman is epitomized in the "Negro-ape metaphor" (Lott, 1999). So strong is this association, even present-day, that priming participants with ape-related words leads to greater endorsement of violence against Black, rather than White, suspects (Goff, Eberhardt, Williams, \& Jackson, 2008b).

Black women and White women are also perceived and stereotyped differently. Although both are stereotyped as childlike and emotional (Ehrenreich \& English, 1978), White women have historically been characterized as angelic (Stephens, 1992) while Black women are more often seen as antagonistic, unmannerly, loud (Niemann, Jennings, Rozelle, Baxter, \& Sullivan, 1994) and hypersexual (Davis \& Cross, 1979). These traits correspond to two different long-standing stereotypes of Black women as Sapphires or Jezebels, respectively. The Sapphire image arose in the mid-twentieth century and depicts 
a nagging, headstrong, and contemptuous woman whose main ambition is to emasculate Black men with her loud, verbal assaults (Bond \& Perry, 1970). In contrast, the Jezebel stereotype can be traced back to the antebellum South and depicts a seductive temptress who uses her sexuality to exploit men's weaknesses (Jewell, 1993). These and other negative stereotypes (e.g. the Gold Digger, the Welfare Queen) remain pervasive in modern depictions of Black women in television, films, music videos, and social media (Thompson, 2013). Black women's sexuality has never been depicted as moral or demure (Davis, 1983), in stark contrast to White women's. Indeed, the ideal virgin in the public consciousness and mass media is portrayed as young, White, and skinny and never a woman of color (Valenti, 2009). Divergent racial stereotypes regarding sexual behavior could imply that ambivalent sexism is differentially directed at Black and White women: Benevolent sexism should be directed more at White women, since they are stereotyped to match benevolent sexism ideals, whereas hostile sexism should be directed at Black women, whose stereotypes contradict these ideals. Black women, then, may receive more hostile sexism for violating benevolent ideals in ways that reflect racial prejudice.

Weitz and Gordon (1993) measured attitudes towards Black women among a large sample of European American college students. They described American women in general as sensitive, attractive, sophisticated, career-oriented, and independent, but Black women in particular as aggressive, argumentative, loud, stubborn, and bitchy. The five traits rated more positively for women in general (determined, attractive, assertive, meditative, and independent) were all considered less positive for Black women, while the five traits considered most negative for women in general (very religious, asexual, loud, too many children, and weak) were rated less negative for Black women. The image 
of Black women as threatening was pervasive enough that participants who scored low on a measure of explicit racism and sexism still endorsed it (Weitz \& Gordon 1993).

In addition to the negative stereotypes, it has been suggested that Black women are often seen as less "appropriately feminine" (Goff et al., 2008b). In an examination of how race and gender affect person perception, Goff, Thomas, and Jackson (2008a) found that Black men and women were both judged as more masculine than their White counterparts, and the conflation of "Blackness" with "maleness" resulted in Black women being rated as less physically attractive. Participants also guessed that Black women were actually men more frequently than they mis-categorized other groups by gender. These findings reflect a larger societal context in which femininity is associated with Whiteness and masculinity is associated with Blackness (Hull, Bell Scott, \& Smith, 1982). Different perceptions of the inherent femininity of Black and White women may account for why Black women who are victims of domestic violence (Esqueda \& Harrison, 2005) or date rape (Willis, 1992) are seen as more culpable than White women or why police officers are not as responsive to victimized minority women, even when they have suffered obvious injuries (Ferraro, 1989).

If Black women are perceived as less feminine than White women and are seen as violating traditional gender norms by being loud, sexually available, and aggressive, it stands to reason that they would more likely be targeted with hostile sexism and that benevolent sexism may be more exclusively applied to White women.

\section{Preliminary Findings}

In an initial test of the hypothesis that benevolent sexism is less expressed toward Black women, we investigated the effects of target race and sexual subtyped behavior on 
perceiver's expressions of ambivalent sexism (McMahon \& Kahn, 2014). In a procedure closely following that of Sibley and Wilson (2004), participants read a vignette about a woman at a bar and then reported their hostile and benevolent attitudes about her. The woman's race and sexual subtype were manipulated in this vignette. In the negative sexual subtype version, the female character was described as enjoying casual flings and as having had sexual relations with numerous men. She consumes alcohol and declines an offer of casual sex by one of the male characters. In the positive sexual subtype version, the female character behaves the same way but is described as not enjoying casual flings and as having had sexual relations with relatively few, if any, men. The former vignette characterized the woman as promiscuous, the latter as chaste.

In the original version of the vignette, the woman is named Kate, which is stereotypically White. Our study manipulated race by changing her name to Tanisha in the Black condition, which both children (Daniel \& Daniel, 1989) and adults (Greenwald, McGhee, \& Schwartz, 1998) recognize as belonging to African American women. Participants then completed a shortened version of the Ambivalent Sexism Inventory (Glick \& Fiske, 1996) in which items were reworded to include the name of the woman about whom they had just read (e.g. "Women like Tanisha have a quality of purity that few men possess;" "Once a woman like Kate gets a man to commit to her, she will usually try to put him on a tight leash").

We hypothesized that Sibley and Wilson's (2004) finding that hostile sexism was expressed more to a female character when her behavior was consistent with a negative subtype (than a positive subtype), and benevolent sexism was expressed more to a female character when her behavior was consistent with the positive subtype (than the negative 
subtype) would be replicated, but only for the White female target. We anticipated that when the female character was Black, expressions of benevolent sexism towards her would be low, regardless of her sexual subtyped behavior. We measured participants' baseline levels of ambivalent sexism and Modern Racism (McConahay, 1986), as well as the strength of their identification with their gender or race (Luhtanen \& Crocker, 1992), as possible moderators.

Results of this study found that the race of the female character affected how she was perceived, but not in the ways expected (see Appendix A). We found that expressions of benevolent sexism were significantly higher towards the chaste Black, rather than White, woman (Appendix A, Fig. A.1). Though it did not reach statistical significance, expressions of hostile sexism were also marginally higher for the promiscuous White, rather than Black, woman (Appendix A, Fig. A.2). Levels of hostile sexism towards the Black female target were the same whether her behavior was consistent with the positive or negative subtype. Sibley and Wilson's (2004) finding that expressions of benevolent sexism were higher when behavior was consistent with the positive, rather than the negative, subtype was not replicated, even when the sample was restricted to men. This could be due to cultural differences between the samples (New Zealand vs. the United States) which lead to the woman in the story being perceived as a "tease" for letting the male protagonist buy her a drink and dance with her, even when she was otherwise characterized as chaste. Though again not significant, the directionality of the relationships suggested that promiscuous White women are evaluated more positively than their Black counterparts, while chaste Black women are evaluated 
more negatively than their White counterparts, revealing a general bias in favor of White women.

The only significant moderator to emerge was baseline hostile sexism, such that participants with higher levels of hostile sexism expressed more benevolent sexism to the female target, but only when she was White (Appendix A, Fig. 1.3).

Taken together, these findings suggest that a Black woman who violates the negative stereotypes of her racial group regarding sexual behavior is more "rewarded" for her actions with subjectively positive benevolent sexism than a White woman who behaves the same way. Conversely, a White woman who violates the idealized expectations of her racial group by being promiscuous is also more "punished" with hostile sexism than her Black counterpart. This system of rewards and punishments serves to direct and control women by promoting certain behaviors and discouraging others (Glick \& Fiske, 1996).

Given the evidence that the ideals of benevolent sexism are incompatible with stereotypes of Black women, we began to suspect that these results could be best understood through a shifting standards framework that took into consideration the stereotypes of different groups, the behavior of individuals within those groups, and the nature of the rewards or punishments given to them.

\section{Shifting Standards Theory}

Monica Biernat has spent over twenty years examining how stereotypes function as standards against which individual members of groups are judged. Her shifting standards model (Biernat, Manis, \& Nelson, 1991) argues that stereotypes can be manifested in counter-stereotypical or contrast effects. That is, stereotypes are still 
operating even when outcomes for members of stereotyped groups are favorable, as when a woman receives more praise for her performance on a math test than her male peer, despite identical performances.

The shifting standards model posits that when one judges a member of a stereotyped group on a stereotyped dimension, they do so with reference to withincategory standards. For instance, there is a stereotype that men are naturally more adept at math than women. Therefore, one is likely to judge the performance of a particular woman in a computational physics class against the relatively lower standard for women and the performance of a man against the relatively higher standard for men. As a result, subjective evaluations of these two individuals as "good at math" may appear identical, but their meanings will not be the same. In the same way that a woman with a height of 5'10" would be considered tall while a man of the same height would be seen as average, "good at math" does not mean the same thing for a woman as it does for a man.

This masking of stereotypes is possible due to the highly subjective nature of language and judgments; adjectives such as "smart", "tall”, or "athletic" are not anchored to any constant meaning. Any measure that displays trait judgments along a continuum, like Likert scales and semantic differentials, allows for the rating points to be adjusted within categories of targets. Alternatively, common-rule scales have units that are fixed, such as scores on standardized tests, monetary or time judgments, and rank orderings. The shifting standards model predicts that common-rule response scales reveal assimilation to stereotypes while subjective response scales will demonstrate null or contrast effects. For example, the man and woman in the above example may be both judged as a 6 on a 7-pt. Likert scale of math ability, but when asked to predict what their 
scores will be on the math section of the GRE, the male is likely to be assigned a higher score than the female, demonstrating an assimilation to the stereotype that men are better at math. This pattern of differential evaluations anchored by group stereotypes has held for judgments across a variety of domains. Assimilation to stereotypes in common-rule, rather than subjective, judgments has been found for gender stereotypes pertaining to women's superior verbal ability, men's athleticism, and men's leadership competence (Biernat \& Manis, 1994; Biernat et al., 1991; Biernat \& Vescio, 2002). The same pattern holds true for racial stereotypes that support African American's athletic prowess and European American's job-related competence and academic ability (Biernat \& Manis, 1994; Kobrynowicz \& Biernat, 1997; Biernat \& Kobrynowicz, 1997.)

Another assumption of the shifting standards model is that evidentiary standards are lower for individuals who are members of groups that are stereotyped as lacking in some domain. These lower standards then produce subjective judgment effects. For instance, the standard for women's math ability is lower than those for men, so a woman's high math score on the GRE looks more impressive. Biernat and Kobrynowicz (1997) demonstrated that, when asked what level of performance was required to meet minimum standards for a job, women were held to lower minimum standards than men, and Black men were held to higher minimum standards than White men. Even though women and Black men needed to provide less evidence to meet perceivers' low standards, perceivers also required more evidence to confirm that a stereotyped individual possessed unexpected traits; that is, women and Black men had to have higher test scores and more job-related skills than White men for judges to perceive them as competent (Biernat \& Kobrynowicz, 1997). 
If the standards for certain groups are lower, then members of these groups will have an easier time surpassing them, which presumably could lead to a favorable outcome. However, evidence suggests that this is not the case, and discrimination still occurs along stereotyped lines. Biernat and Fuegen (2001) found that women applying for a stereotypically masculine job were more likely than men to "make the short list" of applicants. However, the women were less likely to then be hired for the job due to the higher confirmatory standard placed upon them. Because this was a masculine domain, the male applicants were perceived as meeting standards more readily and were consequently hired. These divergent outcomes for men and women speak to the importance of the type of outcome being directed at them when examining the influence of stereotypes.

Zero sum and non-zero sum rewards. We are able to reconcile these seemingly contradictory outcomes based on what we know about stereotyped expectations. According to shifting standards theory, behaviors towards individuals in stereotyped groups will depend on whether the action is zero sum or non-zero sum in nature (Biernat, Vescio, \& Manis, 1998). Zero sum behaviors include choice decisions (e.g. who gets promoted) and the allocation of limited resources. Behaving in one way towards an individual necessarily limits the options available to others: only one applicant can be hired, only one contestant can win first place, and so on. These judgments require that the perceiver takes a cross-category perspective and evaluates each candidate objectively in the context of the others. When zero sum decisions are required and cross-category comparisons are made, these judgments tend to assimilate to stereotypes and favor the 
individuals who belong to the group more strongly associated with that role, behavior, or position (Biernat, 2003).

In contrast, non-zero sum behaviors include actions that can be bestowed upon many individuals without resource depletion, such as nonverbal responses or expressions of praise or criticism. These behaviors invoke a within-category perspective in which targets are compared with the expectations (i.e. stereotypes) of their group. When expectations for a group are low, individuals who surpass them will be rewarded with non-zero sum behaviors such as praise. Though praise would appear to be a positive gesture, it belies the lower expectations that the perceiver held about the abilities of the stereotyped individual and is thus condescending and paternalistic. When non-zero sum decisions are required and within-category comparisons are made, these judgments favor those individuals that exceed the lower expectations of their groups.

In one of the few studies to test the zero sum/non-zero sum distinction, Biernat and Vescio (2002) had participants take the role of the manager of a co-ed softball team and make team selections, assign positions, and judge male and female players. When the players had moderate levels of athleticism, zero sum behaviors, such as assigning field positions and batting order, favored the men. These can be considered zero sum behaviors because there are only a limited number of spots available, and choosing one person to bat first removes this option for another person. This represents assimilation to the stereotype that men are more naturally athletic than women. However, hypothetical non-zero sum behaviors that would be directed at a player who just hit a single, such as cheering loudly, jumping up and down excitedly or saying "nice job!", favored the female players. Due to the lower standards for women's athletic performance, they were 
given more positive verbal and nonverbal feedback when they exceeded these lowered expectations.

The same pattern plays out in the workplace. Gupta, Jenkins, and Beehr (1983) found that while women tended to be evaluated more positively by both subordinates and supervisors than men, zero sum behaviors still assimilated to stereotypes, with male employees getting more promotions and pay raises than their female counterparts.

In both these cases, the positive non-zero sum outcomes for the women who succeed in the workplace or on the field reflect the lower expectations held about their competence. In the same way that benevolent sexism is subjectively positive yet predicated on notions of inferiority, the praise bestowed upon women who exceed their lower standards for competence is the result of patronizing surprise rather than a sincere judgment of quality. In our previous study, expressing benevolent sexism could be characterized as a non-zero sum behavior since judgments and nonverbal responses can be directed at any number of recipients without resource depletion. Given the aforementioned evidence that the expectations of Black women's sexual behavior are more negative than those of White women, an individual Black woman exhibiting more positive behavior would be judged against the relatively lower standard for Black women and would be "rewarded" with benevolent sexism. Though the benevolent sexism expressed towards this woman would be subjectively positive, it would be the result of negative stereotypes and reinforce her subordinate status relative to men. In contrast, in order to see assimilation to the stereotype that Black women are more promiscuous than White women, we would need to measure a zero sum behavior. I propose to add this dependent variable to the current study by having participants select a woman for one 
coveted position in an organization. This represents a zero sum behavior in that selecting one woman necessarily precludes others from holding the same position.

\section{Hypotheses}

The current study seeks to test how a female target's race and sexual behavior influence the allocation of zero sum and non-zero sum behaviors directed at her. In a replication of the findings from the previous study, I predict that more benevolent sexism (a non-zero sum behavior) will be expressed towards a chaste Black woman than a chaste White woman (Hypothesis 1a), while more hostile sexism will be expressed towards a promiscuous White woman than a promiscuous Black woman (Hypothesis 1b). However, a chaste White woman will be more likely to be picked to represent an organization (a zero sum behavior) that supports the positive sexual subtype than a chaste Black woman (Hypothesis 2a) while a promiscuous Black woman is more likely to be picked to represent an organization that supports the negative sexual subtype than a promiscuous White woman (Hypothesis $2 b$ ). A table of the hypothesized results can be found in Appendix B. 


\section{Methods}

\section{Overview}

In order to investigate these hypotheses, I conducted an original experiment that employed a 2 (Race of female target: Black vs. White) by 2 (Sexual subtype: Positive vs. Negative) between-subjects design. Participants read about a woman and then reported their hostile and benevolent attitudes about her (a non-zero sum behavior) and whether she should be picked to represent an organization that supports her sexual subtype (a zero sum behavior).

\section{Participants}

Three hundred forty-seven participants (170 men and 177 women) were recruited through Mechanical Turk (MTurk) for this experiment (more information about MTurk as a data collection tool is provided below). Mean age of participants was 34 years ( $\mathrm{SD}=$ 11.89) and ages ranged from 18 to 72 years. Eighty percent of the participants were White, $7 \%$ were African American, 6\% were Asian American, 5\% were Latino, and 2\% identified as "Other." Most participants had a college degree (38\%) or some college (36\%), while $15 \%$ had a high school diploma, $1 \%$ had less than a high school diploma, and $10 \%$ had an advanced degree. They were compensated 50 cents each from a grant I received from the Society for the Psychological Study of Social Issues in June 2013 to complete this project.

Both genders were included in the sample, as it is quite common to include both men and women in studies of ambivalent sexism (Lee, Fiske, \& Glick, 2010). Both genders endorse benevolent sexism (Glick et al., 2000; Glick \& Fiske, 2001a) and tend not to perceive it as being sexist (Barreto \& Ellemers, 2005). Though men do endorse 
hostile sexism more strongly than women do, these attitudes are still present among women (Glick et al., 1997; Glick et al., 2000). As gender did not moderate the results of our previous study, we did not anticipate any gender differences to emerge in the current study. A series of power analyses were conducted to determine the number of male and female participants needed in order for this study to achieve adequate power based on the data from the previously conducted study (McMahon \& Kahn, 2014). The means, effect sizes and power for the hostile and benevolent evaluations were used in these calculations. It was determined that in order to achieve a power of at least .8 with small to moderate effect sizes on both the hostile and benevolent measures in this study, 150 male and 150 female participants would be needed. This determined the target sample size range, which ended with the final sample of 316 participants.

Participants were also not excluded on the basis of race, as the internal reliabilities and correlations between the hostile and benevolent subscales are equivalent across ethnic groups (Hayes \& Swim, 2013). We tested for interactions with participant race, but as over $80 \%$ of our sample ended up being White, we lacked sufficient size and power to find any differences that might exist.

MTurk is a relatively new and potentially powerful research tool for the social sciences. Individuals can register online as "workers" and are paid small amounts of money to accomplish tasks that have been posted by "requesters". Buhrmester, Kwang, and Gosling (2011) determined that MTurk participants are slightly more demographically diverse (i.e. they are older and have more racial diversity) than standard Internet samples and, importantly, significantly more diverse than typical American college samples. The quality of the data is also not affected by compensation rates. They 
concluded that data obtained on MTurk are at least as reliable as those acquired with more traditional methods. We chose to harness this tool for the present study in order to gather a fast, generalizable sample.

\section{Measures and Procedure}

Eligible participants on MTurk who lived in the United States and were over age 18 were invited to participate in this study. Upon clicking the link on the MTurk website they were directed to a page with the consent form (see Appendix C for recruitment text and measures). Those who wished to proceed and gave their informed consent were provided with a link to the study on Qualtrics.

Premeasures. First, participants provided basic demographic information such as their gender, race, age, zip code, education level, occupation, and political orientation. They were then be given the original 22-item Ambivalent Sexism Inventory (Glick \& Fiske, 1996) in order to assess their baseline levels of hostile and benevolent sexism. Items are rated on a 6-point Likert scale from 0 (strongly disagree) to 5 (strongly agree). This was followed by the six-item Modern Racism Scale (McConahay, 1986) in order to evaluate their attitudes about African Americans. Questions such as, "Blacks should not push themselves where they are not wanted" are rated on a 5-point Likert scale from 1 (strongly disagree) to 5 (strongly agree). After completing a neutral distractor task, participants were randomly assigned into one of four groups: Black target/Positive subtype, Black target/Negative subtype, White target/Positive subtype, or White target/Negative subtype.

Manipulation vignette. Participants read a short story based on the one written by Sibley and Wilson (2004). In order to reduce any ambiguity that may have led to the 
null findings of the previous study regarding benevolent sexism and chaste White women, the vignettes were re-written to more explicitly subtype the woman in the story (see the Manipulation Vignette in Appendix C). The plot centers on two male friends who meet a woman at a bar downtown. One of them strikes up a conversation with her and the two of them spend the evening talking and dancing. At the end of the night the man and woman decide to share a taxi home. In the negative sexual subtype condition, the woman was described as enjoying casual flings and as having had sexual relations with several different men. She consumes several alcoholic drinks, which is a behavior associated with promiscuity and sexual availability (Vélez-Blasini \& Brandt, 2000) and agrees to enter the male protagonist's apartment at the end of the story, presumably in order to engage in casual sex. In the positive sexual subtype condition, the woman was described as not enjoying casual flings and has having been with few, if any, men. She was not described as having any drinks, and at the end of the night tells the male protagonist that she would like to see him again, but will not go home with him that night. The former vignette characterizes the woman as promiscuous, the latter as chaste.

The race of the female target was manipulated by making her name racially indicative. The current study utilized the stereotypically White and Black names used successfully by Bertrand and Mullainathan (2003) in their field study of workplace discrimination: Emily Walsh (White female) and Lakisha Washington (Black female).

Non-zero sum reward. Hostile and benevolent attitudes about the female character described in the vignette were assessed using shortened six-item versions (used in Sibley \& Wilson, 2004) of the hostile and benevolent subscales of the Glick and Fiske's (1996) Ambivalent Sexism Inventory (see Modified ASI in Appendix C). 
Expressions of hostile sexism towards the female target were measured by rewording the hostile sexism subscale items $(2,10,11,15,16$, and 18) of the ASI to be specifically about the female character (e.g. "once a woman like Emily/Lakisha gets a man to commit to her, she will usually try to put him on a tight leash.”) Expressions of benevolent sexism towards the female target were assessed by similarly rewording the benevolent sexism subscale items $(3,8,9,17,19$, and 22) of the ASI (e.g. "women like Emily/Lakisha have a quality of purity that few men possess.") These modified scales allow for the measurement of hostile and benevolent attitudes about this woman in particular, rather than women more globally. As with the original ASI, items were rated on a 6-point Likert scale from 0 (strongly disagree) to 5 (strongly agree), with higher scores indicating stronger expressions of sexism towards the woman in the story.

Trait evaluations. In our previous study, we had included several trait evaluations (warmth, competence, and agency) as impression measures. We included them here as a secondary measure of non-zero sum behaviors in this study. These trait measures were included in order to test whether the "positive" benevolent sexism expressed to the chaste Black woman also translated into more positive overall evaluations of her, or if the positivity directed at the chaste Black woman was confined to the more subtle, sexist measure of benevolent sexism. If the chaste Black woman was also considered more warm, agentic, and competent than the chaste White woman, this could suggest that Black women who conform to traditional norms of femininity are perceived very highly overall. However, if more benevolent sexism is expressed to the chaste Black woman than the chaste White woman (Hypothesis 1a) but then both women are considered equally warm, competent and agentic (or the Black woman as less so than 
the White woman), this would indicate that shifting standards only occurred for Black women with stereotype-inconsistent sexual behavior in an underlying sexist way. In short, these additional non-zero sum measures allow us to differentiate between overall positivity and positivity in a specific sexist dimension.

The traits measure included 12 personality traits, clustered into three subscales. Participants rated the female target on dimensions meant to assess her warmth (sincere, good-natured, friendly, and warm; Cronbach's alpha = .76), competence (intelligent, confident, capable, and competent; Cronbach's alpha $=.84$ ) and agency (competitive, independent, individual, and autonomous; Cronbach's alpha $=.61$ ). They were asked how appropriate each term was to describe the woman on a scale from 1 (very inappropriate) to 5 (very appropriate). Warmth and competence were selected based on their inclusion in the stereotype content model (Fiske, Cuddy, Glick, \& Xu, 2002), while perceptions of agency have been shown to impact hiring decisions (Phelan, Moss-Racusin, \& Rudman, 2008).

Zero sum reward. Participants were then given more information about the woman. They read a short paragraph that described how Emily or Lakisha has been working for an organization called the Wellness Federation for the past 3 years (see Job Selection Measure Appendix C). The organization is looking for someone to be their new public representative. They want someone who best represents the values and goals of the organization to be their advocate. Emily/Lakisha wants the position, but she is competing for it against three other women, all of whom started working there about the same time she did. Participants are asked to pick which of the four should be chosen to represent the organization. This measure could be considered a zero sum behavior since there is only 
one position available, so choosing one woman necessarily restricts options available to the other three. Giving Emily/Lakisha the position she wants is analogous to rewarding her, while denying her something that she wants could be considered a punishment. This measure is similar to other measures of zero sum behavior that involve choosing the best candidate for a particular job (Biernat \& Fuegen, 2001) or position a sports team (Biernat \& Vescio, 2002).

The stated goals of the Wellness Federation, which were pulled from the websites of real organizations, will be contingent upon whether the participant is in the positive or negative sexual subtype condition. In the positive sexual subtype condition, the organization was described as advocating for abstinence-only sex education and funding public ad campaigns that highlight the financial and social costs of teen pregnancy and the benefits of dressing and behaving modestly. Conversely, in the negative sexual subtype condition, the organization supported comprehensive sex education, accessibility to birth control, the HPV vaccine, and treatments for sexually transmitted infections. In this way, the woman described in the vignette works for an organization whose purpose and values closely align with her sexual subtype.

In order for this measure to be zero sum in nature, multiple people had to compete for a limited resource. Emily/Lakisha has three competitors for the desired position within the organization. Fake profiles were written for these women such that there were always two Black women and two White women who could be selected for the position. This was done so that participants would always have the option of picking a woman who was the same race as Emily/Lakisha. We anticipated that participants may feel more pressure to choose Lakisha if the other three options are all White for fear that not doing 
so would appear racist, which individuals often go to great lengths to avoid (Gaertner \& Dovidio, 1986), and that having an equal number of White and Black options would reduce this demand characteristic.

Each profile included the female applicants' age, the number of years they have worked at the organization (always 3 years, between 2-10 months), their education (a Bachelor of Arts or Bachelor of Science degree), the department they work in (e.g. fundraising) and a short quote about why they want to be chosen. While there was some variability in their ages and the number of years they have been working with the organization, all were equally qualified. This was done so that participants looking for a reason to not pick Emily/Lakisha, even unconsciously, could justify it by picking another woman who had been with the organization for longer (up to 3 months) or who was slightly older (up to 3 years). This would be consistent with research suggesting that racial discrimination is more likely to occur when situations are ambiguous (i.e. when there is no socially or morally “correct” response) and one's behavior can be rationalized on the basis of some factor other than race (Dovidio \& Gaertner, 1998; Gaertner \& Dovidio, 1986). The full profiles for the applicants can be found in Appendix C.

The names for these women were also chosen to be stereotypically Black or White. As the most popular last name for African Americans was already being used for the primary female character (Washington), the second and third most popular last names for this group, Jefferson and Booker, were found using U.S. Census data (2000). Two names with above $95 \%$ occurrence rates among Whites were also chosen: Reilly and Olson. The first names for the women were taken from Greenwald et al.'s (1998) initial assessment of the Implicit Associations Test, which required that participants be able to 
quickly deduce the race of a person by their first name. When participants were in the Black condition and Lakisha was up for the position, her competitors were named Shavonn Jefferson, Lauren Reilly, and Meredith Olson. When it was Emily Walsh who was up for the position, her competitors were Jazmine Booker, Shavonn Jefferson, and Meredith Olson. Though participants were picking between these four women, the most essential comparison tested regarding the study's hypotheses was whether the woman from the story is more likely to be chosen for the position when she was Black or White.

Manipulation check. In order to ensure that participants had carefully read the vignette, they were asked to respond to four manipulation check questions in the final step. The first two assessed whether participants could correctly identify her sexual subtype by asking them to report how she was described (enjoying casual flings vs. not enjoying casual flings) and what happened at the end of the story (if she went accepted the male character's invitation to his apartment vs. if she went home alone). The next question asked them to identify her race. Finally, they were to summarize the story in 1-2 sentences. Participants who failed to correctly indicate the woman's race, identify her sexual behavior, or provide a summary of the vignette were excluded from final analyses. They were then thanked for their time and debriefed. 


\section{Results}

\section{Preliminary Analyses}

In total, 347 participants (170 men and 177 women) were gathered on MTurk. Thirty-one participants failed either the race or subtype manipulation check and were excluded from all subsequent analyses. This left a final sample size of 316 participants, 156 of whom were men and 160 of whom were women.

There were five continuous measures of interest: the hostile and benevolent subscales of the Ambivalent Sexism Inventory, the Modern Racism Scale, and the modified hostile and benevolent subscales used as the non-zero sum behavior measure. Responses to the items in each scale were combined to create composite variables that represented the mean responses for that scale. Participants who failed to answer two or more of the items did not receive a mean score. Cronbach's alphas were calculated for the five measures to ensure their internal consistency with this population. All these measures exceeded the standard cut-off of 0.7 , with the Cronbach's alphas being .91 for the Modern Racism Scale, .90 for the benevolent subscale, .93 for the hostile subscale, .87 for the modified BS measure, and .86 for the modified HS measure.

A series of Confirmatory Factor Analyses were then run in AMOS to verify a single-factor structure for each measure. Error variances were assumed to be uncorrelated. As the benevolent sexism measure contains distinct three subscales, separate CFAs were run for the subscales that contained more than three items (protective paternalism and heterosexual intimacy). Analysis results suggest that a single-factor model does not tolerably fit several of the scales, including the Modern Racism Scale $\left[x^{2}\right.$ $(9)=43.49, p<.0001, \mathrm{GFI}=.95, \mathrm{CFI}=.97, \mathrm{RMSEA}=.12]$, the hostile sexism subscale from 
the ASI $\left[x^{2}(44)=216.00, p<.0001, \mathrm{GFI}=.88, \mathrm{CFI}=.92, \mathrm{RMSEA}=.12\right]$, the modified benevolent sexism measure $\left[x^{2}(9)=123.60, p<.0001, \mathrm{GFI}=.87, \mathrm{CFI}=.89, \mathrm{RMSEA}=.2\right]$, and the heterosexual intimacy subcomponent of the benevolent sexism subscale, $\left[x^{2}(2)=\right.$ $14.42, p=.001, \mathrm{GFI}=.98, \mathrm{CFI}=.97, \mathrm{RMSEA}=.15]$. The evaluation of poor model fit is based on the RMSEAs of the above measures being above the cutoff of 0.1 . The scales that did fit a single-factor model include the modified hostile sexism measure $\left[x^{2}(9)=\right.$ 29.23, $p<.0001, \mathrm{GFI}=.97, \mathrm{CFI}=.98, \mathrm{RMSEA}=.09]$ and the protective paternalism subcomponent of the benevolent sexism scale $\left[x^{2}(2)=6.07, p=.05, \mathrm{GFI}=.99, \mathrm{CFI}=.99\right.$, RMSEA=.09], which both have RMSEAs below the cutoff of 0.1. Given the age and widespread use of these measures (Lee et al., 2010; Hogg, 2013), issues with the model fit were not anticipated. It is possible that the underlying factor structure of the modified benevolent scale differed here because it was completed after participants read the manipulation vignette and were primed with race and sexual subtype. The activation of racial stereotypes and sexual behavior may have altered responses to the benevolent sexism subscale in such a way that the original single-factor structure was no longer appropriate. However, as is reported below, the measures behaved as otherwise anticipated, with the correlations between scales and the mean differences by gender occurring in the predicted directions. The reliabilities, as reported above, were also very high, indicating the scales were all internally consistent. The issue of model fit for these measures is further addressed in the discussion. For the purposes of this project, though the results of some of the CFAs were poor, the planned analyses were conducted. 


\section{Descriptive Statistics}

Prior to testing the study hypotheses, relevant descriptive and correlational statistics were examined. Specifically, the relationship between the hostile and benevolent subscales of the ASI and their differential endorsement by participant gender was explored.

A Pearson's Correlation was computed to ensure that the expected positive relationship between the hostile and benevolent subscales (Glick \& Fiske, 1996) was present. As anticipated, there was a moderate positive relationship between the two components of ambivalent sexism, $r(311)=.40, p<.01$. Previous research had established that persons with sexist attitudes also tend to hold racist attitudes (Glick \& Fiske, 1996; Sidanius \& Pratto, 1999). This held true for the current sample participants as well, as responses to the Modern Racism Scale were significantly correlated with both hostile, $r(312)=.53, p<.01$, and benevolent, $r(315)=.30, p<.01$, sexism (see Table 2$)$.

Results of an independent sample t-test confirmed that men $(M=3.27, S D=0.95)$ and women $(M=3.19, S D=0.98)$ did not differ in their endorsement of benevolent sexism, $t(313)=.701, p=.48$. However, men $(M=3.30, S D=1.04)$ did report greater endorsement of hostile sexism than women $(M=2.74, S D=1.01), t(310)=4.83, p$ $<.0001$. Both of these findings are consistent with prior research showing that while men tend to hold more hostile sexist beliefs than women, both genders equally endorse benevolent sexism (Glick \& Fiske, 2001a).

Again, the correlations between the hostile and benevolent scales, the modern racism and ambivalent sexism scales, and the gender differences observed in endorsement of hostile sexism are all consistent with the literature. These findings, in 
light of the poor model fits for the scales (as indicated by RMSEAs), suggest that testing the hypotheses is still appropriate. The planned analyses were carried out and reported below.

\section{Non-zero sum measures}

In order to examine the differential application of hostile and benevolent sexism towards the Black and White female targets (non-zero sum outcome), a factorial MANOVA was conducted. This allowed for an examination of the interaction effect of our two independent variables, as well as any main effects, on both dependent variables simultaneously, while taking into account the shared variance between the dependent variables and minimizing family-wise error.

The 2 (Race: Black vs. White) x 2 (Subtype: Positive vs. Negative) x 2 (Outcomes: Hostile and Benevolent Evaluations) MANOVA revealed a significant main effect of subtype, Wilks' Lambda $=.86, F(2,307)=25.44, p<.0001$, partial $\eta^{2}=.14$, and a non-significant effect of race, Wilks' Lambda $=.99, F(2,307)=1.56, p=.21$, partial $\eta^{2}$ $=.01$. Contrary to expectations, the MANOVA indicated no significant interaction between race and subtype, Wilks' Lambda $=.99, F(2,307)=1.27, p=.28$, partial $\eta^{2}=.01$. Though the interaction was non-significant, we chose to still examine the simple effects to see if there would be some indication of support for our predictions. With a nonsignificant interaction, we cannot say that what we find in the simple effects is unique to this comparison alone and not the other comparison conditions. However, it can give us suggestive evidence for the hypotheses. Univariate ANOVAs were then used to assess the two non-zero sum a priori comparisons directly. Means and standard deviations for each experimental group and outcome variable are provided in Table 3. 
Hypothesis 1a. It had been predicted that, consistent with shifting standards, expressions of benevolent sexism would be higher for the chaste Black target than the chaste White target. Despite the non-significant interaction, a one-way ANOVA was conducted to evaluate the benevolent evaluations of the Black and White targets when they were in the positive subtype. The results were significant, $F(1,143)=4.09, p<.05$, partial $\eta^{2}=.03$, indicating that the chaste Black woman $(M=3.74, S D=1.05)$ received more benevolent evaluations than the chaste White woman $(M=3.37, S D=1.12)$, see Figure 1. Despite the non-significant interaction between the target's race and sexual subtype in the above MANOVA, the simple effect demonstrated here gives suggestive support to Hypothesis 1a, which also replicated the previous finding in our prior study. However, because the interaction was not significant, we cannot strongly conclude that Hypothesis 1a was supported.

Hypothesis 1b. It was anticipated that expressions of hostile sexism would be higher for the promiscuous White target than the promiscuous Black target. Despite the non-significant interaction, a one-way ANOVA was conducted to evaluate the hostile evaluations of the Black and White targets when they were in the negative subtype. Results indicated that there was no significant difference between the amounts of hostile sexism directed at the Black $(M=2.82, S D=1.13)$ and White $(M=2.89, S D=0.98)$ promiscuous targets, $F(1,168)=0.23, p=.63$, partial $\eta^{2}=.001$, see Figure 2 . The previous study had found a non-significant trend between the two groups, but as no trend emerged in this study, Hypothesis $1 \mathrm{~b}$ was not supported.

Impressions of target. Traits were included as a secondary measure of impressions of the female target. If it was found that more benevolent sexism was 
directed at the chaste Black female, the inclusion of these traits would indicate whether the Black target was evaluated more positively in general or if that effect was confined to the benevolent sexism subscale. This allowed for the differentiation between more positive evaluations of the Black target overall and positivity only in a subtly sexist manner. A 2 (Race: Black vs. White) x 2 (Subtype: Positive vs. Negative) x 3 (Impression traits: Warmth, Competence, and Agency) MANOVA revealed a significant main effect of subtype, Wilks' Lambda $=.78, F(3,302)=28.97, p<.0001$, partial $\eta^{2}=$ .22. There was no significant effect of race, Wilks' Lambda $=.99, F(3,302)=.23, p=.87$, partial $\eta^{2}=.002$, or race and subtype interaction, Wilks' Lambda $=.99, F(3,302)=.88, p$ $=.45$, partial $\eta^{2}=.01$.

Examining the main effect of subtype, women who were chaste were thought to be more warm $(M=4.12, S D=0.50)$ than women who were promiscuous $(M=3.59, S D$ $=0.4), t(311)=8.11, p<.0001$. The chaste women were also seen as more competent $(M$ $=4.08, S D=.05)$ than the promiscuous women $(M=3.55, S D=0.05), t(310)=7.16, p<$ .0001 and more agentic $(M=3.66, S D=0.05)$ than promiscuous women, $(M=3.48, S D$ $=0.04), t(313)=2.61, p=.03$. As indicated above, these ratings did not significantly differ by the race of the target. Participants thus took into account both race and subtype of the target when they made their benevolent evaluations, but were not significantly influenced by race when assessing the target on other traits. These findings, in light of the partial support of Hypothesis 1a, suggest that while the chaste Black woman might receive more benevolent sexism than her White counterpart, the two women do not significantly differ on the trait impressions. Rather than the Black target's chaste 
behavior translating into higher ratings of warmth, competence, and agency, she was instead only potentially regarded more positively in a subtle, sexist dimension.

Replication of Sibley and Wilson (2004). Our previous study did not replicate Sibley and Wilson's (2004) finding that more benevolent sexism was expressed to chaste (rather than promiscuous) women and more hostile sexism was expressed to promiscuous (rather than chaste) women. It was questioned whether this pattern would be applied to both Black and White women. It was predicted that this pattern would hold for White women, but not for Black women.

White target. Despite the non-significant race by subtype interaction in the MANOVA, in order to replicate Sibley and Wilson's (2004) analyses, we restricted the sample to the White only condition. We then replicated Sibley and Wilson's analyses, using sexual subtype and HS and BS as repeated measures. When the sample was restricted to the White condition, there was a significant interaction between the sexual subtype condition (Positive vs. Negative) and repeated measures of sexism (Hostile and Benevolent Evaluations), Wilks' Lambda $=.84, F(3,162)=31.29, p<.0001$, partial $\eta^{2}=$ .16. One-way ANOVAs were used to examine whether Sibley and Wilson's (2004) pattern of findings held up in the White condition of the current study.

Replicating Sibley and Wilson (2004), a one-way ANOVA confirmed that more benevolent sexism was expressed to the White target when she was chaste $(M=3.37, S D$ $=1.1)$ than when she was promiscuous, $(M=2.81, S D=0.90), F(1,162)=12.68, p<$ .0001 , partial $\eta^{2}=.07$, while more hostile sexism was expressed to the White target when she was promiscuous $(M=2.89, S D=0.99)$ than when she was chaste, $(M=2.39, S D=$ 
$0.95), F(1,162)=11.13, p=.001$, partial $\eta^{2}=.06$. These findings represent a replication of Sibley and Wilson (2004) for White females.

Black target. Despite the non-significant interaction from the first MANOVA, it was then tested whether the same results would emerge when participants read about the Black target, Lakisha. When the sample was restricted to the Black condition, there was a significant interaction between the sexual subtype condition (Positive vs. Negative) and repeated measures of sexism (Hostile and Benevolent Evaluations), Wilks' Lambda=.89, $F(3,146)=18.33, p<.0001$, partial $\eta^{2}=.11$. One-way ANOVAs were used to test whether Sibley and Wilson's (2004) pattern of findings held up in the Black condition of the current study.

Consistent with Sibley and Wilson (2004), more benevolent sexism was expressed to the Black target when she was chaste $(M=3.74, S D=1.05)$ than when she was promiscuous, $(M=2.89, S D=0.99), F(1,149)=26.27, p<.0001$, partial $\eta^{2}=.15$. However, expressions of hostile sexism did not significantly differ when the Black target was chaste $(M=2.62, S D=0.93)$ or promiscuous, $(M=2.81, S D=1.13), F(1,147)=$ $1.32, p=.25$, partial $\eta^{2}=.01$. These simple effects in the Black condition suggest that Sibley and Wilson's (2004) pattern of results do not necessarily apply to women of color, as comparable amounts of hostile sexism were directed at the Black target even when she was chaste. This suggests that racial attitudes may be more strongly related to the level of hostile sexism that is applied to Black females.

\section{Zero sum measures}

The second set of hypotheses concerned whether the target woman would be more likely to be picked to represent a positively or negatively subtyped organization when she 
was Black or White. A logistic regression analysis was conducted to evaluate the relationships between the likelihood of getting picked for the job and the target woman's race, sexual subtype, and the interaction between race and subtype. The outcome variable indicated whether the female target (Emily or Lakisha) was selected for the job (coded $1=$ picked, $0=$ not picked). In the overall model, the three predictors together (race, subtype, and the interaction of race and subtype) were significantly related to the log odds of getting picked for the job, $\chi^{2}(3)=9.11, p=.028$, Cox-Snell $R^{2}=.03$.

However, when the predictors were examined separately in follow up analyses, only subtype emerged as a marginally significant predictor of the log odds of getting picked, $\mathrm{B}=-.53$, Wald $\chi^{2}$ statistic $=2.32, p=.11$, such that being promiscuous marginally decreased the log likelihood of getting chosen for the job by .52. Controlling for the other variables, race, $\mathrm{B}=.22$, Wald $\chi^{2}$ statistic $=0.43, p=.51$, and the interaction of race and subtype, $\mathrm{B}=-.32$, Wald $\chi^{2}$ statistic $=0.86, p=.50$, were not significant predictors of getting chosen for a job at the Wellness Federation. Though the interaction between race and subtype was non-significant, we examined the simple effects to see if there would be suggestive support for the hypotheses. The specific a priori comparisons associated with the zero sum hypotheses were subsequently tested (2a-2b).

Hypothesis 2a. It was predicted that Emily would be more likely than Lakisha to be chosen for a position at a positively subtyped organization, as this would be consistent with the racial stereotypes of White women as chaste. Despite the non-significant interaction, a 2 X 2 contingency table analysis was conducted to assess the relationship between race (Black vs. White) and whether the target was picked (Yes vs. No) when she was in the positive subtype. Results can be seen in Figure 3. There was no significant 
relationship between the two variables, $\chi^{2}(1, N=146)=0.43, p=.51$, Phi $=.05$. Contrary to the hypothesis, Emily was not statistically more likely to be chosen than Lakisha to represent the positively subtyped organization, $\chi^{2}(1, N=69)=0.13, p=.72$. Furthermore, there was no significant difference between the rates at which Emily, $\chi^{2}(1, N=74)=$ $0.87, p=.35$, and Lakisha, $\chi^{2}(1, N=72)=0.00, p=1$, were picked (vs. not picked) when they were chaste.

That this effect occurs even though there was some suggestive support that more benevolent sexism was expressed to Lakisha than Emily suggests that Lakisha, though she receives more "praise" in the form of benevolent sexism for her good behavior, experiences no marked advantage on the zero sum outcome. It was predicted that Lakisha would be at a disadvantage for this zero sum outcome, given the negative stereotypes of her race. Instead, there was no statistically significant difference between the rates at which the two women were picked. While this null result does not directly support Hypothesis 2a, the partial support for the finding that the "positive" benevolent sexism directed at Lakisha does not lead to her getting selected for the job more often consistent with shifting standards research that non-zero sum rewards for behavior do not necessarily lead to zero sum rewards (Gupta, Jenkins, \& Beehr, 1983; Biernat \& Fuegen, 2001; Biernat \& Vescio, 2002).

Other selection. Over $60 \%$ of participants (194 persons) did not select the female target from the story for the job. Follow-up tests examined what race of applicant participants chose for the position when they did not pick the target. That is, what was the race of the woman they selected if they did not pick the target? If participants picked another White woman (Lauren Reilly) for a job at the positively subtyped organization 
rather than one of the two Black women (Shavonn Jefferson and Jazmine Booker), then this would offer indirect support for Hypothesis $2 \mathrm{a}$, which associates White women with the positive subtype. For participants that did not choose the target woman, a logistic regression was used to determine the likelihood of picking a candidate of the opposite race (coded 0 ) or the same race (coded 1) given the race condition, subtype condition, and the interaction of race and subtype. In the overall regression model, the three predictors together were significantly related to the log odds of picking a candidate of the same race, $\chi^{2}(3)=70.00, p<.001$, Cox-Snell $R^{2}=.30$.

In breaking down the effects, when the predictors were examined separately, race was the only significant predictor of the outcome, $\mathrm{B}=4.14$, Wald $\chi^{2}$ statistic $=15.02, p<$ .0001 , while subtype, $\mathrm{B}=1.65$, Wald $\chi^{2}$ statistic $=2.28, p=.13$, and the interaction, $\mathrm{B}=-$ 1.66, Wald $\chi^{2}$ statistic $=2.01, p=.16$, were not significant. Despite the non-significant interaction, we continued to examine the follow up effects to get an indication of patterns of support. A follow-up 2 X 2 contingency table analysis was conducted to assess the relationship between the race of the target (Black vs. White) and the race of the candidate who was ultimately chosen (opposite vs. same race of the target woman) when she was in the positive subtype. There was a significant relationship between these two variables, $\chi^{2}(1, N=77)=31.50, p<.0001, \mathrm{Phi}=.64$, indicating that participants who read about Emily but did not choose her were more likely to then pick a woman of the opposite race (Black) for the position, $\chi^{2}(1, N=41)=37.10, p<.0001$, Figure 4 . This result suggests that instead of choosing a woman whose race was stereotypically consistent with the organization, participants in the White condition were more likely to choose a Black woman. 
Conversely, participants who read about Lakisha but then did not choose did not significantly differ in the rates at which they picked another Black applicant or the White applicants, $\chi^{2}(1, N=36)=1.78, p=.18$, Figure 5. This may indicate that the benevolent sexism expressed to Lakisha in the positive subtype not only failed to significantly increase perceptions of her warmth, competence and agency and make her more likely to be picked for a job, the possible benefits also did not extend to other members of her racial group. Participants who read about Lakisha expressed more benevolent sexism towards her than those who read about Emily (Hypothesis 1a), which is suggestive of shifting standards. However, neither Lakisha nor the other Black candidate received zero sum rewards for behaving in ways consistent with the positive subtype. If they had, then Lakisha would have been picked more often than Emily or the other Black candidate would have been selected more often than the two White candidates. Despite the nonsignificant interactions, taken together, these findings suggest that there was not something about Lakisha in particular that participants did not like; neither Black candidate benefitted from her chaste behavior on the zero sum outcome.

Hypothesis 2b. Given the racial stereotypes of Black women, it was predicted that Lakisha would be more likely than Emily to be chosen to represent a negatively subtyped organization. A 2 X 2 contingency table analysis was conducted to assess the relationship between race (Black vs. White) and whether the target was picked (Yes vs. No) when she was in the negative subtype. Results can be seen in Figure 6. Again, there was no significant relationship between these variables, $\chi^{2}(1, N=170)=0.01, p=.76$, Phi $=-.02$. As there was no significant difference between the rates at which Lakisha and Emily were chosen to represent the negatively subtyped organization, $\chi^{2}(1, N=53)=$ 
$0.47, p=.49$, our hypothesis was not supported. Subtype greatly influenced whether the woman was picked for a job, such that both Emily, $\chi^{2}(1, N=90)=11.38, p=.001$, Phi $=$ -.13 , and Lakisha, $\chi^{2}(1, N=80)=12.80, p<.0001$, Phi $=-.20$, were far less likely to be picked (vs. not picked) when they were characterized as promiscuous.

Other selection. Next the race of applicant participants picked for the position when they did not pick the target was examined. If participants picked another Black woman (Shavonn Jefferson) for a job at the negatively subtyped organization rather than one of the two White women (Lauren Reilly and Meredith Olson), this would offer indirect support for Hypothesis 2b, which associates Black women with the negative subtype.

As stated above, race was the only significant predictor of the outcome, $B=4.14$, Wald $\chi^{2}$ statistic $=15.02, p<.0001$, with subtype, $\mathrm{B}=1.65$, Wald $\chi^{2}$ statistic $=2.28, p$ $=.13$, and the interaction, $\mathrm{B}=-1.66$, Wald $\chi^{2}$ statistic $=2.01, p=.16$, being nonsignificant. Despite the non-significant interaction, a follow-up 2 X 2 contingency table analysis was conducted to assess the relationship between the race of the target (Black vs. White) and the race of the candidate who was chosen (opposite vs. same race) when she was in the negative subtype. There was a significant relationship between these two variables, $\chi^{2}(1, N=117)=31.10, p<.0001$, Phi $=.52$. The same pattern emerged for Emily as in the positive subtype: participants who did not choose her were more likely to select a woman of the opposite race (Black) for the job, $\chi^{2}(1, N=61)=36.21, p<.0001$, Figure 7. This finding, coupled with the identical pattern for Emily in the positive subtype, indicates that participants in the White condition tended to choose Black job candidates regardless of their behavior, which is suggestive of impression management. 
However, participants who read about Lakisha but did not pick her were then marginally more likely to select another Black woman for the position, $\chi^{2}(1, N=56)=2.57, p=.11$, Figure 8 . That participants who read about Lakisha in the positive condition did not differ in the rates with which they subsequently chose a Black or a White applicant, $\chi^{2}(1, N=$ $36)=1.78, p=.18$, while these rates marginally different in the negative condition, is consistent with the idea that Blackness is associated with promiscuity on a zero sum outcome (Hypothesis 2b).

\section{Moderators}

Baseline levels of ambivalent sexism, modern racism, and participant gender were examined separately as possible moderators of each of the above effects. As recommended by Aiken and West (1991), the continuous variables were centered with the mean set at zero in order to simplify interpretation of the interaction effects. To test whether the potential moderators influenced the non-zero sum behaviors towards the female target, they were entered into hierarchical regressions. The race condition, sexual subtype condition, and centered moderator were in the first step, the interactions of race and subtype, subtype and centered moderator, and race and centered moderator were in the second step, and the interaction between race, subtype, and the centered moderator were in the third step. Post-manipulation scores on the modified hostile and benevolent sexism subscales were the dependent variables. If the three-way interaction term was significant (or approached significance) in the third step, Interaction software was used to test the two-way interaction and simple effects.

Benevolent evaluations in chaste subtype. The data were broken down by sexual subtype in order to see if participants' level of hostile sexism, modern racism, 
benevolent sexism, or gender interacted with target race on their application of benevolent sexism. We wanted to know if any of these potential moderators impacted the benevolent sexism directed at the Black and White targets in the chaste condition, which is consistent with Hypothesis 1a.

Hostile sexism as moderator. First, hostile sexism was examined as a potential moderator of the effect of target race and sexual subtype on benevolent sexism. The three-way interaction between participants' baseline hostile sexism, the target race, and the target subtype tended toward significance, $\mathrm{B}=.29, t(304)=1.42, p=.16$, adjusted $\mathrm{R}^{2}$ $=.21$, suggesting that hostile sexism may moderate the relationship between race and sexual subtype on benevolent sexism toward the female target. As Hypothesis 1a concerned the benevolent sexism directed only at chaste women, only the positive sexual subtype was subsequently tested. Despite the non-significant three-way interaction, the simple effects were examined in order to further explore how an individual's hostile sexism impacts how they perceive different races of chaste women. The two-way interaction between hostile sexism and target race on benevolent sexism in the chaste condition was subsequently examined and found to be significant, $\mathrm{B}=-.38, \mathrm{SE}=.15$, $t(140)=-2.54, p=.01$. This indicates that the effect of baseline hostile sexism on benevolent evaluations in the chaste condition differed for the Black and White targets. A test of the simple slopes confirmed that higher baseline hostile sexism predicted more benevolent evaluations of both the chaste White, $\mathrm{B}=.63, \mathrm{SE}=.11, t(140)=5.93, p$ $<.0001$, and chaste Black, $\mathrm{B}=.25, \mathrm{SE}=.11, t(140)=2.34, p=.02$, targets (Figure 9). The slope was significantly steeper for the White target. The slopes suggest that individuals high in hostile sexism directed more benevolent sexism at the female when she was 
White than when she was Black. Though there was a non-significant three-way interaction, the significant two-way interaction pattern suggests that participants' baseline hostile sexism might impact the benevolent sexism they expressed to the chaste Black and White targets.

Benevolent Sexism as moderator. We examined whether participants' baseline benevolent sexism interacted with target race to affect benevolent sexism directed to the chaste target. The three-way interaction between participants' baseline benevolent sexism, the target race, and the target subtype was not significant, $\mathrm{B}=.016, t(306)=$ $0.10, p=.92$, adjusted $\mathrm{R}^{2}=.57$, indicating that benevolent sexism did not interact with target race and sexual subtype on evaluations of benevolent sexism. Despite the nonsignificant interaction, follow up analyses were run in order to further elucidate how participants' benevolent sexism impact heir benevolent evaluations of the chaste targets. The two-way interaction between benevolent sexism and target race on benevolent evaluations of the chaste target was then examined and found to be non-significant, $\mathrm{B}=$ $.02, \mathrm{SE}=.11, t(140)=-.15, p=.88$. There was no main effect of target race, $\mathrm{B}=.03, \mathrm{SE}$ $=.11, t(140)=-.29, p=.77$, but there was a main effect of baseline benevolent sexism, $\mathrm{B}=3.53, \mathrm{SE}=.08, t(140)=45.69, p<.0001$, indicating participants with higher baseline benevolent sexism tended to express more benevolent sexism overall. Participants' baseline benevolent sexism did not moderate their benevolent evaluations of the target by race in the positive subtype.

Modern Racism as moderator. Next we examined whether participants' levels of modern racism interacted with target race to affect benevolent sexism. The three-way interaction between participants' modern racism, the target race, and the target subtype 
was significant, $\mathrm{B}=.79, t(307)=3.23, p=.001$, adjusted $\mathrm{R}^{2}=.20$. The two-way interaction between modern racism and target race in the positive subtype was then tested and found to be significant, $\mathrm{B}=.95, \mathrm{SE}=.19, t(141)=5.02, p<.0001$. Breaking down the interaction, the simple slopes indicated that higher scores on the Modern Racism Scale predicted more benevolent evaluations, but only for the chaste White target, $\mathrm{B}=$ $.86, \mathrm{SE}=.15, t(141)=5.86, p<.0001$, Figure 10. Modern racism was not related to benevolent evaluations of the chaste Black target, $\mathrm{B}=-.09, \mathrm{SE}=.12, t(141)=-0.73, p$ $=.47$.

Gender as moderator. Finally, we examined whether participants' gender interacted with the target race to affect benevolent sexism toward at the chaste target. The three-way interaction between participants' gender, the target race, and the target subtype was not significant, $\mathrm{B}=-.42, t(307)=-.92, p=.36$, adjusted $\mathrm{R}^{2}=.11$, indicating that gender did not interact with target race on evaluations of benevolent sexism in the positive subtype. Despite the non-significant finding, the two-way interaction was examined in order to better understand how participants' gender interacted with target race to impact benevolent evaluations of the chaste target. The two-way interaction between participant gender and the race of the target was examined and found to be not significant, $\mathrm{B}=.05, \mathrm{SE}=.36, t(141)=.13, p=.89$. There was also no main effect of target race, $\mathrm{B}=-.43, \mathrm{SE}=.56, t(141)=-.77, p=.44$, or participant gender, $\mathrm{B}=-.09, \mathrm{SE}=$ $.26, t(141)=-.38, p=.71$. Participant gender was not a moderator of the relationship between target race and benevolent evaluations.

Hostile evaluations in promiscuous subtype. Next, we looked at the negative sexual subtype to see if participants' baseline hostile sexism, benevolent sexism, modern 
racism, and gender moderated the relationship between target race and hostile evaluations, which is consistent with Hypothesis $1 \mathrm{~b}$. That is, we tested whether any of the potential moderators impacted the hostile evaluations of the promiscuous Black and White targets (Hypothesis 1b).

Hostile sexism as moderator. First, we examined if participants' baseline hostile sexism moderated the effect of target race on hostile evaluations. In the regression analyses, the three way interaction between participants' baseline hostile sexism, target race, and target subtype trended toward significance, $\mathrm{B}=.21, t(301)=1.55, p=.12$, adjusted $\mathrm{R}^{2}=.61$. As Hypothesis $1 \mathrm{~b}$ concerned the hostile sexism directed only at promiscuous women, only the negative sexual subtype was subsequently examined. Despite the non-significant three-way interaction, the two-way interaction was examined. The two-way interaction between hostile sexism and target race on hostile evaluations in the negative subtype was not significant, $\mathrm{B}=.15, \mathrm{SE}=.09, t(164)=1.50, p=.13$, as was the main effect of target race, $\mathrm{B}=.01, \mathrm{SE}=.15, t(164)=.08, p=.94$. There was a significant main effect of participants' baseline hostile sexism on their hostile evaluations of the target, such that higher baseline hostile sexism predicted more hostile evaluations, $\mathrm{B}=.69, \mathrm{SE}=.07, t(164)=9.87, p<.0001$, Figure 11.

Benevolent Sexism as moderator. We examined whether participants' baseline benevolent sexism interacted with target race to affect hostile sexism directed to the promiscuous target. The three-way interaction between participants' baseline benevolent sexism, target race, and target subtype was not significant, $\mathrm{B}=.20, t(304)=.86, p=.39$, adjusted $\mathrm{R}^{2}=.15$. Benevolent sexism did not interact with target race and subtype on evaluations of hostile sexism. Though this interaction was not significant, the two-way 
interaction was examined in order to better understand how an individuals' benevolent sexism might impact the hostile sexism they direct at promiscuous Black and White women. The two-way interaction between benevolent sexism and target race on hostile evaluations in the negative subtype was not significant, $\mathrm{B}=.14, \mathrm{SE}=.16, t(164)=.85, p$ $=.39$, as was the main effect of target race, $\mathrm{B}=-.07, \mathrm{SE}=.16, t(164)=-.05, p=.62$. There was a significant main effect of participants' baseline benevolent sexism on their hostile evaluations of the target, such that higher baseline benevolent sexism predicted more hostile evaluations overall, $\mathrm{B}=.24, \mathrm{SE}=.11, t(164)=27.15, p<.0001$.

Modern Racism as moderator. Next we examined whether participants' levels of modern racism interacted with race to affect hostile sexism toward the promiscuous target. Regression analyses confirmed a significant three-way interaction between modern racism, race, and subtype, $\mathrm{B}=.47, t(305)=2.10, p=.04$, adjusted $\mathrm{R}^{2}=.25$. The two-way interaction between modern racism and target race in the negative subtype was then tested and found to be not significant, $\mathrm{B}=.19, \mathrm{SE}=.16, t(166)=1.19, p=.24$. There was no main effect of race, $\mathrm{B}=.04, \mathrm{SE}=.15, t(166)=.25, p=.80$, but there was a main effect of modern racism, $\mathrm{B}=2.79, \mathrm{SE}=.11, t(166)=26.52, p<.0001$, such that higher modern racism scores predicted more hostile evaluations of both the promiscuous Black and White targets, Figure 12.

Gender as moderator. We tested whether participants' gender interacted with the target race to affect hostile sexism toward at the promiscuous target. The three-way interaction between participant gender, target race, and target subtype was not significant, $\mathrm{B}=-.07, t(305)=-.17, p=.87$, adjusted $\mathrm{R}^{2}=.08$. Though the interaction was not significant, it was previously found in our study, consistent with prior research, that the 
male participants endorsed hostile sexism more strongly than the female participants, $t(310)=4.83, p<.0001$. The two-way interaction was examined in order to explore whether participants' gender influenced the hostile sexism they directed at the promiscuous Black and White targets. The subsequent two-way interaction between participant gender and target race was also not significant, $\mathrm{B}=.21, \mathrm{SE}=.31, t(166)=$ $.67, p=.50$. There was no main effect of race, $\mathrm{B}=-.26, \mathrm{SE}=.50, t(166)=-.53, p=.59$, but there was a main effect of sex $, \mathrm{B}=3.84, \mathrm{SE}=.37, t(166)=10.32, p<.0001$, such that women tended to express less hostile sexism. Though there was a main effect of gender, participant gender did not moderate the relationship between target race and on evaluations of hostile sexism in the negative subtype.

Likelihood of being picked. To determine whether baseline levels of hostile and benevolent sexism, participant gender, and modern racism moderated the zero sum behavior measure (selecting the female target for the job), hierarchical logistic regressions were employed. The dependent variable was whether the woman was picked or not (coded $1=$ picked, $0=$ not picked). In the same manner as above, the race condition, sexual subtype condition, and centered moderator were in the first step, the interactions of race and subtype, subtype and centered moderator, and race and centered moderator were in the second step, and the interaction between race, subtype, and the centered moderator were in the third step.

Hostile sexism as moderator. First, hostile sexism was examined as a potential moderator of the effect of target race and sexual subtype on the likelihood of picking the target for the job. The three-way interaction between participants' baseline hostile sexism, the target race, and the target subtype, was non-significant, $\mathrm{B}=-.52$, Wald $\chi^{2}$ 
statistic $=1.32, p=.25$. There were no significant main effects of race, $\mathrm{B}=.29, \mathrm{SE}=.34$, Wald $=.73, p=.39$, subtype, $\mathrm{B}=-.49, \mathrm{SE}=.33$, Wald $=2.16, p=.14$, or hostile sexism, $\mathrm{B}=-$ $.19, \mathrm{SE}=.23, \mathrm{Wald}=.73, p=.39$. Despite the non-significant three-way interaction, follow-up analyses were run in order to explore how an individual's hostile sexism may impact how they treat chaste and promiscuous women seeking a job.

In the positive sexual subtype, the two-way interaction between participants' hostile sexism and target race on the likelihood of picking the target was subsequently examined and found to be non-significant, $\mathrm{B}=.01, \mathrm{SE}=.08, t(153)=.08, p=.94$.

However, in the negative condition, the two-way interaction between hostile sexism and target race was marginally significant, $\mathrm{B}=-.11, \mathrm{SE}=.07, t(164)=-1.68, p=.10$. This indicates that the effect of hostile sexism on the likelihood of picking the target in the negative subtype condition may differ for the Black and White targets. A test of the simple slopes confirmed that the higher participants' baseline hostile sexism, the less likely they were to pick the Black target, $\mathrm{B}=-.10, \mathrm{SE}=.05, t(164)=2.01, p=.05$. The likelihood of picking the White target in the negative subtype condition was not affected by baseline hostile sexism, $\mathrm{B}=.02, \mathrm{SE}=.05, t(164)=.37, p=.71$. Though there was not a significant three-way interaction, the marginally significant two-way interaction in the negative subtype suggests that participants' baseline hostile sexism impacts their likelihood of selecting the Black, but not White, target for a job when she is promiscuous.

Benevolent sexism as moderator. Next we tested whether participants' baseline benevolent sexism interacted with target race and sexual subtype to affect the likelihood of choosing the target for a job. The three-way interaction between participants' baseline benevolent sexism, the target race, and the target subtype was not significant, $\mathrm{B}=.04$, 
Wald $\chi^{2}$ statistic $=.006, p=.94$. There were no significant main effects of race, $\mathrm{B}=.18, \mathrm{SE}$ $=.34, \mathrm{Wald}=.27, p=.60$, subtype $\mathrm{B}=-.53, \mathrm{SE}=.33, \mathrm{Wald}=2.59, p=.11$, or benevolent sexism, $\mathrm{B}=.18, \mathrm{SE}=.24$, Wald= $=.56, p=.45$. Despite the non-significant three-way interaction, follow-up analyses were run in order to investigate the potential impact of participants' baseline benevolent sexism on their likelihood of choosing whether a promiscuous or chaste woman should be selected for a job.

In the positive sexual subtype, the two-way interaction between participants' benevolent sexism and target race on the likelihood of picking the target was examined and found to be non-significant, $\mathrm{B}=.004, \mathrm{SE}=.09, t(153)=.05, p=.96$. Similarly, the two-way interaction between participants' benevolent sexism and target race on the likelihood of picking the target in the negative sexual subtype was also not significant, $\mathrm{B}=.004, \mathrm{SE}=.08, t(153)=-.06, p=.95$. Participants' baseline benevolent sexism did not moderate their likelihood of picking the target.

Modern Racism as moderator. Next we examined whether participants' levels of modern racism interacted with target race to affect their likelihood of choosing the target. The three-way interaction between participants' modern racism, the target race, and the target subtype was not significant, $\mathrm{B}=-.10$, Wald $\chi^{2}$ statistic $=.03, p=.85$. There were no significant main effects of race, $\mathrm{B}=.22, \mathrm{SE}=.34$, Wald=.40, $p=.53$, subtype, $\mathrm{B}=-.50, \mathrm{SE}$ $=.33, \mathrm{Wald}=2.30, p=.13$, or modern racism, $\mathrm{B}=-.13, \mathrm{SE}=.31$, Wald $=.17, p=.68$. Despite this non-significant interaction, follow-up analyses were run in order to further investigate whether participants' modern racism affected their likelihood of choosing whether a promiscuous or chaste woman should be selected for a job. 
In the positive sexual subtype, the two-way interaction between participants' modern racism and target race on the likelihood of picking the target was examined and found to be non-significant, $\mathrm{B}=.08, \mathrm{SE}=.09, t(153)=.86, p=.39$. The two-way interaction between participants' modern racism and target race on the likelihood of picking the target in the negative sexual subtype was also not significant, $\mathrm{B}=.09, \mathrm{SE}=$ $.08, t(164)=1.14, p=.26$. Participants' modern racism did not moderate their likelihood of picking the target.

Gender as a moderator. Finally, we examined whether participants' gender interacted with target race and sexual subtype. When gender was used as a predictor in the regression analyses, it was significantly related to the log odds of picking the target, $\chi^{2}(1)=3.80, p=.05$, Cox-Snell $R^{2}=.05$, and the three way interaction of participant gender, target race, and target subtype was marginally significant, $\mathrm{B}=-1.85$, Wald $\chi^{2}$ statistic $=3.76, p=.052$.

To follow up on this effect, the data were then split into two groups, male and female, in order to better examine the effect of gender on the primary zero sum outcome. For female participants, the three predictors together (race, subtype, and their interaction) were significantly related to the log odds of getting picked for the job, $\chi^{2}(3)=10.29, p=$ .016 , Cox-Snell $R^{2}=.06$. However, when examined separately, only subtype was a significant predictor of the log odds of getting picked, $\mathrm{B}=-1.33$, Wald $\chi^{2}$ statistic $=7.53$, $p=.01$, such that female participants were more likely to not pick the target for a job when she was promiscuous than when she was chaste, $\chi^{2}(1, N=99)=9.71, p=.002$. Target race, $\mathrm{B}=-.23$, Wald $\chi^{2}$ statistic $=0.23, p=.63$, and the interaction of race and 
subtype, $\mathrm{B}=.63$, Wald $\chi^{2}$ statistic $=0.86, p=.35$, were not significant predictors of the zero sum outcome.

For male participants, the interaction between the target's race and sexual subtype was marginally significant in the logistic regression, $\mathrm{B}=-1.22$, Wald $\chi^{2}$ statistic $=3.30, p$ $=.07$. Follow-up tests confirmed that, for men, subtype was related to whether Lakisha was chosen for the job, $\chi^{2}(1, N=73)=4.23, p=.04$, Phi $=-.24$. Specifically, there was no significant difference between the rate at which Lakisha was picked (vs. not picked) for the job when she was chaste, $\chi^{2}(1, N=37)=.03, p=.87$. However, Lakisha was significantly more likely not to be picked (vs. picked) for the job when she was promiscuous, $\chi^{2}(1, N=36)=7.11, p=.01$. For male participants, Emily's sexual subtype was not significantly related to whether she was selected for the job or not, $\chi^{2}(1, N=83)$ $=.21, p=.64$. 


\section{Discussion}

The present study tested how a woman's race and sexual subtyped behavior impacted (non-zero sum) expressions of ambivalent sexism towards and (zero sum) cross-category decisions about her. We had predicted a significant interaction effect of race and sexual subtype consistent with shifting standards theory, such that expressions of benevolent sexism would be higher for a chaste Black woman than a chaste White woman, while expressions of hostile sexism would be higher for a promiscuous White woman than a promiscuous Black woman. We also expected decisions about who should represent sexually subtyped organizations to be consistent with racial stereotypes, such that a White woman would be more likely to be chosen to represent a positively subtyped organization while a Black woman would be more likely to be chosen to represent a negatively subtyped organization.

Ultimately, only Hypothesis 1a received partial support. Though the MANOVA interaction was not significant, the follow-up univariate ANOVA suggested that participants who read about a chaste woman expressed more benevolent sexism toward her when she was Black than when she was White. This finding, though not directly supported, is a replication of our previous study (McMahon \& Kahn, 2014). Given that the benevolent sexism ideals of purity and defenselessness are incompatible with the stereotypes of Black women as promiscuous (Jewell, 1993) and aggressive (Weitz \& Gordon, 1993), we maintain that this seemingly contradictory finding is indicative of shifting standards, whereby individuals who exceed the lower expectations of their stereotyped group receive non-zero sum rewards (such as praise) for their stereotypeinconsistent behavior. It is because expectations for Lakisha's behavior were more 
negative that participants tended to report that she should be "cherished and protected" and "set on a pedestal by her man" when she surpassed them by being chaste, even more so than her White counterpart. These effects were particularly strong for participants who highly endorsed hostile sexism.

Another key finding is that the chaste Black target was not evaluated any more positively on the trait measures than the chaste White target. Traits related to warmth, competence, and agency were included in order to determine whether the increased benevolent sexism expressed to a chaste Black woman coincided with more positive evaluations of her overall. The results suggested that participants might only treat her differently on the one positively-valenced sexist measure of benevolent sexism. Shifting standards may have only occurred for the Black target when her sexual behavior (subtype) was inconsistent with the stereotypes of her race, and did not extend to the other non-zero sum impressions made of her. In other words, the Black target may have been "praised" with benevolent sexism for her behavior but this accolade did not translate into more positive evaluations overall. Instead, there was a "halo effect of chastity" on the trait evaluations, such that the women were considered warmer, more competent, and more agentic when they were characterized as chaste rather than promiscuous, regardless of their race.

Furthermore, the trend to display increased benevolent sexism towards the chaste Black target did not result in greater zero sum rewards for her. Instead, there was no significant difference between how often the Black and White targets were chosen to represent an organization that supported the positive subtype, suggesting that Lakisha received no statistically significant advantage for her behavior when it was a zero sum 
resource. She was not picked statistically less often than Emily (as had been predicted in Hypothesis 2a), but that she was not picked more often after being "praised" so highly with benevolent sexism is consistent with previous shifting standards findings that individuals who receive non-zero sum rewards for exceeding the low expectations of their stereotyped group are not subsequently offered zero sum rewards (Gupta, Jenkins, \& Beehr, 1983; Biernat \& Fuegen, 2001; Biernat \& Vescio, 2002). Overall, these key findings might suggest a pattern whereby Black women who conform to traditional gender norms are rewarded for their behavior with increased subtle, sexist praise, but are not perceived more highly in other domains and are not rewarded with tangible, zero-sum resources.

While we had predicted that more hostile sexism would be directed at the promiscuous White target than the promiscuous Black target (Hypothesis 1b), we did not find that hostile sexism was significantly differentially applied based on race. Instead, the White and Black targets did not significantly differ in the amounts of hostile sexism they received when they were promiscuous. This suggests that shifting standards were not taking place; rather, the women were equally punished for violating the chastity ideals of their gender, irrespective of race.

Another outcome of these divergent non-zero sum findings is that, although the interaction in the MANOVA was not significant, we were able see trends that suggest a replication Sibley and Wilson (2004) in the White condition but not in the Black. Specifically, for the White target, more benevolent sexism was expressed when she was chaste and more hostile sexism was expressed when she was promiscuous. However, when the target was Black, she received more benevolent sexism when chaste but 
amounts of hostile sexism toward her did not significantly differ when her behavior was consistent with the positive and negative subtypes. These findings, though not directly supported by the MANOVA interaction, both lend support to Sibley and Wilson's (2004) conclusions about ambivalent sexism and sexual subtype and qualify them by race: this pattern of results may not generalize to women of color. As this is the first study of ambivalent sexism to explicitly examine how a woman's race may impact the hostile and benevolent evaluations of her, that we were able to demonstrate that a previously uncontested assumption might not necessarily apply to women of every race hints at the magnitude of other studies within this literature that could benefit from a more intersectional paradigm.

While greater non-zero sum behaviors were expected for targets with stereotypeinconsistent behavior, we had anticipated zero sum behaviors would favor those women whose behavior was consistent with the stereotypes of her race. Specifically, we predicted that a promiscuous Black woman would be more likely to be picked to represent a negatively subtyped organization than a promiscuous White woman (Hypothesis $2 \mathrm{~b}$ ). This hypothesis received only very marginal support, as the Black and White targets did not significantly differ in how often they were chosen to work at both the positively and negatively subtyped organizations. Participants were thus more attuned to the woman's sexual behavior than her race when they made their hiring decisions, such that the rate at which both Emily and Lakisha were chosen (rather than not chosen) for the job did not significantly differ when they were chaste but they were far more likely not to be picked when they were promiscuous. 
When participants did not choose the target for the position, the applicant they did select was greatly impacted by the race of the woman about whom they had just read. Specifically, participants who read about Emily (i.e. who were randomly assigned to the White condition) and did not choose her were subsequently more likely to choose a Black woman for the job in both subtype conditions. This indicates that our efforts to reduce the pressure participants would feel to pick a Black applicant out of fear of appearing racist were less successful. However, effects of subtype differed slightly in the Black condition: Participants who did not choose Lakisha when she was chaste did not differ in the rates at which they chose another Black or White applicant while, though it did not reach conventions of statistical significance, there was a trend in the negative subtype indicating that those who did not pick Lakisha were then marginally more likely to pick another Black applicant for the job. This would be consistent with Hypothesis $2 b$, which associated promiscuity with Blackness on the zero sum measure in the negative subtype.

\section{Limitations}

There are several potential methodological limitations to this study. The modified Ambivalent Sexism Inventory scale, borrowed from Sibley and Wilson (2004), does not use items from the original benevolent sexism scale that measure heterosexual intimacy. These items all refer to men as the subject of the sentence (e.g. "men are complete without women"), and rewriting them to refer to specific women could potentially alter their original meaning. As a result, this measure of benevolent sexism only reflects the protective paternalism and gender differentiation factors and may not generalize to evaluations driven by needs for heterosexual intimacy. 
When confirmatory factor analyses were conducted on these established measures in order to ensure an underlying single-factor structure, results suggested that four out of six measures did not fit this model. Specifically, only the modified hostile sexism subscale (Sibley \& Wilson, 2004) and the protective paternalism component of the original ASI (Glick \& Fiske, 1996) produced RMSEA fit indices below the standard cutoffs. While issues with model fit were not anticipated, these results indicate that these scales may no longer be measuring what they are presumed to measure. It is possible that the Modern Racism Scale may not be sensitive to more current expressions of racial prejudice (Neville, Lilly, Duran, Lee, \& Browne, 2000). Hayes and Swim (2013), in their investigation of how different races of participants respond to measures of sexism, only examined how well the HS and BS scales together fit a two-factor structure; to my knowledge, the ASI has not received the same level of scrutiny as it did during its conception (Glick \& Fiske, 1996). These scales might benefit from new exploratory factor analyses. Again, the underlying factor structure of the modified benevolent sexism scale may have produced poor fit indices because it was completed after participants read the manipulation vignette and were primed with race and sexual subtype, leading to the activation of racial and sexual constructs that may have altered responses to the scale in such a way as to render the original single-factor structure inappropriate. Future examinations of these modified scales should test their factor structure prior to any manipulation procedures to reduce possible priming effects.

Even though the results of the CFAs were mixed, the scales still behaved as expected. The HS and BS subscales of the ASI, the Modern Racism Scale, and the modified HS and BS scales all had internal reliabilities above .86. We also observed 
relationships between the scales that are consistent with prior research, such as moderate correlations between the HS and BS subscales (Glick \& Fiske, 1996) and between the measures of sexism and racism (Sidanius \& Pratto, 1999), and expected gender differences between men and women in their endorsement of HS (Glick \& Fiske, 2001a). Given how well the protective paternalism component of the BS scale fit a single-factor structure (while the heterosexual intimacy component did not), future examinations of benevolent sexism could limit to the protective paternalism items.

Contrary to expectations (Hypothesis 1b), hostile sexism was not differentially applied based on the target's race. Three different ideas might explain this finding. First, previous shifting standards research has relied exclusively on non-zero sum measures with a positive valence, such as cheering and saying "nice job!" on the softball field (Biernat \& Vescio, 2002) or offering positive evaluations in the workplace (Gupta, Jenkins, \& Beehr, 1983). The modified hostile sexism scale used here, with its denunciations of women's sexual manipulation, complaining, thanklessness, and power grabbing, is far more negative. To my knowledge, this was the first time that a non-zero sum measure with a negative valance has been tested. One could have reasonably expected the same sort of pattern to take place; imagine how a boy and a girl on a co-ed sports team who both underperform might not experience the same level of derision from their teammates, as the boy was expected to be better given the stereotypes of male athleticism. That there was no significant difference in the amounts of hostile sexism expressed to the promiscuous women may suggest that shifting standards occurs more exclusively with positive non-zero sum behaviors than with negative ones. 
Alternatively, participants may have been responding to different attributes of the female target when they made their hostile evaluations. That is, the White target's evaluations may have been impacted exclusively by her promiscuous behavior while evaluations of the Black target were also influenced by the other negative stereotypes of her racial group, which characterize Black women as loud, antagonistic, unmannerly (Niemann et al., 1994) and less "appropriately feminine" (Goff et al., 2008b). The statistically comparable amounts of hostile sexism expressed to the Black target when she was chaste as when she was promiscuous lend support to the claim that Lakisha was judged not only by her sexual behavior, but also in line with stereotypes of her race. Somewhat conversely, one might have expected these same negative stereotypes to also decrease the expressions of benevolent sexism directed at the Black target when she was chaste. Finally, one could also take these results at face value and conclude that promiscuous women are equally punished for violating the chastity ideals of their gender, irrespective of their race.

The zero sum measure utilized here was created for this study. Though it was closely based off other measures used within the shifting standards literature that require participants to select from a pool of candidates the person that should be given a job (Biernat \& Fuegen, 2001) or a desirable position on a sports team (Biernat \& Vescio, 2002) based on their characteristics, it had not been validated in any previous studies. Therefore, we cannot say conclusively whether the findings gathered here reflect reality or are the spurious results of a faulty measure.

Another possible limitation is that participants are not given as much information about the other three applicants as they are the woman in the story. It is likely that 
participants were able to infer the sexual behavior of the other women because they are 1) described as sharing "similar values" to the woman in the story, who has been explicitly subtyped, and 2) tied to organizations that support either the positive or negative sexual subtype, and people tend to want to work for organizations whose values are congruent with their own (Judge \& Bretz, 1992). However, there was no race manipulation check for the three other women the way there was for the target. We investigated what race of applicant participants chose when they did not choose the woman from the story, but with a name as the only racial cue, we cannot say for sure that participants correctly inferred the race of the other candidate they picked.

Finally, we had included two Black and two White applicants in an effort to reduce the pressure on the participant to select the only Black woman out of fear of appearing biased. However, those in the White condition overwhelmingly picked a Black candidate when given the chance, suggesting that their primary motivation for this task became not to appear racist. We may have been able to see the predicted effects had our zero sum measure been more subtle.

\section{Implications}

Results of this study indicated that women's race and sexual subtyped behavior influences other's subtle sexist reactions and behavior towards them. Though the potentially higher levels of benevolent sexism expressed towards the chaste Black woman are subjectively positive in nature, they belie the lower expectations held for her behavior and reveal the impact of negative racial stereotypes. It is because Black women are expected to be hypersexual that a Black woman who is described as chaste elicits surprise and applause. This is similar to how showering a female athlete with praise when 
she performs well (Biernat \& Vescio, 2002) reveals the lower expectations held for her competence and is therefore well-intentioned in spirit but condescending in nature. This contrast effect, rather than suggesting that this negative stereotype of Black women is obsolete or false, underscores how it is still operating to affect perceptions of Black women who do not conform to the negative stereotype of their racial group.

Though the effect size for the increased benevolent sexism to chaste Black women (relative to chaste White women) was small, this finding should not be discounted. It is noteworthy that this effect emerged following a manipulation as subtle as changing the female target's name. Prentice and Miller (1992) have argued that effects can still be important even when they are statistically small when researchers demonstrate how even a minimal manipulation of the independent variable can account for some variance of the dependent variable. In this study, changing the woman's name from Emily to Lakisha was enough to create a significant increase in benevolent sexism (though this finding was not directly supported by the MANOVA.) This finding has consequences for women in the real world insofar as it could produce differential treatment, perhaps in the form of racial and gender-based microaggressions, or commonplace verbal or behavioral slights that communicate negative perceptions of a person or their group (Sue, 2010). For instance, Black teenagers participating in a chastity ball, wearing a purity ring, or dressing modestly might receive increased praise for these actions in ways that communicate to them that they were not expected to behave like this based on their racial identity. These microaggressions build on each other over time to produce negative psychological consequences, such as higher stress, feelings of powerlessness, and loss of integrity (Sue, Capodilupo, \& Holder, 2008). 
Furthermore, the chaste Black woman in our study was not statistically more likely to be given a job related to her subtype than her White counterpart. This could suggest that Black women who choose to conform to benevolent sexist ideals may receive increased praise for their "good" behavior, but might experience confusion when it does not lead to more tangible rewards. The pattern of non-zero sum rewards not necessarily leading to zero sum rewards could contribute to the overall differential treatment of Black and White women highlighted previously. For instance, the resume bearing a Black woman's name might be highly praised by the hiring manager, but that does not mean that candidate is any more likely to get a callback (Bertrand \& Mullainathan, 2003). In the same way, Black women may receive more positive evaluations on the job than their White female coworkers, but they are still paid 13 cents less on the dollar (National Women's Law Center, 2013). One might anticipate that Black women in another subtype that elicits benevolent sexism, motherhood, may also be denied zero sum rewards relative to White mothers (elaborated below).

The Black target did not experience significantly different levels of hostility when she was chaste as when she was promiscuous, suggesting that Black women may continue to experience hostility regardless of their adherence to traditional norms of chastity. Again, this could come in the form of racial and gender-based microaggressions, such as insinuations that a Black woman who is chaste or a good mother does so in spite of her race or is somehow less desirable than her White counterpart. As previously stated, these experiences can lead to negative psychological consequences (Sue, Capodilupo, \& Holder, 2008). 
The treatment of women who were characterized as promiscuous was overwhelmingly negative in this study: they received more hostile evaluations, were considered less warm, competent, and agentic, and were less likely to be selected for a job they wanted than women who were chaste. The effect sizes for the hiring outcome for Emily and the hostile evaluations and impressions of agency for both women were small, while the effect sizes for the hiring outcomes for Lakisha and impressions of warmth and competence for both women were medium-sized. These findings hint at very real-world consequences for women who are perceived this way, both in the domains of person perception and hiring practices. Women who have a reputation of promiscuity in the workplace may find themselves being treated as though they are incompetent or unfriendly. Experiences of workplace incivility have been linked to greater psychological distress and decreased job satisfaction (Cortina, Magley, Williams, \& Langhout, 2001). Furthermore, our findings suggest that these women may be passed over for promotions, which has serious implications for their financial well-being.

In the spirit of Mortensen and Cialdini's Full-Cycle Model (2010), this project began with the observation that Black women are not afforded the same chivalrous and protective treatments as White women (Sojourner Truth's quote, Missing White Woman Syndrome, etc.) I demonstrated in this controlled experiment that benevolent sexism may be differentially applied based on a woman's race and behavior in a way that is consistent with shifting standards. It is my hope that this first step in elucidating the relationship between ambivalent sexism and race will be useful for one day predicting more applied outcomes in my future research. 


\section{Future Directions}

Non-zero sum behaviors, in the form of hostile and benevolent sexism, can be endlessly directed at women whose behavior does not conform to the stereotypes of their race. However, the present study was unable to demonstrate shifting standards of hostile sexism toward promiscuous White women. Future studies may want to examine if this effect emerges in a more applied setting. For example, young, White celebrities who are considered promiscuous may be greater targets of shame in the media than their Black counterparts. We see this in the divergent reactions to Miley Cyrus and Rihanna's sexualized performances. Punishments could also be observed in the criminal justice domain as well, with White women who violate expectations of their racial group by being prostitutes receiving more severe punishments upon arrest than Black prostitutes. Evidence suggests that prostitutes are seen as violating cultural values (Rosenblatt, Greenberg, Solomon, Pyszczynski, \& Lyon, 1989), but the strength of this perception and subsequent treatment of this woman might differ depending on her race. This could come in the form of a judge recommending harsher bonds or a police officer using more force or callous language. These and other experiments would help to clarify if and how reactions to women who violate traditional gender roles by being promiscuous are influenced by her race.

Ambivalent sexism researchers may want to test how hostile and benevolent sexism are expressed based on not only subtypes but also concurrent racial categorizations and stereotypes. In the domain of shifting standards, future research will want to explore whether more negative non-zero sum behaviors, such as expressions of hostility, disgust, or ridicule, shift in the same fashion as the previously-established 
positive non-zero sum behaviors. Further explorations of how ambivalent sexism is applied to women of different races may want to make use of indirect measures of implicit attitudes, especially given the social sensitivity of this topic (Greenwald, Poehlman, Uhlmann, \& Banaji, 2009). Though the ambivalent sexism literature has long differentiated between subtypes of women based on their adherence to traditional gender roles (Glick et al., 1997), it could be that race itself functions as a subtype. Instead of characterizing targets in a study as chaste or promiscuous, racial groups could be activated and endorsement of ambivalent sexism subsequently measured.

Zero sum behaviors towards women, according to shifting standards theory, should assimilate to stereotypes of their race. That is, people should be more likely to give finite resources to a woman whose sexual behavior is consistent with the positive stereotypes of her race. Though that effect was not clearly demonstrated here, it would be premature to assume that it would not be observed in other domains, especially when participants do not have sufficient motivation or opportunity to avoid a racist outcome (Fazio \& Olson, 2003). For instance, police officers may spend more time and resources responding to a chaste woman's plea for help, such as in the reporting of an attempted rape or sexual harassment, when the woman is White rather than Black. Participants may also be more willing to give zero sum rewards to a chaste White woman after they have first been given the opportunity to establish their credentials as nonprejudiced individuals (Monin \& Miller, 2001). It would be important to test whether these effects would extend to not only just one woman but entire racial groups of women. For example, organizations and social policies that promote sexual purity (e.g. abstinence-only sex education, chastity balls, etc.) may receive more financial support, in the form of 
individual donations or grants, or votes when they are seen as benefitting White, rather than Black, women and girls.

Again, this study neither intends to portray benevolent sexism as a positive thing, nor to imply that benevolent sexism ought to be expressed toward Black and White women equally. We maintain that it is an insidious form of subtle prejudice that reinforces the subordinate status of women by praising women who conform to traditional gender roles and expectations. By knowing who benevolent and hostile sexism are more directed toward and when, we can more effectively target and inform different intervention strategies.

Using a modified version of Sibley and Wilson's (2004) basic vignette, we were able to easily manipulate the female target's race and sexual behavior. Though it has been suggested that vignettes may lack external validity (Gould, 1996), decision-making and impression formation based on limited information is a well-established tenet of social psychology (Fiske, Gilbert, \& Lindzey, 2010). In hiring, academic, or admissions processes, individuals are often reduced to words on a page. Vignettes, rather than pictures or real interactions, allow us to provide participants with enough information to form impressions and make decisions about individuals without being influenced by their attractiveness, clothing, voice, body language, or racial stereotypicality. Experimenters looking to further increase their written manipulation's ecological validity could make use of Facebook or other social media profiles.

This study has important theoretical implications as well. We have demonstrated how Sibley and Wilson's (2004) findings regarding expressions of hostile and benevolent sexism may not generalize to women of color. Future studies will also want to examine 
how ambivalent sexism is differentially applied to Hispanic and Asian Americans, as well as other ethnic groups in other settings. Though ambivalent sexism has been measured and found in many countries (Glick et al., 2000), it would be hasty to assume that our results could be easily replicated in other predominantly White countries. The stereotype of Black women as sexually available has its roots in slavery in the American antebellum South (Jewell, 1993); it is possible that our findings would not generalize to countries that do not share this history. Instead, results may be contingent upon the ethnic groups that exist in a particular country and the stereotypes about those groups that are specific to that time and location.

A crucial next step will be to test what pattern of results emerges for Black and White women when the subtypes are based on traditional roles rather than sexual behavior; that is, when the comparison is between mothers/housewives and career women. A host of zero sum behaviors could be related to these subtypes, such as financial support or votes for the Equal Pay Act, efforts to recruit women into STEM fields, subsidies for stay-at-home mothers, paid maternity leave, prenatal care, etc. These zero sum outcomes may correspond to the traditional/nontraditional subtypes. For instance, it has been argued that idealized motherhood is White (Roberts, 1993). One might predict that in a study similar to this one, a Black mother is regarded with benevolent sexism (non-zero sum) for violating the norms of her race but then not granted a monetary subsidy (zero sum) that would help her family. 


\section{Conclusion}

In summation, this study found suggestive evidence that more benevolent sexism may be expressed to a chaste Black woman than a chaste White woman. However, there was no significant difference between the chaste Black and White women on the trait evaluations that assessed their warmth, competence, and agency. The chaste Black woman was also not statistically any more likely to be picked for a job she wanted. Black women who choose to conform to traditional gender norms may receive praise in the form of benevolent sexism, but they may not be perceived any more positively overall or be given tangible rewards for their behavior.

The paradigm proposed here is the first in a long line of research to bring a muchneeded intersectionality perspective to the ambivalent sexism literature. It calls into question the generalizability of many studies that use the ASI, which have, to my knowledge, failed to broach the subject of race. To the extent that this proves a fruitful line of inquiry, others may be encouraged to examine more constructs related to gender through the lens of race, and theories of racism in the context of gender. A more thorough and representative understanding of gender and racial prejudice will eliminate the overwhelming bias in the field that the primary targets of sexism are White women and the primary targets of racism are Black men, resulting in a discipline better able to address discrimination in all its contemporary forms. 
Table 1

Correlations Between Hostile Sexism, Benevolent Sexism, and Modern Racism

$\begin{array}{llll}\text { Measure } & 1 & 2 & 3\end{array}$

\begin{tabular}{|c|c|c|c|}
\hline 1. Hostile Sexism & - & $.40 *$ & $.53 *$ \\
\hline $\begin{array}{l}\text { 2. Benevolent } \\
\text { Sexism }\end{array}$ & $.40 *$ & - & $.30 *$ \\
\hline 3. Modern Racism & $.53 *$ & $.30 *$ & - \\
\hline
\end{tabular}

* Correlation is significant at the 0.01 level (2-tailed)

Table 2

Means and Standard Deviations for the Non-zero Sum Outcomes

\begin{tabular}{|c|c|c|c|c|c|}
\hline & Race & Subtype & Mean & SD & $\mathbf{N}$ \\
\hline Hostile & White & Positive & 2.39 & .95 & 74 \\
\hline \multirow[t]{3}{*}{ Evaluations } & & Negative & 2.89 & .98 & 90 \\
\hline & Black & Positive & 2.61 & .93 & 68 \\
\hline & & Negative & 2.82 & 1.13 & 80 \\
\hline \multirow{4}{*}{$\begin{array}{l}\text { Benevolent } \\
\text { Evaluations }\end{array}$} & White & Positive & 3.37 & 1.12 & 74 \\
\hline & & Negative & 2.81 & .90 & 90 \\
\hline & Black & Positive & 3.70 & 1.05 & 68 \\
\hline & & Negative & 2.89 & .99 & 80 \\
\hline \multirow[t]{4}{*}{ Warmth } & White & Positive & 4.08 & .43 & 71 \\
\hline & & Negative & 3.63 & .58 & 90 \\
\hline & Black & Positive & 4.11 & .44 & 72 \\
\hline & & Negative & 3.56 & .67 & 80 \\
\hline \multirow[t]{4}{*}{ Competence } & White & Positive & 4.02 & .46 & 73 \\
\hline & & Negative & 3.62 & .69 & 89 \\
\hline & Black & Positive & 4.11 & .48 & 72 \\
\hline & & Negative & 3.48 & .77 & 78 \\
\hline \multirow[t]{4}{*}{ Agency } & White & Positive & 3.61 & .42 & 73 \\
\hline & & Negative & 3.54 & .59 & 90 \\
\hline & Black & Positive & 3.71 & .48 & 72 \\
\hline & & Negative & 3.45 & .70 & 80 \\
\hline
\end{tabular}


Figure 1: Expressions of benevolent sexism to White and Black targets (Hypothesis 1a).

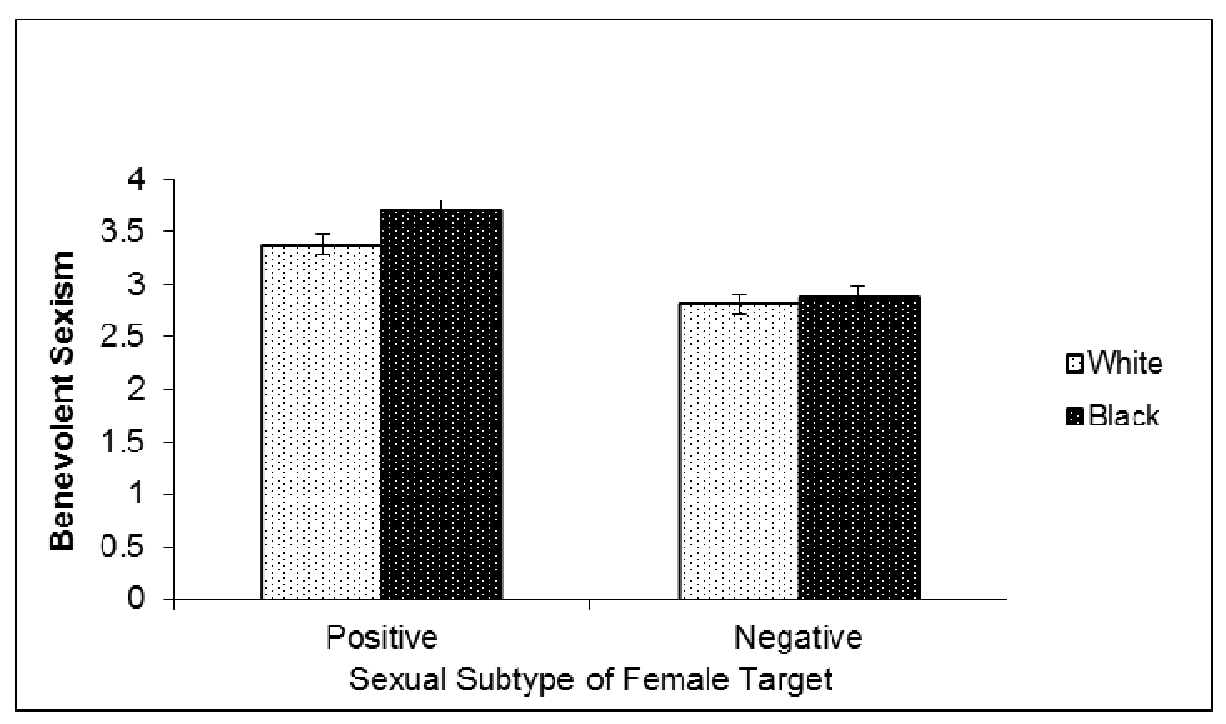

Figure 2: Expressions of hostile sexism to White and Black targets (Hypothesis 1b).

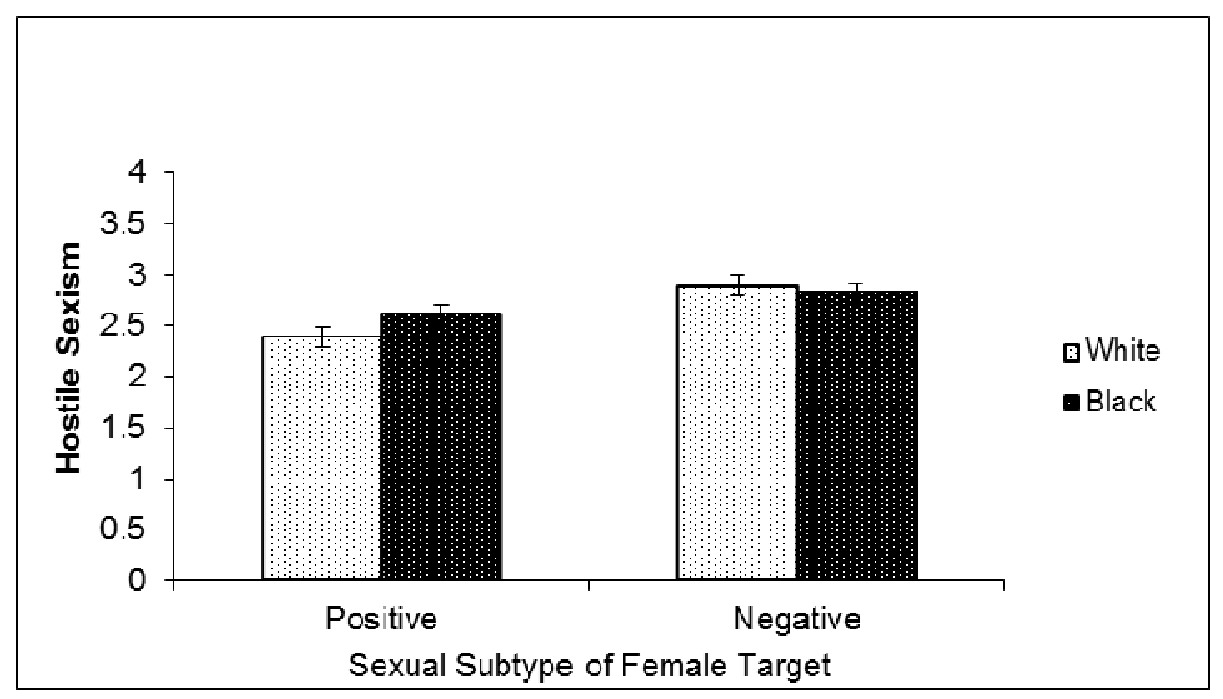


Figure 3: Rates at which targets were chosen to represent the positively subtyped organization (Hypothesis 2a).

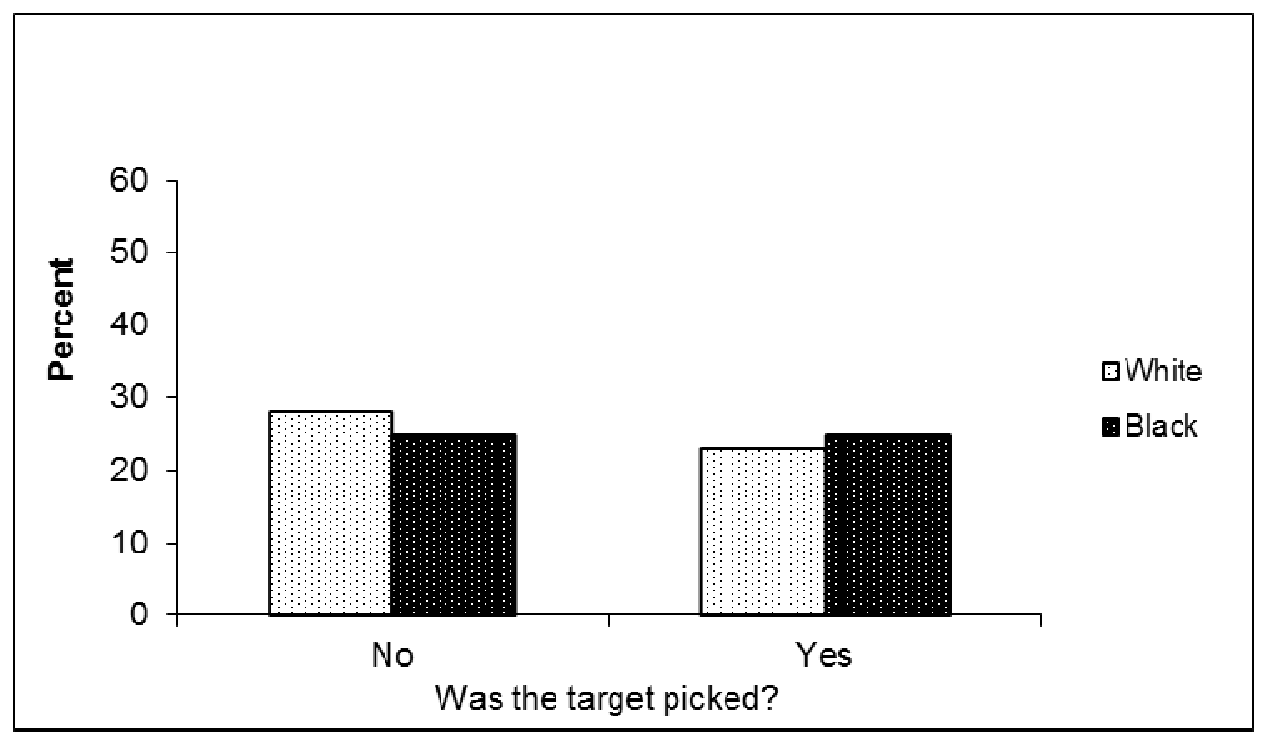

Figure 4: Race of other applicant selected for the positively subtyped organization in the White female condition.

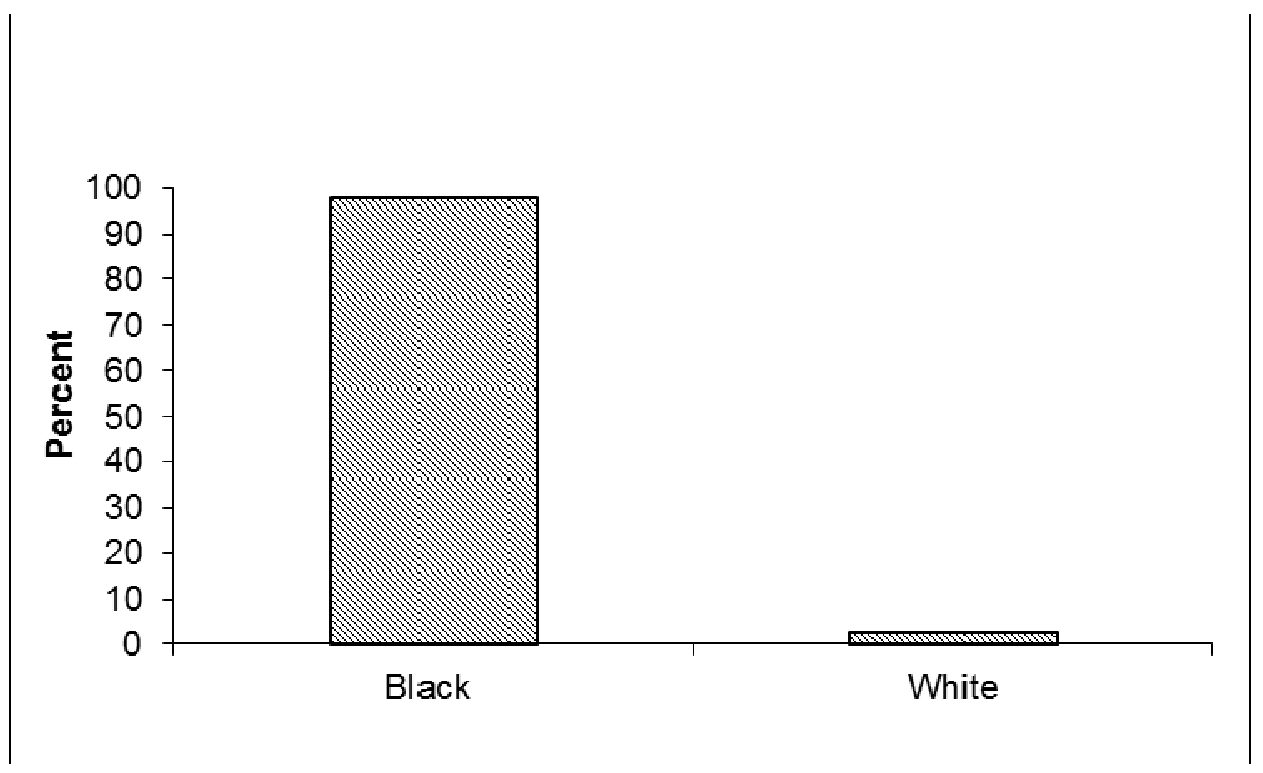


Figure 5: Race of other applicant selected for the positively subtyped organization in the Black female condition.

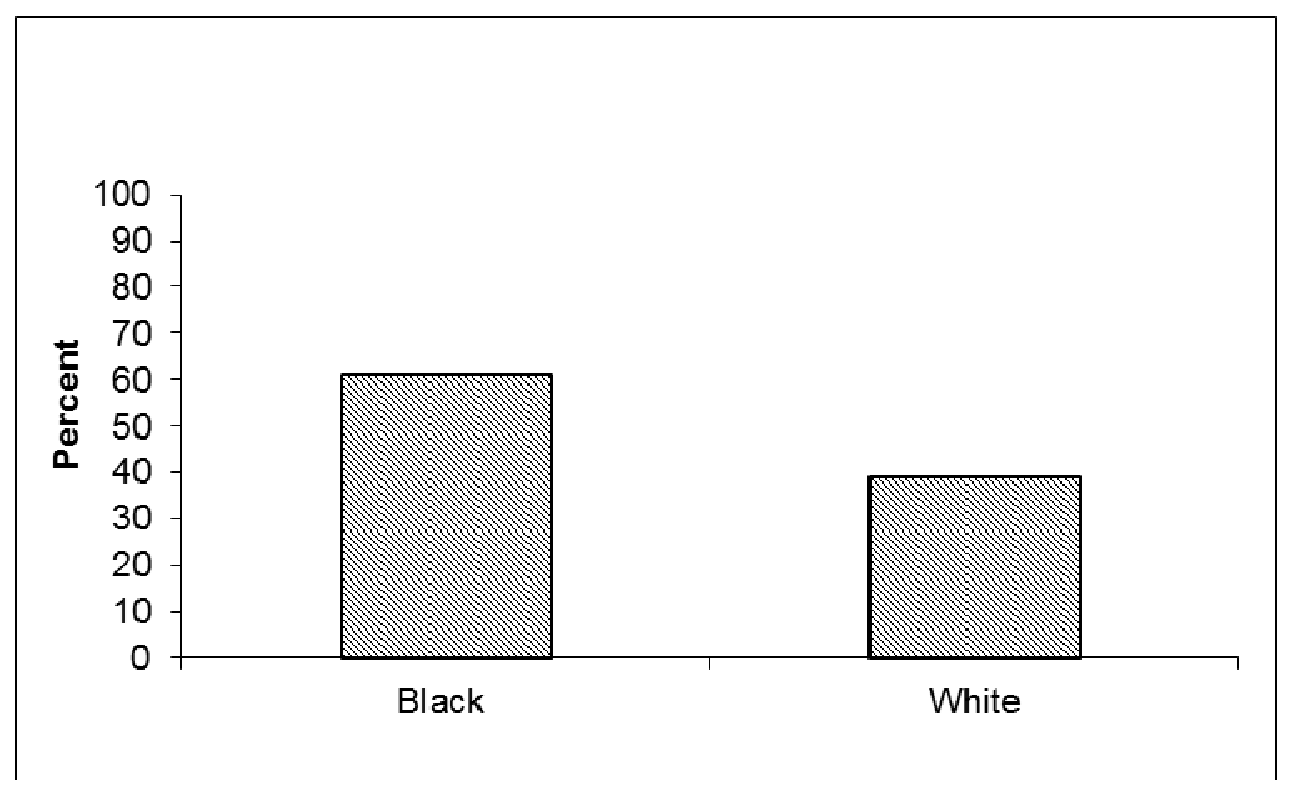

Figure 6: Rates at which targets were chosen to represent the negatively subtyped organization (Hypothesis 2b).

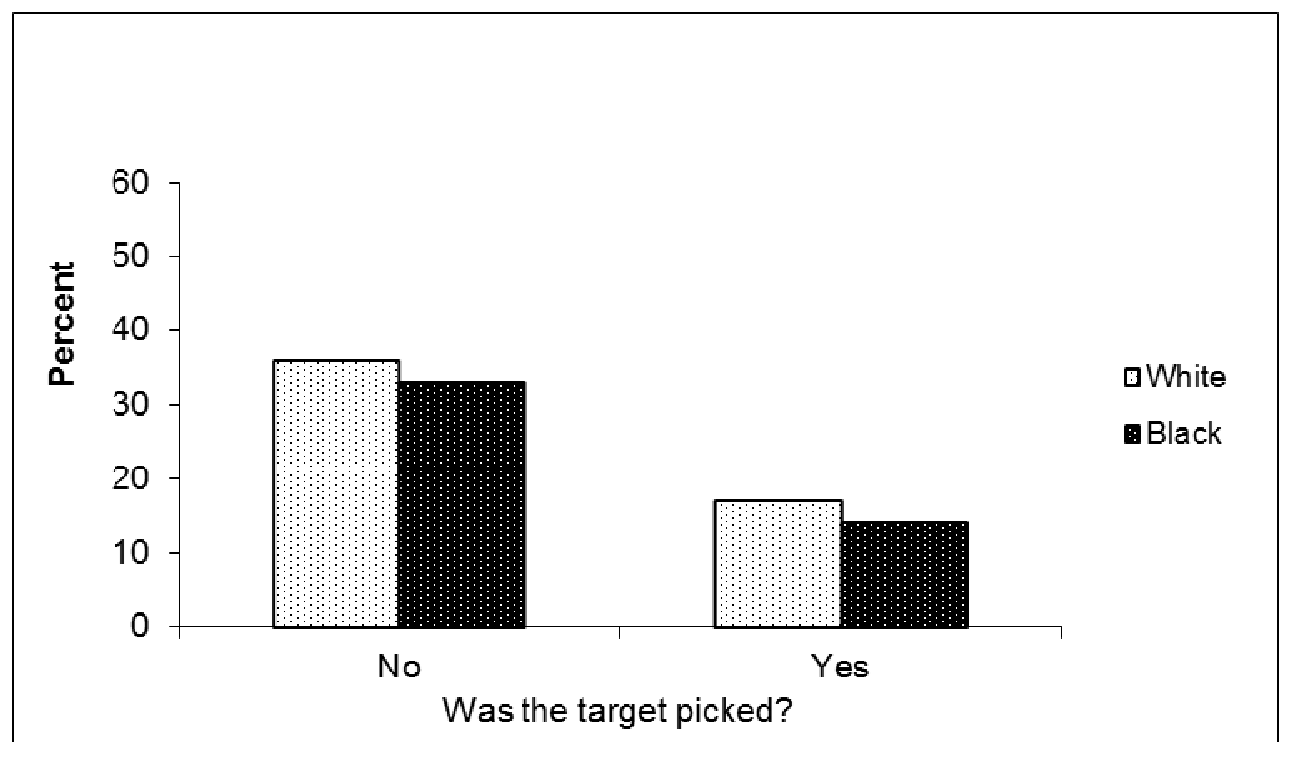


Figure 7: Race of other applicant selected for the negatively subtyped organization in the White female condition.

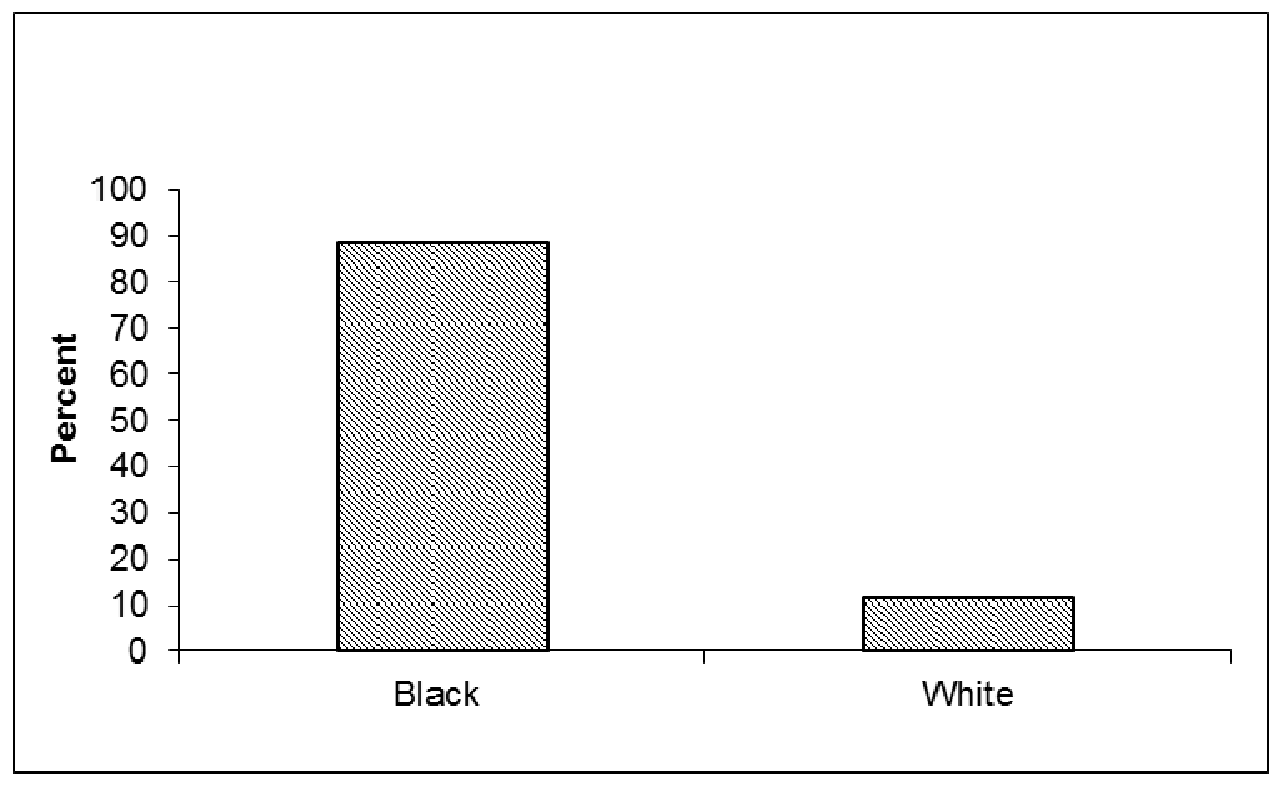

Figure 8: Race of other applicant selected for the negatively subtyped organization in the Black female condition.

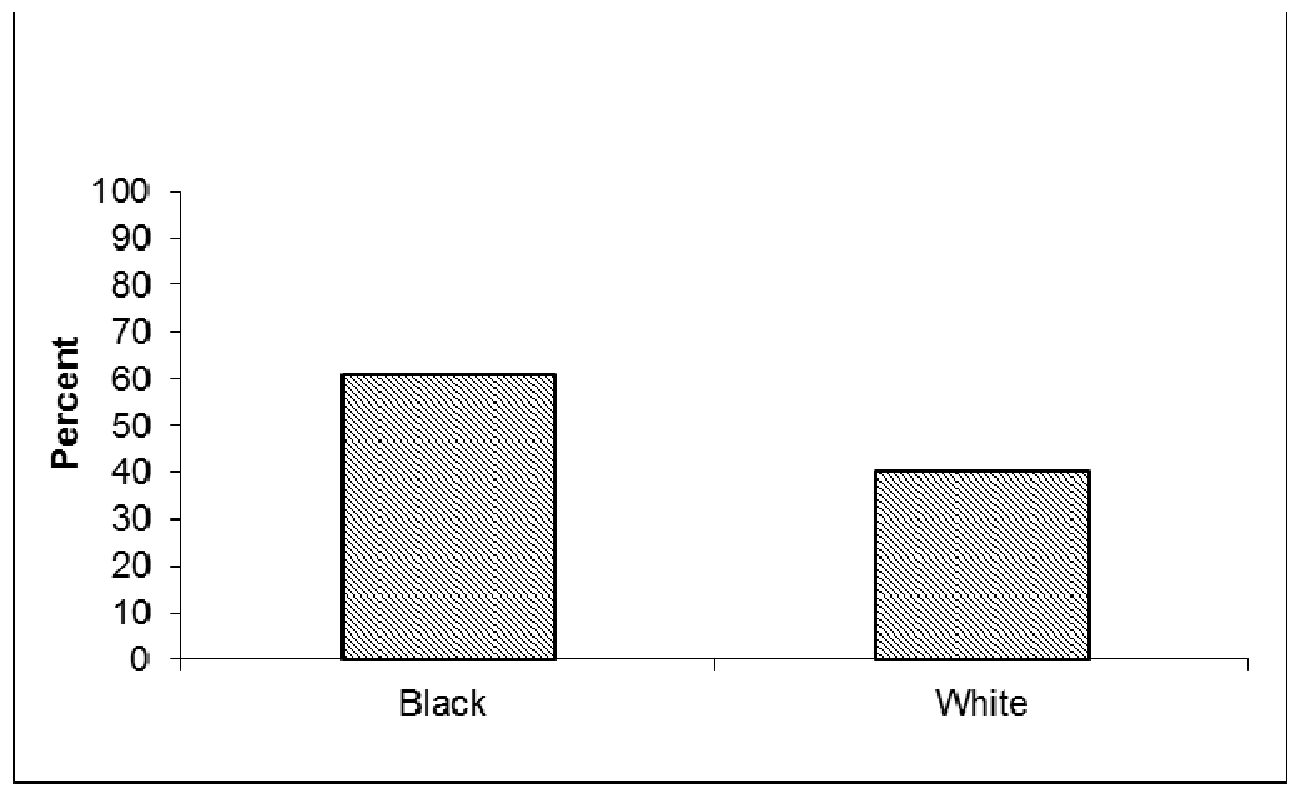


Figure 9: The interaction of target race and participants' baseline hostile sexism on benevolent evaluations of the chaste targets. Both the Black and White simple slopes are significant.

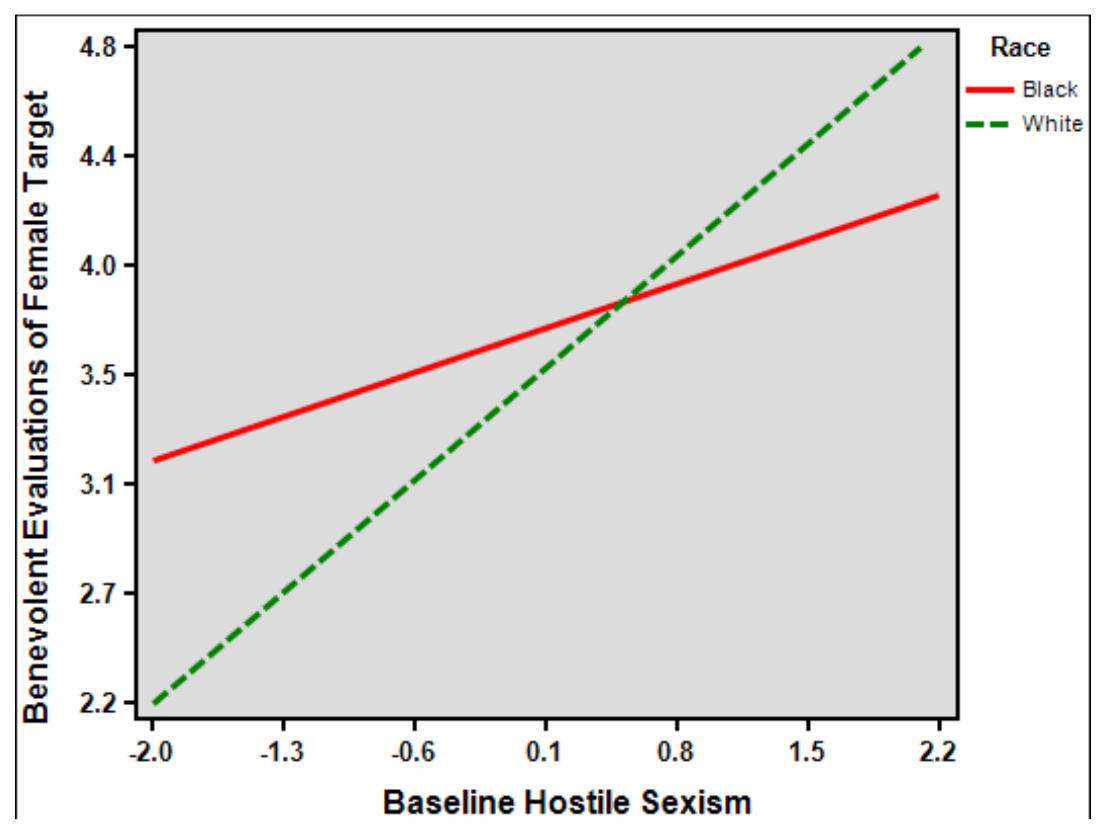

Figure 10: The interaction of target race and participants' modern racism score on benevolent evaluations of the chaste targets. Only the simple slope of the White target is significant.

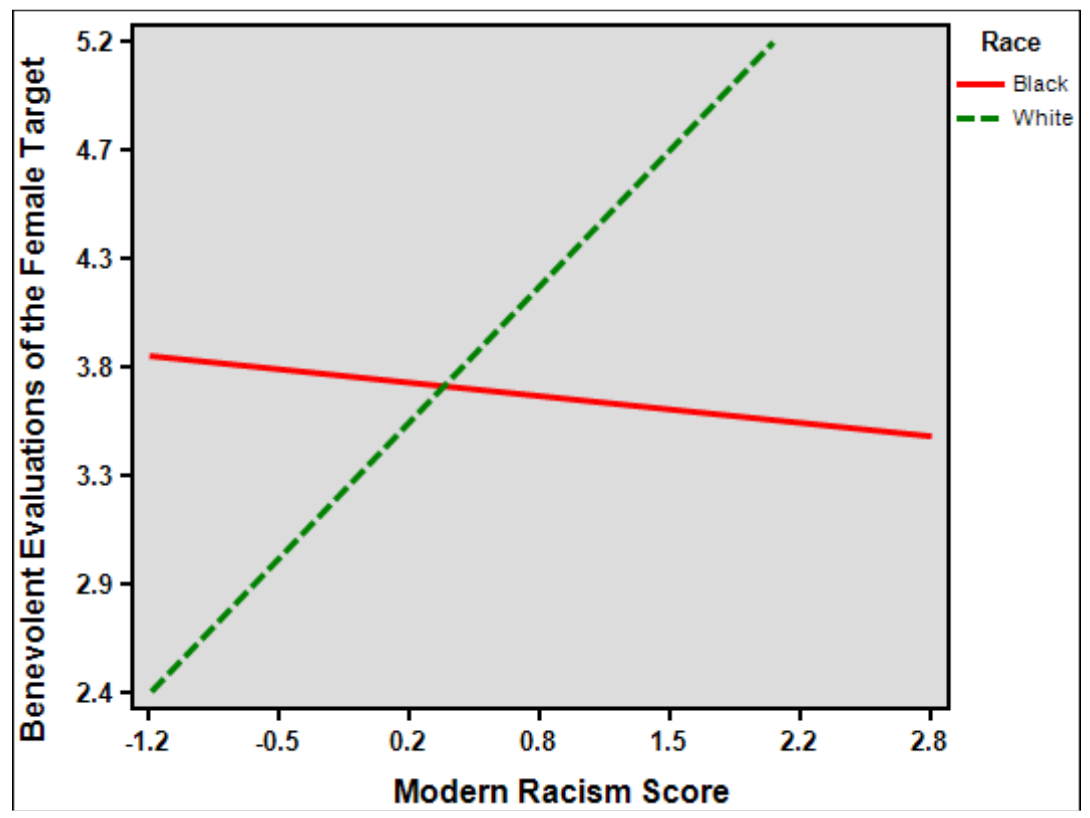


Figure 11: The interaction of target race and participants' baseline hostile sexism on hostile evaluations of the promiscuous targets. Both the Black and White simple slopes are significant.

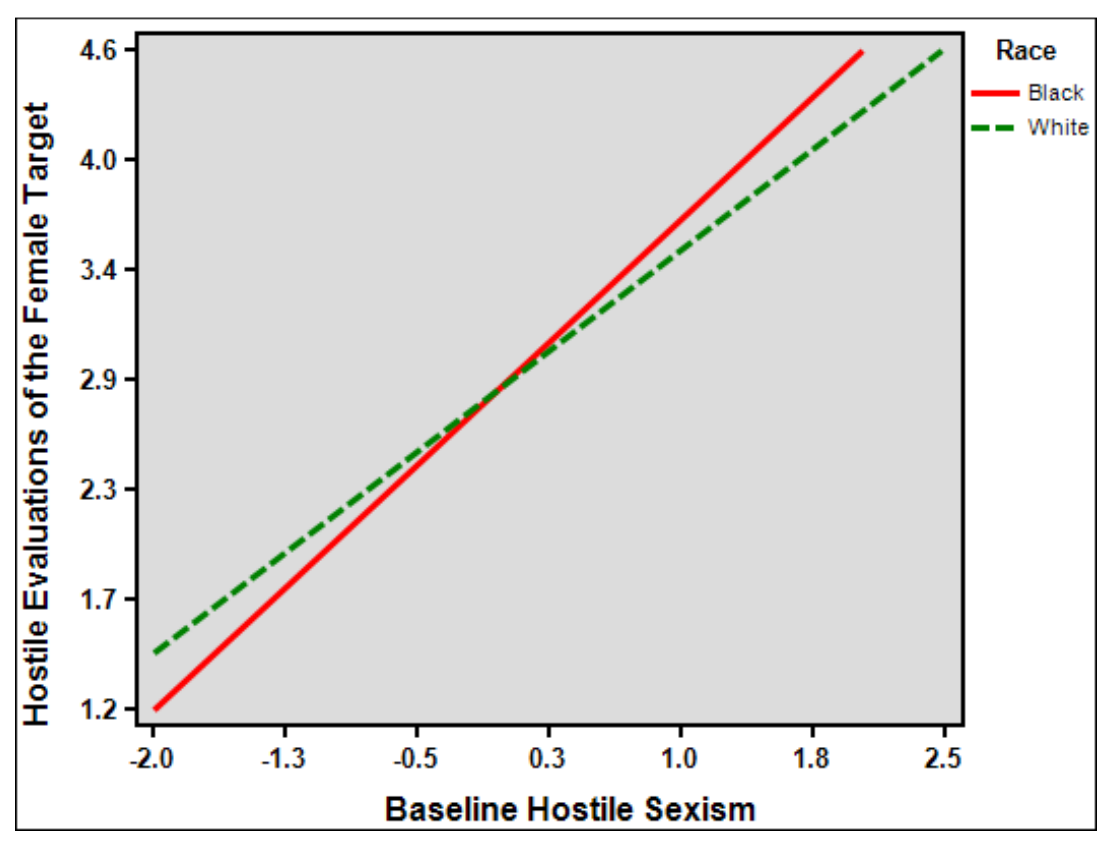

Figure 12: The interaction of target race and participants' modern racism on hostile evaluations of the promiscuous targets. Both the Black and White simple slopes are significant.

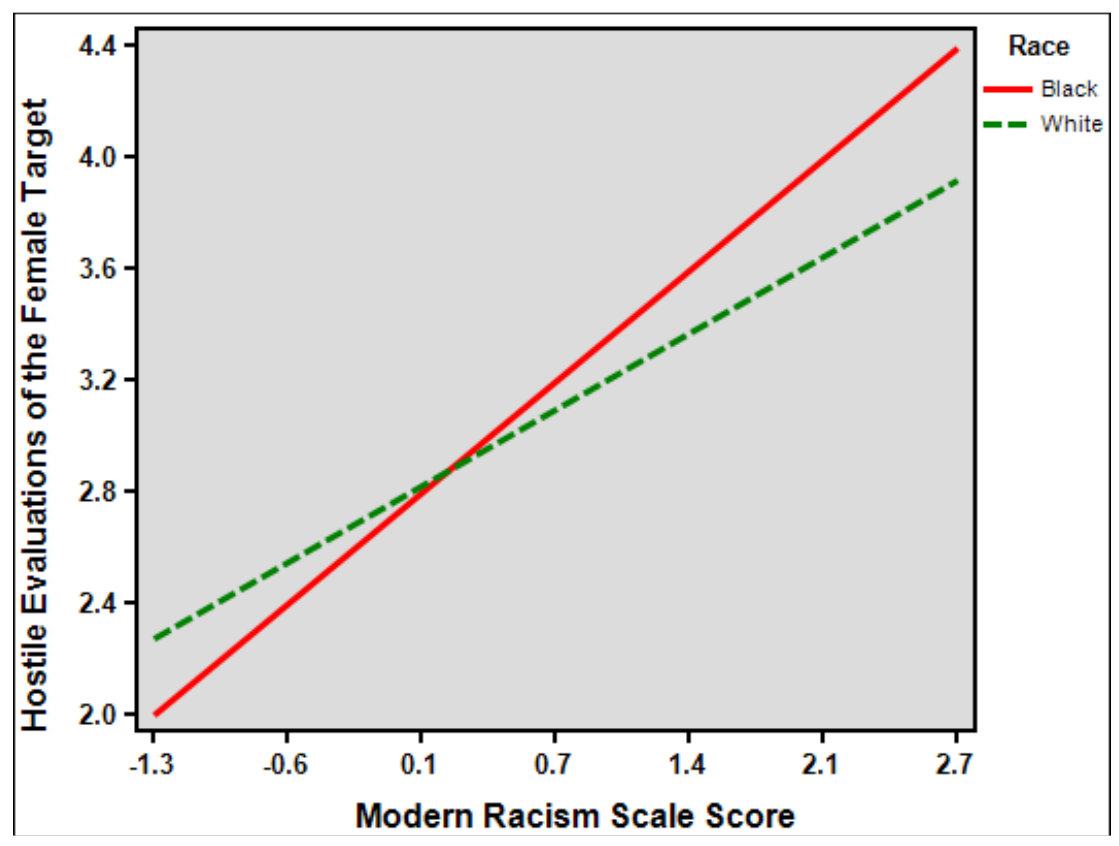




\section{References}

Abrams, D., Tendayi Viki, G., Masser, B. M., \& Bohner, G. (2003). Perceptions of stranger and acquaintance rape: The role of benevolent and hostile sexism in victim blame and rape proclivity. Journal of Personality and Social Psychology, $84,111-125$.

Aiken, L. S., \& West, S. G. (1991). Multiple regression: Testing and interpreting interactions. Newbury Park, CA: Sage Publications Inc.

Ainscough, T. L., \& Motley, C. M. (2000). Will you help me please? The effects of race, gender and manner of dress on retail service. Marketing Letters, 11, 129-136.

Allport, G. W. (1954) The Nature of Prejudice. Reading, MA: Addison-Wesley.

Altman, A. (2012). Sandra Fluke on her role in the contraception controversy: 'I would do this again.' Retrieved December 29, 2013 from http://swampland.time.com/2012/03/08/sandra-fluke-on-her-role-in-thecontraception-controversy-i-would-do-this-again/

Armstrong, C. L. (2013). Conclusion: The next Frontier in Gender Representation. Media Disparity: A Gender Battleground, 217-227.

Ayres, I., \& Siegelman, P. (1995). Race and gender discrimination in bargaining for a new car. American Economic Review, 85, 304-321.

Barreto, M., \& Ellemers, N. (2005). The burden of benevolent sexism: How it contributes to the maintenance of gender inequalities. European Journal of Social Psychology, 35, 633-642.

Beal, F. (1971). Double jeopardy: To be black and female. Radical Education Project. 
Becker, J. C., \& Wright, S. C. (2011). Yet another dark side of chivalry: Benevolent sexism undermines and hostile sexism motivates collective action for social change. Journal of Personality and Social Psychology, 101, 62-78.

Bertrand, M., \& Mullainathan, S. (2003). Are Emily and Greg more employable than Lakisha and Jamal? A field experiment on labor market discrimination (No. w9873). National Bureau of Economic Research.

Biernat, M. (2003). Toward a broader view of social stereotyping. American Psychologist, 58, 1019-1027.

Biernat, M. (1995). The shifting standards model: Implications of stereotype accuracy for social judgment. In Y.T. Lee, L. J. Jussim, \& C. R. McCauley (Eds.), Stereotype accuracy: Toward appreciating group differences (pp. 87-114). Washington, DC: American Psychological Association.

Biernat, M., \& Fuegen, K. (2001). Shifting standards and the evaluation of competence: Complexity in gender-based judgment and decision making. Journal of Social Issues, 57, 707-724.

Biernat, M., \& Kobrynowicz, D. (1997). Gender- and race-based standards of competence: Lower minimum standards but higher ability standards for devalued groups. Journal of Personality and Social Psychology, 72, 544-557.

Biernat, M., \& Manis, M. (1994). Shifting standards and stereotype-based judgments. Journal of Personality and Social Psychology, 66, 5-20.

Biernat, M., Manis, M., \& Nelson, T. F. (1991). Comparison and expectancy processes in human judgment. Journal of Personality and Social Psychology, 61, 203-211. 
Biernat, M., \& Vescio, T. K. (2002). She swings, she hits, she's great, she's benched: Implications of gender-based shifting standards for judgment and behavior. Personality and Social Psychology Bulletin, 28, 66 -77.

Biernat, M., Vescio, T. K., \& Manis, M. (1998). Judging and behaving toward members of stereotyped groups: A shifting standards perspective. In C. Sedikides, J. Schopler, \& C. A. Insko (Eds.), Intergroup cognition and intergroup behavior (pp. 151-175). Mahwah, NJ: Erlbaum.

Blee, K. M. (2002). Inside organized racism: Women in the hate movement. Berkeley, CA: University of California Press.

Bond, J. C., \& Perry, P. (1970). Is the Black male castrated? In T. Cade (Ed.), The Black woman: An anthology (pp. 113-118). New York: The New American Library, Inc.

Boonstra, H. (2010). Sex education: another big step forward-and a step back, The Guttmacher Policy Review, 13, 27-28.

Bosson, J. K., Pinel, E. C., \& Vandello, J. A. (2010). The emotional impact of ambivalent sexism: Forecasts versus real experiences. Sex Roles, 62, 520-531.

Buchanan, N. T., Settles, I. H., \& Woods, K. C. (2008). Comparing sexual harassment subtypes among Black and White women by military rank: Double jeopardy, the jezebel, and the cult of true womanhood. Psychology of Women Quarterly, 32, $347-361$.

Buhrmester, M., Kwang, T., \& Gosling, S. D. (2011). Amazon's mechanical turk: A new source of inexpensive, yet high-quality, data?. Perspectives on Psychological Science, 6, 3-5. 
Carpenter, S., \& Trentham, S. (2001). Should we take "gender" out of gender subtypes? The effects of gender, evaluative valence, and context on the organization of person subtypes. Sex Roles, 45, 455-480.

Christopher, A. N., \& Mull, M. S. (2006). Conservative ideology and ambivalent sexism. Psychology of Women Quarterly, 30, 223-230.

Cortina, L. M., Magley, V. J., Williams, J. H., \& Langhout, R. D. (2001). Incivility in the workplace: incidence and impact. Journal of Occupational Health Psychology, 6, 64-80.

Cowan, G., \& O'Brien, M. (1990). Gender and survival vs. death in slasher films: A content analysis. Sex Roles, 23, 187-196.

Cozier, Y., Palmer, J. R., Horton, N. J., Fredman, L., Wise, L. A., \& Rosenberg, L. (2006). Racial discrimination and the incidence of hypertension in US black women. Annals of Epidemiology, 16, 681-687.

Cozier, Y. C., Yu, J., Coogan, P. F., Bethea, T. N., Rosenberg, L., \& Palmer, J. R. (2014). Racism, segregation, and risk of obesity in the Black women's health study. American Journal of Epidemiology, 179, 875-883.

Crenshaw, K. L. (1993). Mapping the margins: intersectionality, identity politics, and violence against women of color. Stanford Law Review, 43, 1241-1299.

Cunningham, W. A., Preacher, K. J., \& Banaji, M. R. (2001). Implicit attitude measures: Consistency, stability, and convergent validity. Psychological Science, 12, 163 170.

Daniel, J. E. \& Daniel J. L. (1998). Preschool children's selection of race-related personal names. Journal of Black Studies, 28, 471-490. 
Dardenne, B., Dumont, M., \& Bollier, T. (2007). Insidious dangers of benevolent sexism: Consequences for women's performance. Journal of Personality and Social Psychology, 93, 764-779.

Davis, A. Y. (1983). Women, race, and class. New York: Vintage

Davis, G. L., \& Cross, H. J. (1979). Sexual stereotyping of Black males in interracial sex. Archives of Sexual Behavior, 8, 269-279.

Devine, P. G., \& Baker, S. M. (1991). Measurement of racial stereotype subtyping. Personality and Social Psychology Bulletin, 17, 44-50.

Dovidio, J.F., \& Gaertner, S.L. (1998). On the nature of contemporary prejudice: The causes, consequences, and challenges of aversive racism. In J. Eberhardt \& S.T. Fiske (Eds.), Confronting racism: The problem and the response (pp. 3-32). Newbury Park, CA: Sage.

Eagly, A. H., \& Mladinic, A. (1994). Are people prejudiced against women? Some answers from research on attitudes, gender stereotypes, and judgments of competence. In W. Stroebe \& M. Hewstone (Eds), European Review of Social Psychology (Vol. 5, pp. 1-35). New York, Wiley.

Ehrenreich, B., \& English, D. (1978). For her own good: One hundred and fifty years of the experts' advice to women. Garden City, NY: Anchor/Doubleday.

Esqueda, C. W., \& Harrison, L. A. (2005). The influence of gender role stereotypes, the woman's race, and level of provocation and resistance on domestic violence culpability attributions. Sex Roles, 53, 821-834.

Fahs, B. (2010). Daddy's little girls: On the perils of chastity clubs, purity balls, and ritualized abstinence. Frontiers: A Journal of Women Studies, 31, 116-142. 
Faludi, S. (1992). Backlash: The undeclared war against American women. New York: Doubleday.

Fazio, R. H., \& Olson, M. A. (2003). Implicit measures in social cognition research: Their meaning and use. Annual Review of Psychology, 54(1), 297-327.

Ferraro, K. J. (1989). Policing woman battering. Social Problems, 36, 61-74.

Fiske, S. T., Cuddy, A. J., Glick, P., \& Xu, J. (2002). A model of (often mixed) stereotype content: competence and warmth respectively follow from perceived status and competition. Journal of Personality and Social Psychology, 82, 878902.

Fiske, S. T., Gilbert, D. T., \& Lindzey, G. (Eds.). (2010). Handbook of social psychology (Vol. 2). John Wiley \& Sons.

Forbes, G. B., Adams-Curtis, L. E., Hamm, N. R., \& White, K. B. (2003). Perceptions of the woman who breastfeeds: The role of erotophobia, sexism, and attitudinal variables. Sex Roles, 49, 379-388.

Gaertner, S.L., \& Dovidio, J.F. (1986). The aversive form of racism. In J.F. Dovidio \& S.L. Gaertner (Eds.), Prejudice, discrimination, and racism (pp. 61-89). Orlando, FL: Academic Press.

Glick, P., Diebold, J., Bailey-Werner, B., \& Zhu, L. (1997). The two faces of Adam: Ambivalent sexism and polarized attitudes toward women. Personality and Social Psychology Bulletin, 23, 1323-1334.

Glick, P., \& Fiske, S. T. (2001a). An ambivalent alliance: Hostile and benevolent sexism as complementary justifications for gender inequality. American Psychologist, 56, 109-118. 
Glick, P., \& Fiske, S. T. (1996). The Ambivalent Sexism Inventory: Differentiating hostile and benevolent sexism. Journal of Personality and Social Psychology, 70, $491-512$.

Glick, P., Fiske, S. T., Mladinic, A., Saiz, J. L., Abrams, D., Masser, B., ...Lopez, W. (2000). Beyond prejudice as simple antipathy: Hostile and benevolent sexism across cultures. Journal of Personality and Social Psychology, 79, 763-775.

Glick, P., Sakalli-Ugurlu, N., Ferreira, M. C., \& de Souza, M. A. (2002). Ambivalent sexism and attitudes toward wife abuse in Turkey and Brazil. Psychology of Women Quarterly, 26, 292-297.

Goff, P. A., Eberhardt, J. L.,Williams, M. J., \& Jackson, M. C. (2008b). Not yet human: Historical dehumanization and contemporary consequences. Journal of Personality and Social Psychology, 94, 292-306.

Goff, P. A., \& Kahn, K. B. (2013). How psychological science impedes intersectional thinking. Du Bois Review: Social Science Research on Race, 10, 365-384.

Goff, P. A., Thomas, M. A., \& Jackson, M. C. (2008a). “Ain't I a woman?”: Towards an intersectional approach to person perception and group-based harms. Sex Roles, $59,392-403$.

Gottschall, J., Allison, E., De Rosa, J., \& Klockeman, K. (2006). Can literary study be scientific?: Results of an empirical search for the virgin/whore dichotomy. Interdisciplinary Literary Studies, 7, 1-17.

Gould, D. (1996). Using vignettes to collect data for nursing research studies: how valid are the findings?. Journal of Clinical Nursing, 5, 207-212. 
Greenwald, A. G., McGhee, D. E., \& Schwartz, J. L. K. (1998). Measuring individual differences in implicit cognition: the implicit association test. Journal of Personality and Social Psychology, 74, 1464-1480.

Greenwald, A. G., Poehlman, T. A., Uhlmann, E. L., \& Banaji, M. R. (2009). Understanding and using the Implicit Association Test: III. Meta-analysis of predictive validity. Journal of Personality and Social Psychology, 97(1), 17-41.

Grossman, L. (2008). Stephanie Meyer: A new J.K. Rowling? Retrieved December 28, 2013 from http://content.time.com/time/magazine/article/0,9171,1734838,00.html.

Gupta, N., Jenkins, G. D., Jr., \& Beehr, T. A. (1983). Employee gender, gender similarity, and supervisor-subordinate cross-evaluations. Psychology of Women Quarterly, 8, 174-184.

Hartmann, U. (2009). Sigmund Freud and his impact on our understanding of male sexual dysfunction. The Journal of Sexual Medicine, 6, 2332-2339.

Hayes, E. R., \& Swim, J. K. (2013). African, Asian, Latina/o, and European Americans' responses to popular measures of sexist beliefs: some cautionary notes. Psychology of Women Quarterly, 37, 155-166.

Hearnshaw, F. J. C. (1935). Chivalry. In E. Seligman (Ed.) Encyclopedia of the Social Sciences (436-440). New York: Macmillan.

Hogg, M. A. (2013). Intergroup relations. In Handbook of social psychology (pp. 533561). Springer Netherlands.

hooks, b. (1981). Ain't I a woman: Black women and feminism. New York: South End. 
Hopper, J. (2013). Read the “stomach-churning” sexual assault accusations against R. Kelly in full. Retrieved December 29, 2013 from http://blogs.villagevoice.com/music/2013/12/read_the_stomac.php

Hull, G. T., Bell Scott, P., \& Smith, B. (1982). But some of us are brave: All the women are White, all the Blacks are men: Black women's studies. New York: Feminist.

Hurd, R. (1762). Letters on Chivalry and Romance. A. Millar, W. Thurlbourn, and J. Woodyer.

Jackman, M. R. (1994). Velvet Glove: Paternalism and Conflict in Gender, Class, and Race Relations. University of California Press.

Jewell, K. S. (1993). From mammy to Miss America and beyond: Cultural images and the shaping of U.S. social policy. New York: Routledge.

Jost, J. T., \& Kay, A. C. (2005). Exposure to benevolent sexism and complementary gender stereotypes: Consequences for specific and diffuse forms of system justification. Journal of Personality and Social Psychology, 88, 498-509.

Judge, T. A., \& Bretz, R. D. (1992). Effects of work values on job choice decisions. Journal of Applied Psychology, 77, 261-298.

Kahn, K.B., Barreto, M., \& Kaiser, C. (2012). Stay silent or shout out? How benevolent sexism modifies attitudes towards females who confront sexism. Poster presented at Group Processes and Intergroup Relations, San Diego, CA.

Karam, B. (2010). Gender and the Media. Media Studies: Media History, Media and Society, 2, 304 .

Kilianski, S. E., \& Rudman, L. A. (1998). Wanting it both ways: Do women approve of benevolent sexism? Sex Roles, 39, 333-352. 
Kincaid, J. (2010). Hannah Montana's bare, unprotected back: Miley Cyrus's vanity fair outing. The Velvet Light Trap, 65, 5-6.

Kobrynowicz, D., \& Biernat, M. (1997). Decoding subjective evaluations: How stereotypes provide shifting standards. Journal of Experimental Social Psychology, 33, 579-601.

Krieger, N., Waterman, P. D., Hartman, C., Bates, L. M., Stoddard, A. M., Quinn, M. M., ... \& Barbeau, E. M. (2006). Social hazards on the job: workplace abuse, sexual harassment, and racial discrimination--a study of Black, Latino, and White lowincome women and men workers in the United States. International Journal of Health Services, 36, 51-85.

Lee, T. L., Fiske, S. T., \& Glick, P. (2010). Next gen ambivalent sexism: Converging correlates, causality in context, and converse causality, an introduction to the special issue. Sex Roles, 62, 395-404.

Lott, T. L. (1999). The invention of race: Black culture and the politics of representation. Malden, MA: Blackwell Publishers.

Luhtanen, R., \& Crocker, J. (1992). A collective self-esteem scale: Self-evaluation of one's social identity. Personality and Social Psychology Bulletin, 18, 302-318.

Madon, S., Guyll, M., Aboufadel, K., Montiel, E., Smith, A., Palumbo, P., \& Jussim, L. (2001). Ethnic and national stereotypes: The Princeton trilogy revisited and revised. Personality and Social Psychology Bulletin, 27, 996-1010.

Marcus, S. (2012). Celebrity Virgins: Stars who spoke publically about being a virgin. Retrieved December 28, 2013, from 
http://www.huffingtonpost.com/2012/12/04/celebrity-virgins-stars-who-spokeabout-being-virgin_n_2239884.html.

Masser, B. M., \& Abrams, D. (2004). Reinforcing the glass ceiling: The consequences of hostile sexism for female managerial candidates. Sex Roles, 51, 609-615.

Masser, B., Viki, G. T., \& Power, C. (2006). Hostile sexism and rape proclivity amongst men. Sex Roles, 54, 565-574.

McConahay, J. B. (1986). Modern racism, ambivalence, and the modern racism scale. In J. D. Dovidio \& S. L. Gaertner (Eds.), Prejudice, discrimination, and racism (pp. 91-125). Orlando, FL: Academic Press.

McMahon, J.M. \& Kahn, K.B. (2014). Benevolent racism?: Target race as a predictor of benevolent sexism. Poster presented at the annual meeting of the Society for Personality and Social Psychology, Austin, TX.

Min, S. and Feaster, J. C. (2010). Missing children in national news coverage: Racial and gender representations of missing children cases. Communication Research Reports, 27, 201-216.

Monin, B., \& Miller, D. T. (2001). Moral credentials and the expression of prejudice. Journal of Personality and Social Psychology, 81, 33-43.

Mortensen, C. R., \& Cialdini, R. B. (2010). Full-cycle social psychology for theory and application. Social and Personality Psychology Compass, 4, 53-63.

National Women's Law Center (2013). Closing the wage gap is crucial for women of color and their families. Retrieved from http://www.nwlc.org/resource/closingwage-gap-crucial-women-color-and-their-families 
Neal, M. A. (2013, July 11). The Kelly conversations: Mark Anthony Neal, professor of Black popular culture. [Real Media File]. Retrieved from http://www.wbez.org/blogs/jim-derogatis/2013-07/kelly-conversations-markanthony-neal-professor-black-popular-culture.

Neville, H. A., Lilly, R. L., Duran, G., Lee, R. M., \& Browne, L. (2000). Construction and initial validation of the Color-Blind Racial Attitudes Scale (CoBRAS). Journal of Counseling Psychology, 47, 59-70.

Niemann, Y. F., Jennings, L., Rozelle, R. M., Baxter, J. C., \& Sullivan, E. (1994). Use of free responses and cluster analysis to determine stereotypes of eight groups. Personality and Social Psychology Bulletin, 20, 379-390.

Osborne, D., \& Davies, P. G. (2012). When benevolence backfires: Benevolent sexists' opposition to elective and traumatic abortion. Journal of Applied Social Psychology, 42, 291-307.

Phelan, J. E., Moss-Racusin, C. A., \& Rudman, L. A. (2008). Competent yet out in the cold: Shifting criteria for hiring reflect backlash toward agentic women.Psychology of Women Quarterly, 3, 406-413.

Pomeroy, S. (1995). Goddesses, whores, wives, and slaves: Women in classical antiquity. New York, Schocken.

Prentice, D. A., \& Miller, D. T. (1992). When small effects are impressive. Psychological Bulletin, 112, 160-164.

Purdie-Vaughns, V., \& Eibach, R. P. (2008). Intersectional invisibility: The distinctive advantages and disadvantages of multiple subordinate-group identities. Sex Roles, $59,377-391$ 
Ristock, J. L. (1997). Kiss and kill: Some impacts of cultural representations of women's sexualities. Undisciplined Women: Tradition and Culture in Canada, 139-151.

Roberts, D. E. (1993). Racism and Patriarchy in the Meaning of Motherhood. American University Journal of Gender, Social Policy \& the Law, 1, 1-38.

Rosenberg, L., Palmer, J. R., Wise, L. A., Horton, N. J., \& Corwin, M. J. (2002). Perceptions of racial discrimination and the risk of preterm birth. Epidemiology, $13,646-652$.

Rosenblatt, A., Greenberg, J., Solomon, S., Pyszczynski, T., \& Lyon, D. (1989). Evidence for terror management theory: I. The effects of mortality salience on reactions to those who violate or uphold cultural values. Journal of Personality and Social Psychology, 57, 681-690.

Rothenberg, P. S. (Ed.). (2004). Race, class, and gender in the United States: An integrated study. Macmillan.

Sakallı-Uğurlu, N. (2010). Ambivalent sexism, gender, and major as predictors of Turkish college students' attitudes toward women and men's atypical educational choices. Sex roles, 62, 427- 437.

Sakalh-Uğurlu, N., \& Glick, P. (2003). Ambivalent sexism and attitudes toward women who engage in premarital sex in Turkey. Journal of Sex Research, 40, 296-302.

Shepherd, M., Erchull, M. J., Rosner, A., Taubenberger, L., Queen, E. F., \& McKee, J. (2011). "I'll get that for you": The relationship between benevolent sexism and body self-perceptions. Sex Roles, 64, 1-8. 
Sibley, C. G., \& Wilson, M. S. (2004). Differentiating hostile and benevolent sexist attitudes toward positive and negative sexual female subtypes. Sex Roles, 51, $687-696$.

Sidanius, J., \& Pratto, F. (1999). Social Dominance: An Intergroup Theory of Social Hierarchy and Oppression. New York: Cambridge University Press.

Six, B., \& Eckes, T. (1991). A closer look at the complex structure of gender stereotypes. Sex Roles, 24, 57-71.

Smith, M. (2013). Miley Cyrus, Sinéad O'Connor and the future of feminism. The Conversation, 1-1.

Smith, M. D. (2013). Understanding the R. Kelly phenomenon-and then ending it. Retrieved December 29, 2013, from http://feministing.com/2013/12/19/understanding-the-r-kelly-phenomenon-andthen-ending-it/.

Stanton, E. C., Anthony, S. B., \& Gage, M. J. (Eds.) (1881). History of Woman Suffrage. New York: Fowler \& Wells.

Stephens, T. (1992). Review of disfigured images: The historical assault on AfroAmerican women. Explorations in Sights and Sounds, 12, 41-42.

Sue, D. W. (2010). Microaggressions in everyday life: Race, gender, and sexual orientation. John Wiley \& Sons.

Sue, D. W., Capodilupo, C. M., \& Holder, A. (2008). Racial microaggressions in the life experience of Black Americans. Professional Psychology: Research and Practice, 39, 329-336. 
Swim, Janet K. (1994). "Perceived versus meta-analytic effect sizes: An assessment of the accuracy of gender stereotypes." Journal of Personality and Social Psychology, 66, 21-36.

Tatum, B. D. (2001). Defining racism: Can we talk. Race, class, and gender in the United States: An integrated study, 100-107.

Tavris, C., \& Wade, C. (1984). The longest war: Sex differences in perspective (2nd ed.). San Diego, CA: Harcourt Brace Jovanovich.

Taylor, T. R., Williams, C. D., Makambi, K. H., Mouton, C., Harrell, J. P., Cozier, Y., ... \& Adams-Campbell, L. L. (2007). Racial discrimination and breast cancer incidence in US Black women: The Black women's health study. American Journal of Epidemiology, 166, 46-54.

Thomas, C. A., \& Esses, V. M. (2004). Individual differences in reactions to sexist humor. Group Processes \& Intergroup Relations, 7, 89-100.

Thompson, K. (2013, October 10). Essence: Black women still poorly depicted in media. The Washington Post. Retrieved from http://www.washingtonpost.com/blogs/shethe-people/wp/2013/10/10/essence-black-women-still-poorly-depicted-in-media/.

U.S. Census Bureau. (2000). Genealogy Data: Frequently Occurring Surnames from Census 2000. Retrieved from http://www.census.gov/genealogy/www/data/2000surnames/index.html

Valenti, J. (2009). The purity myth: How America's obsession with virginity is hurting young women. Seal Press.

Vélez-Blasini, C. J., \& Brandt, H. J. (2000). Alcohol expectancies, date setting, age, and beverage choice as predictors of estimated likelihood of sexual behaviors in 
hypothetical dating situations. Journal of Applied Social Psychology, 30, 19541976.

Viki, G. T., Massey, K., \& Masser, B. (2005). When chivalry backfires: Benevolent sexism and attitudes toward Myra Hindley. Legal and Criminological Psychology, 10, 109-120.

Weitz, R., \& Gordon, L. (1993). Images of black women among anglo college students. Sex Roles, 28, 19-34.

Willis, C. E. (1992). The effects of sex role stereotype, victim and defendant race, and prior relationship on rape culpability attributions. Sex Roles, 26, 213-226.

Young, I. M. (2003). The logic of masculinist protection: Reflections on the current security state. Signs: Journal of Women in Culture and Society, 29, 1-25. 
Appendix A

Results of Previous Study (McMahon \& Kahn, 2014)

Figure A.1: Benevolent sexism evaluations of the female target as a function of race and sexual subtype.

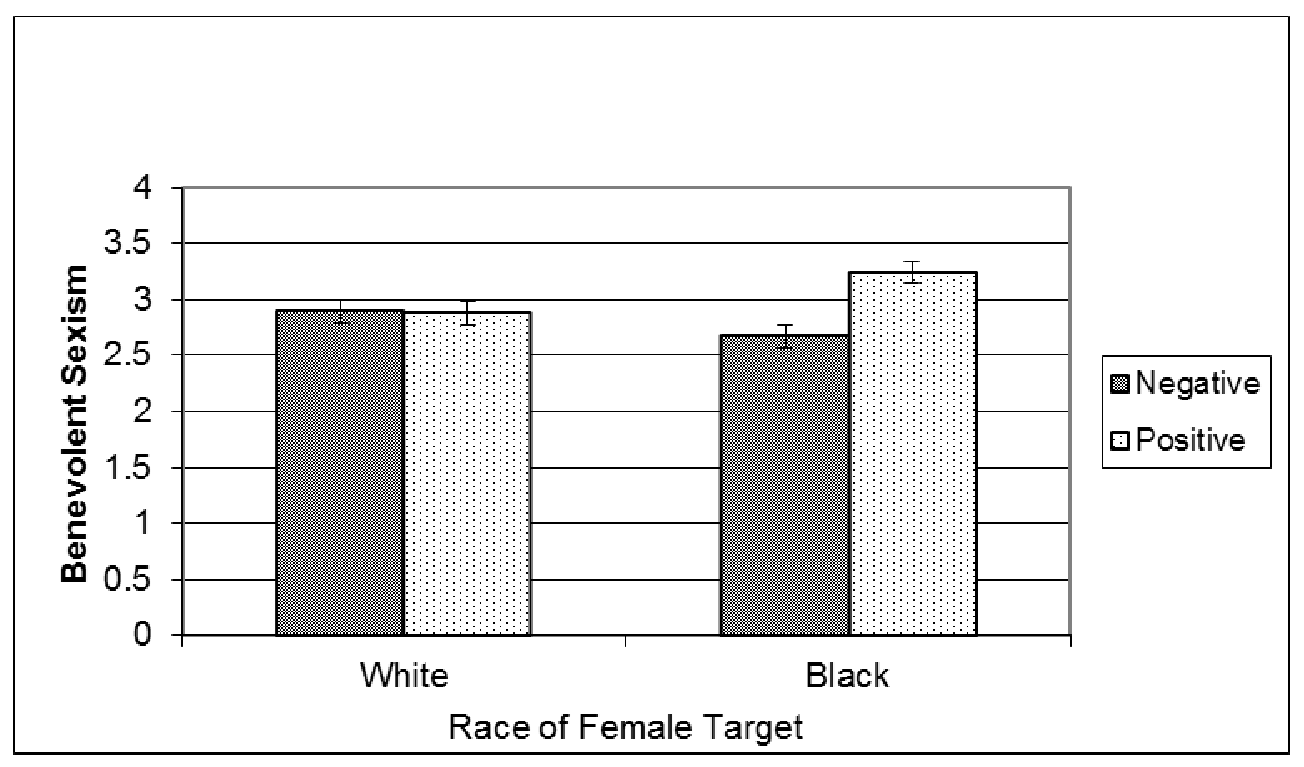

Figure A.2: Hostile sexism evaluations of the female target as a function of race and sexual subtype.

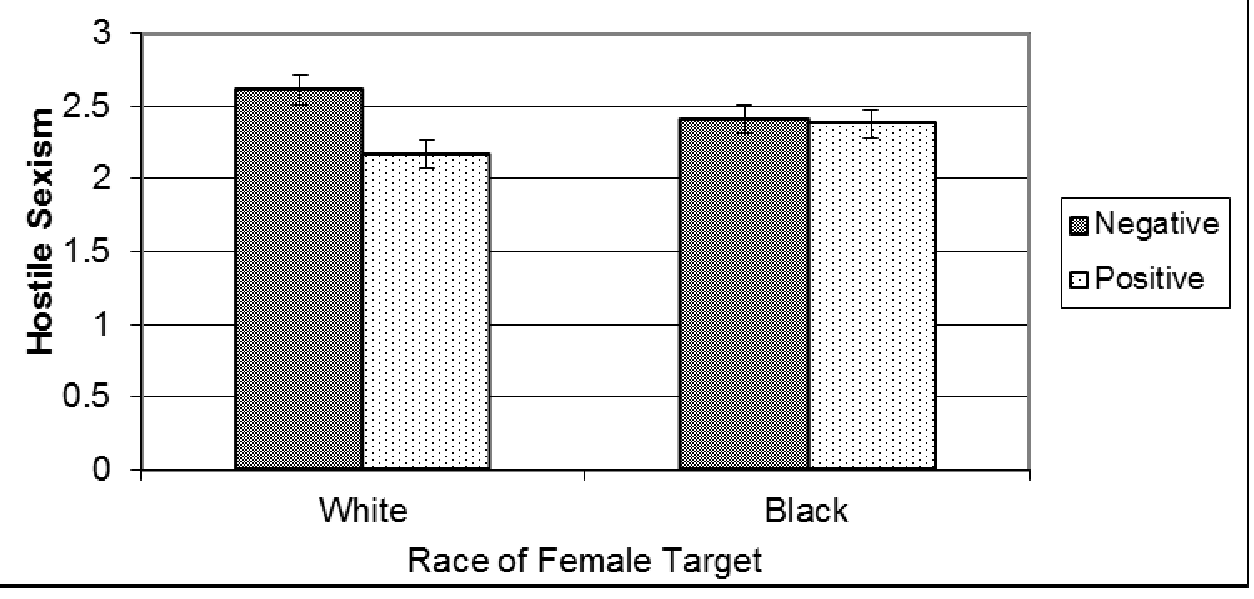


Figure A.3: Hostile sexism moderating benevolently sexist evaluations of a White female target in the positive subtype condition. The slope for the White condition is significant; the slope for the Black condition is not.

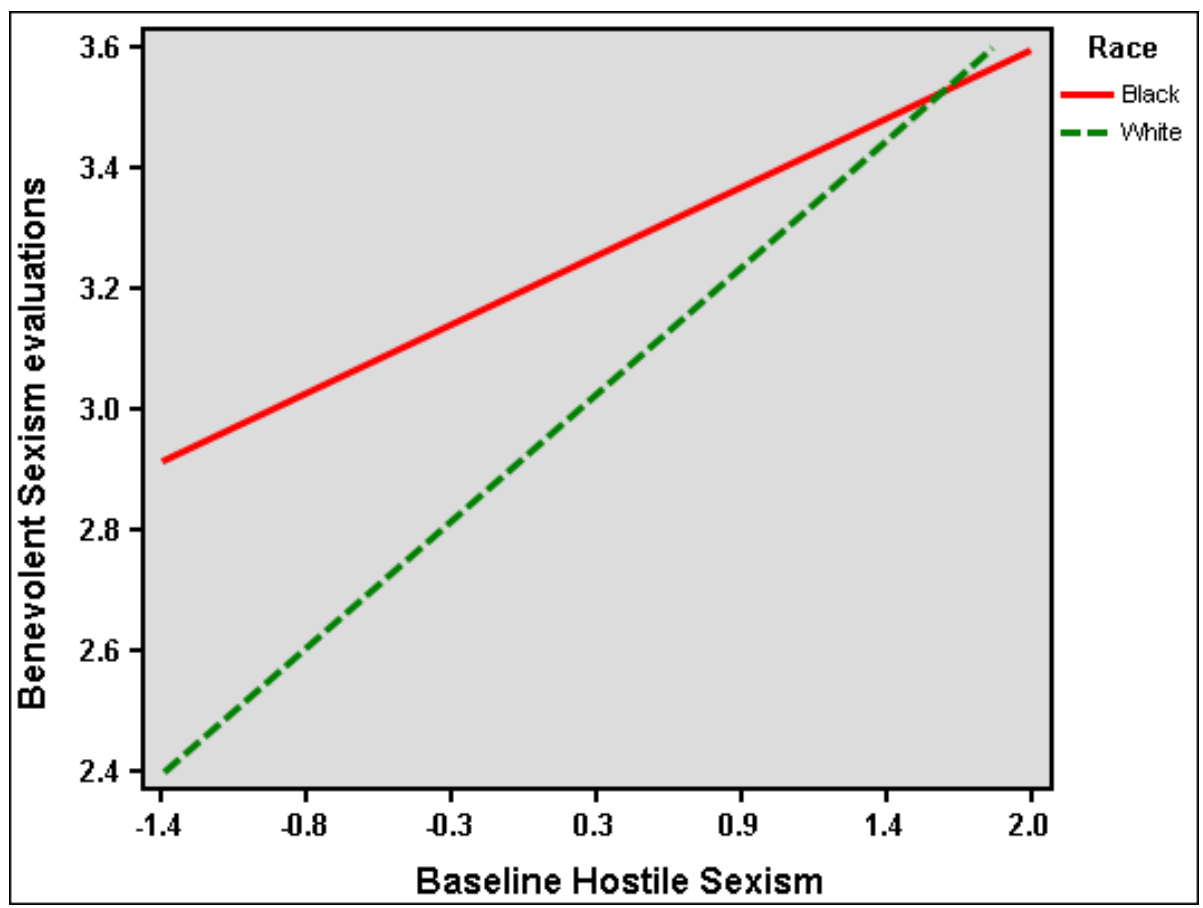




\section{Appendix B}

Hypotheses

Predicted outcomes given the type of behavior and the female target's sexual subtype and race.

\section{Behavior toward target}

Non-zero sum: Behavior is

opposite of stereotype

\section{Chaste}

Black More BS than White

White Less BS than Black

\section{Promiscuous}

Black Less HS than White

White
Zero sum: Behavior is in line with stereotype

Less likely to be picked than White

More likely to be picked than Black

More likely to be picked than White Less likely to be picked than Black 


\section{Appendix C \\ Study Materials}

You are invited to participate in a research study conducted by Jean McMahon from Portland State University in the psychology department. The researcher hopes to learn about attitudes that people have towards others. It is being conducted in partial fulfillment of the requirements for a master's degree under the supervision of Dr. Kimberly Kahn.

If you decide to participate, you will be asked to fill out some surveys and read a short story. While participating, you may be uncomfortable answering some of the questions. You are welcome to stop the survey at any time, and your answers will be completely anonymous.

There are no right or wrong answers to these questions -- what matters is your opinion.

If you have questions or concerns about your participation in this study, contact Jean McMahon at mcmah@pdx.edu. If you have concerns about your rights as a research subject, please contact Research and Strategic Partnerships, Market Center Building 6th Floor, Portland State University, (503) 725-4288.

Please click on one of the following buttons:

I have read the above paragraph and I agree to participate

- I have read the above paragraph and I do not agree to participate 


\section{Premeasures}

Instructions: First, we want to know more about you personally. Please fill in some basic information about yourself.

Sex:

Male _ Female

Race/Ethnicity:

African American/Black

Asian American/Asian

Latino/Hispanic

White/Caucasian

Other

How old are you?

What is the zipcode of your current residence?

What is your occupation?

What is your highest level of education?

_ Less than high school degree

High school degree

Some college

College degree

Advanced degree (e.g. Masters, PhD, JD)

What is your political orientation?

1) Extremely liberal

2) Moderately liberal

3) Slightly liberal

4) Neither liberal or conservative

5) Slightly conservative

6) Moderately conservative

7) Extremely conservative 
13. Men are complete without women.

$-0 \_1-3-3 \quad 5$

14. Women exaggerate problems they have at work.

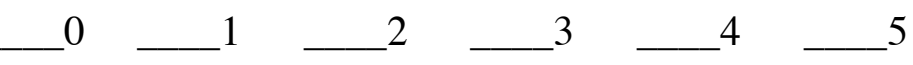

15. Once a woman gets a man to commit to her, she usually tries to put him on a tight leash.
0
1
2
3
$4 \quad 5$

16. When women lose to men in a fair competition, they typically complain about being discriminated against.

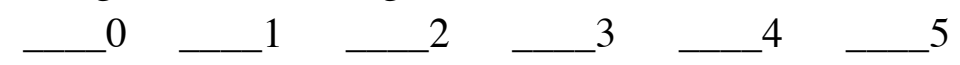

17. A good woman should be set on a pedestal by her man.
.
$0 \quad 1$
1
3
$4 \quad 5$

18. There are actually very few women who get a kick out of teasing men by seeming sexually available and then refusing male advances.

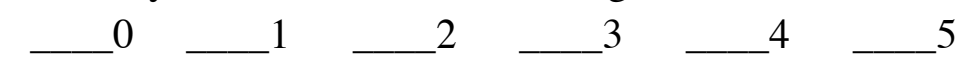

19. Women, compared to men, tend to have a superior moral sensibility.

${ }^{0}-1-2-3-4$

20. Men should be willing to sacrifice their own well being in order to provide financially for the women in their lives.
0
1
2
34 5

21. Feminists are making entirely reasonable demands of men.
0
1
2
3
4
5

22. Women, as compared to men, tend to have a more refined sense of culture and good taste.

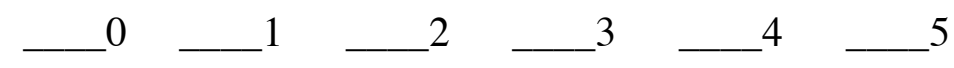

\section{Modern Racism Scale}

1. Discrimination against Blacks is no longer a problem in the United States.
Strongly Disagree
Disagree
Neither
Agree
Strongly Agree

2. It is easy to understand the anger of Black people in America.

Strongly Disagree

Disagree Neither Agree Strongly Agree

3. Blacks are getting too demanding in their push for equal rights. Strongly Disagree Disagree Neither Agree Strongly Agree

4. Blacks should not push themselves where they are not wanted. Strongly Disagree Disagree Neither Agree Strongly Agree 5. Over the past few years, Blacks have gotten more economically than they deserve. Strongly Disagree Disagree Neither Agree Strongly Agree 6. Over the past few years, the government and news media have shown more respect 
to Blacks than they deserve.

Strongly Disagree ___ Disagree $\_$Neither ___ Agree ___ Strongly Agree

Instructions: For the next part of the study, we will ask you to read a short story about three people at a bar. We will also ask your opinions about the people mentioned in the story. Afterwards you will be asked several questions about what happened in the story, so please read carefully.

Mike and Joel were downtown getting a drink when Mike first met Lakisha Washington (Emily Walsh). Joel had known Lakisha (Emily) for about a year. When Mike asked him what she was like, Joel said that she didn't enjoy casual flings and hadn't been with any guys that he knew of (she enjoyed having casual flings and had been with a few different guys that he knew of).

Lakisha (Emily) walked in and saw Mike and Joel having a beer. She wandered over toward them. "Hey, what are you up to tonight?" Joel asked her. "I'm supposed to be meeting a friend but it doesn't look like she's going to show up," Lakisha (Emily) replied as she sat down next to them.

Mike and Lakisha (Emily) really hit it off. As the night continued, they discovered that they had a lot in common. (Mike ended up buying her several drinks and) They ended up dancing for nearly an hour. When they got back to the table, Joel had already left and it was getting late.

Mike turned to her and asked, "Do you want to come back to my place?" Lakisha (Emily) looked back at him. "I'd like to get to know you better first," she replied "here's my number. Call me and we'll hang out again soon." ("Sure, why not," she replied.) 


\section{Manipulation Check}

Instructions: Now we want to see what you remembered from the story you've just read.

1. Please summarize in 1-2 sentences what happened in the story.

2. How did Joel describe the woman to his friend in the story?

$$
\text { She enjoyed having casual flings }
$$

She was not interested in casual flings

She had a serious boyfriend

3. What happened at the end of the story?

The woman gave Mike her phone number

The woman went to Mike's apartment

The woman left with her friends

4. What race is the woman in the story?

African American/Black

Asian American/Asian

Caucasian/White 


\section{Modified Ambivalent Sexism Inventory (Non-zero sum behavior measure)}

Instructions: For the next part of the story, we are interested in your impression of the woman you just read about. Even though you don't have much information, people often form an impression of someone with very little information.

Please rate your agreement with the following statements:

1. Many women like Lakisha/Emily are actually seeking special favors, such as hiring policies that favor them over men, under the guise of asking for "equality."

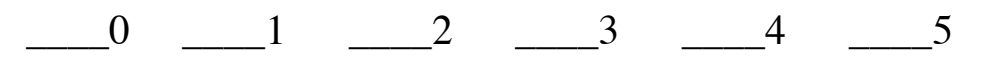

2. In a disaster, women like Lakisha/Emily ought not necessarily to be rescued before men.

${ }^{0} \_1 \quad-2 \_3-4 \quad 5$

3. Many women like Lakisha/Emily have a quality of purity that few men possess.

$\begin{aligned} & 0 \\ & -1\end{aligned}-2 \_3-4 \quad 5$

4. Women like Lakisha/Emily should be cherished and protected by men.

$\begin{aligned} & 0 \\ & -1\end{aligned} 2-3 \quad 3 \quad 4 \quad 5$

5. Most women like Lakisha/Emily fail to appreciate fully all that men do for them.

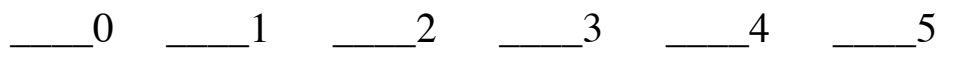

6. Women like Lakisha/Emily seek to gain power by getting control over men.
0
1
2 3 4 5

Once to put him on a tight leash.

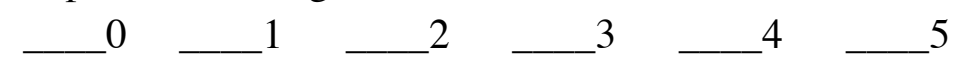

8. When women like Lakisha/Emily lose to men in a fair competition, they typically complain about being discriminated against.
0
1
2
3
4 5

9. There are actually very few women like Lakisha/Emily who get a kick out of teasing men by seeming sexually available and then refusing male advances. $-0 \quad 1 \quad-2 \_3-4 \quad 5$

10. A good woman like Lakisha/Emily should be set on a pedestal by her man.

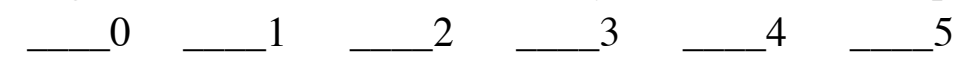

11. Women like Lakisha/Emily, compared to men, tend to have a superior moral sensibility.

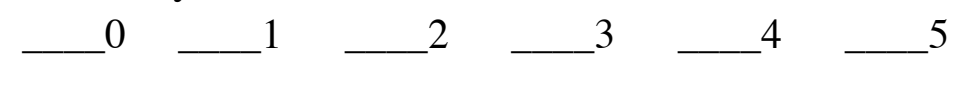


12. Women like Lakisha/Emily, as compared to men, tend to have a more refined sense of culture and good taste.

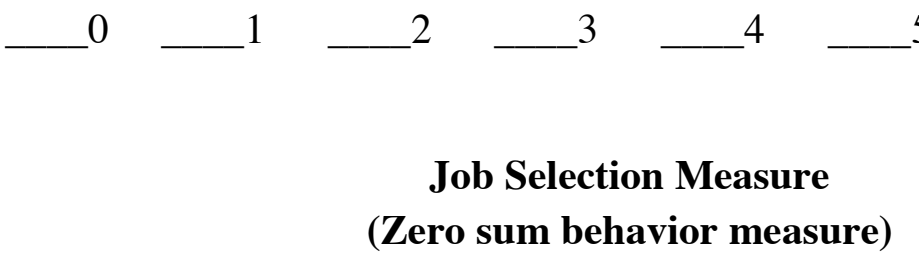

Instructions: Now we're going to tell you more about the woman you read about. Please read the following paragraph about her and make your selection carefully.

Lakisha/Emily has been involved in an organization called the Wellness Federation for the past several years. This organization advocates for abstinence-only sex education and funds public ad campaigns that highlight the financial and social costs of teen pregnancy and the benefits of dressing and behaving modestly (supports comprehensive sex education, as well as easy accessibility to birth control options, the HPV vaccine, and treatments for sexually transmitted infections).

The organization is looking for someone to become their new public representative. They want someone who best represents the values, morals, and goals of the organization to be their advocate. Lakisha/Emily really wants them to choose her. However, she is competing for the position with 3 other women. They all started working there about the same time she did and share similar values and goals.

A profile of each of the applicants is given below. Please select the person that you think should be the public representative for the Wellness Federation.

\section{Lakisha Washington / Emily Walsh}

Age: 26

Years at the Organization: 3 years, 7 months

Education: Bachelor of Arts

Department: Education

Why do you want this position: "I enjoy working here and being able to help members of the community."

\section{Meredith Olson}

Age: 29

Years at the Organization: 3 years, 2 months

Education: Bachelor of Arts

Department: Tech Operations

Why do you want this position: "I have always wanted to be a part of an organization that is so dedicated to helping people." 


\section{Shavonn Jefferson}

Age: 25

Years at the Organization: 3 years, 10 months

Education: Bachelor of Science

Department: Fundraising

Why do you want this position: "I think this organization provides a much-needed service for the community."

\section{Lauren Reilly / Jazmine Booker}

Age: 26

Years at the Organization: 3 years, 6 months

Education: Bachelor of Arts

Department: Human Resources

Why do you want this position: "I really like being able to help people live healthier lives."

Who should be picked to be the public representative of the Wellness Federation?

_ Lakisha Washington / Emily Walsh

Meredith Olson

Shavonn Jefferson

Lauren Reilly / Jazmine Booker 


\section{Debriefing Text}

If you have any comments, feedback, or thoughts on the study, please leave them here:

Thank you for participating in my study!

I am investigating how people perceive women of different races. Research on modern forms of sexism has shown that women who conform to traditional gender roles are seen as pure and worthy of protection (benevolent sexism), while those who do not conform are viewed more negatively (hostile sexism). To my knowledge, no one has examined how the race of the woman could affect whether she will be treated with hostile or benevolent sexism and then whether she'll be rewarded for this behavior. The story you read included a woman who was either White or Black. Examining attitudes towards this woman in the context of race will help me to answer the question of how women become targets of bias.

If you have questions or concerns about your participation in this study, contact Jean McMahon at mcmah@pdx.edu. If you have concerns about your rights as a research subject, please contact Research and Strategic Partnerships, Market Center Building 6th Floor, Portland State University, (503) 725-4288.

*****MTurk payment information will be displayed on the next page.***** 